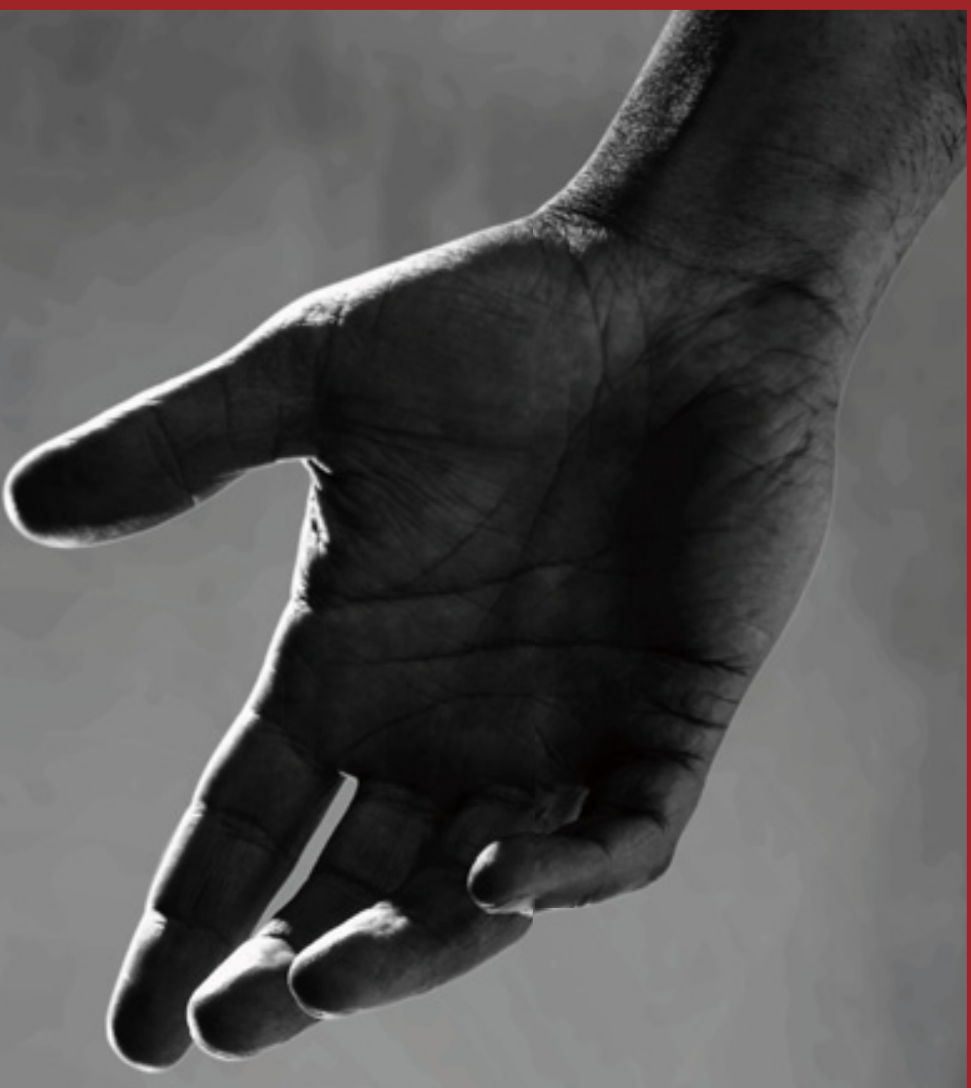

\title{
Preventing suicide
}

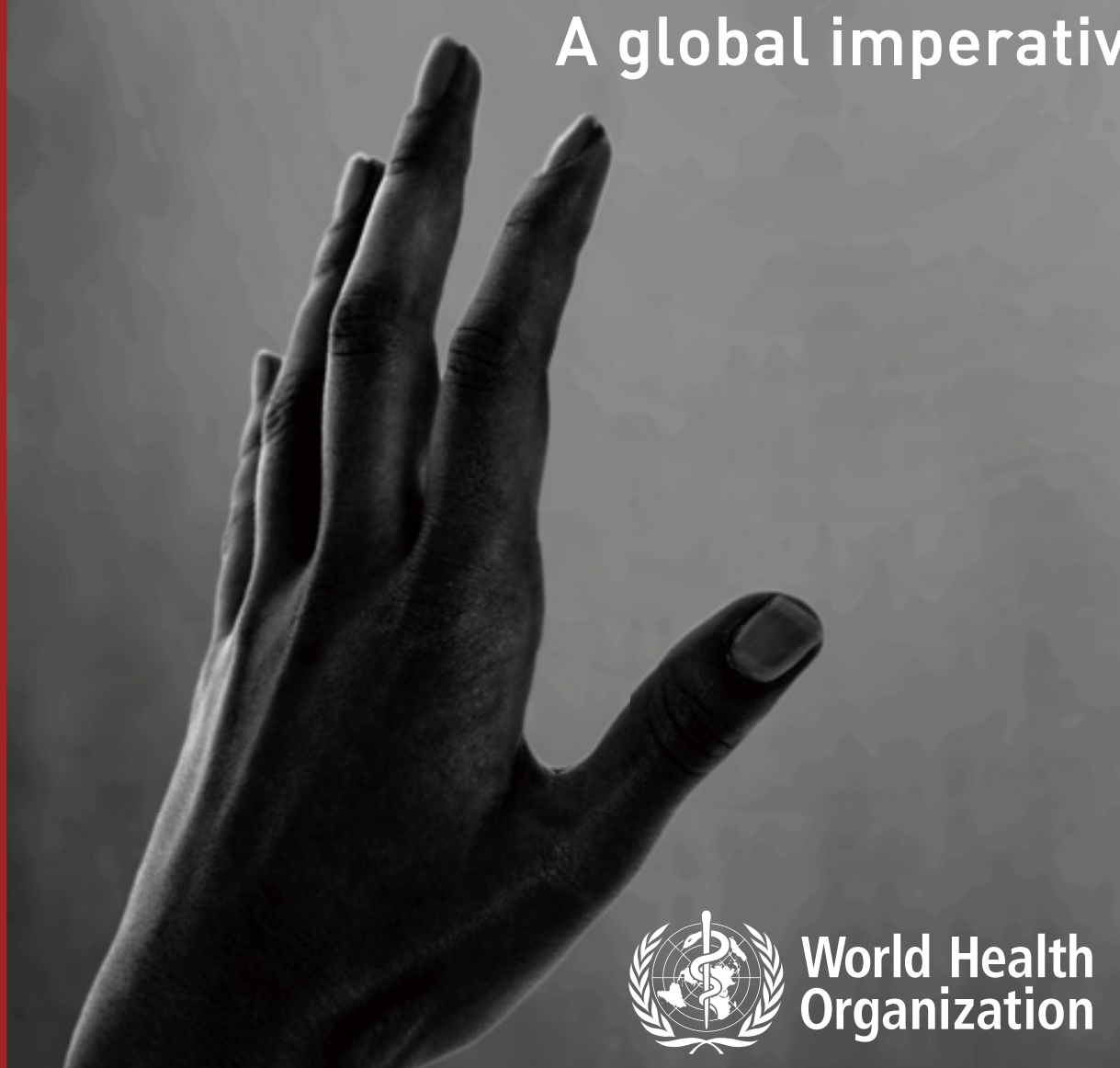




\section{Preventing suicide}

A global imperative

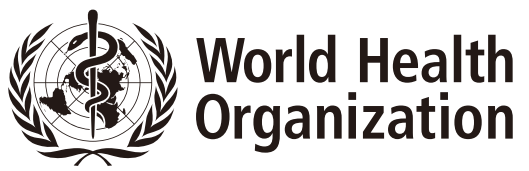




\section{WHO Library Cataloguing-in-Publication Data}

Preventing suicide: a global imperative.

1.Suicide, Attempted. 2.Suicide - prevention and control. 3.Suicidal Ideation. 4.National Health Programs. I.World Health Organization.

ISBN 9789241564779

(NLM classification: HV 6545)

@ World Health Organization 2014

All rights reserved. Publications of the World Health Organization are available on the WHO website (www.who.int) or can be purchased from WHO Press, World Health Organization, 20 Avenue Appia, 1211 Geneva 27, Switzerland (tel.: +41 22791 3264; fax: +41 22791 4857; e-mail: bookorders@who.int).

Requests for permission to reproduce or translate WHO publications -whether for sale or for non-commercial distribution- should be addressed to $\mathrm{WHO}$ Press through the $\mathrm{WHO}$ website (www.who.int/about/licensing/copyright_form/en/index.html).

The designations employed and the presentation of the material in this publication do not imply the expression of any opinion whatsoever on the part of the World Health Organization concerning the legal status of any country, territory, city or area or of its authorities, or concerning the delimitation of its frontiers or boundaries. Dotted lines on maps represent approximate border lines for which there may not yet be full agreement.
The mention of specific companies or of certain manufacturers' products does not imply that they are endorsed or recommended by the World Health Organization in preference to others of a similar nature that are not mentioned. Errors and omissions excepted, the names of proprietary products are distinguished by initial capital letters.

All reasonable precautions have been taken by the World Health Organization to verify the information contained in this publication. However, the published material is being distributed without warranty of any kind, either expressed or implied. The responsibility for the interpretation and use of the material lies with the reader. In no event shall the World Health Organization be liable for damages arising from its use.

Printed in Luxembourg 


\section{CONTENTS}

02

03

04

06

\section{FOREWORD}

PREFACE

ACKNOWLEDGEMENTS

\section{Executive summary}

\section{Introduction}

\section{Global epidemiology of suicide and suicide attempts}

Suicide mortality

Suicide attempts

\section{Risk and protective factors, and related interventions}

Health system and societal risk factors

Community and relationship risk factors

Individual risk factors

What protects people from the risks of suicide?

\section{The current situation in suicide prevention}

What is known and what has been achieved

What are countries doing about suicide prevention now?

Current legal status of suicide around the world and perspectives for change

\section{Working towards a comprehensive national response for suicide prevention}

How can countries create a comprehensive national strategy and why is it useful? How can progress be tracked when evaluating a national suicide prevention strategy? The cost and cost-effectiveness of suicide prevention efforts

\section{The way forward for suicide prevention}

What can be done and who needs to be involved?

Forging a way forward

What does success look like?

\section{Key messages}

\section{REFERENCES}

\section{ANNEXES}

Annex 1. Estimated numbers and rates of suicide by sex and age, 2000 and 2012 Annex 2: WHO Member States grouped by WHO Region and average income per capita 


\section{FOREWORD}

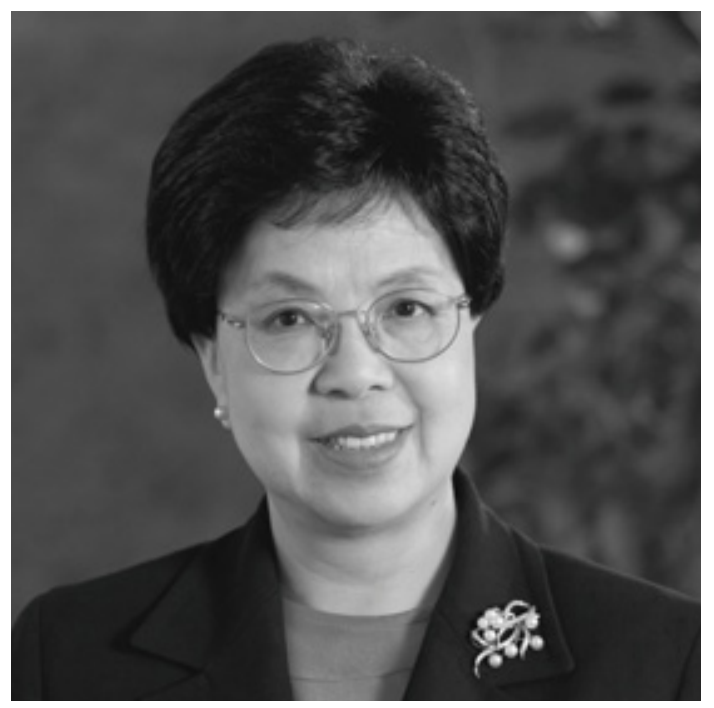

Every suicide is a tragedy. It is estimated that over 800000 people die by suicide and that there are many suicide attempts for each death. The impact on families, friends and communities is devastating and far-reaching, even long after persons dear to them have taken their own lives.

Unfortunately, suicide all too often fails to be prioritized as a major public health problem. Despite an increase in research and knowledge about suicide and its prevention, the taboo and stigma surrounding suicide persist and often people do not seek help or are left alone. And if they do seek help, many health systems and services fail to provide timely and effective help.

Yet, suicides are preventable. This report encourages countries to continue the good work where it is already ongoing and to place suicide prevention high on the agenda, regardless of where a country stands currently in terms of suicide rate or suicide prevention activities. With timely and effective evidence-based interventions, treatment and support, both suicides and suicide attempts can be prevented. The burden of suicide does not weigh solely on the health sector; it has multiple impacts on many sectors and on society as a whole. Thus, to start a successful journey towards the prevention of suicide, countries should employ a multisectoral approach that addresses suicide in a comprehensive manner, bringing together the different sectors and stakeholders most relevant to each context.
In the WHO Mental Health Action Plan 2013-2020, WHO Member States have committed themselves to work towards the global target of reducing the suicide rate in countries by $10 \%$ by 2020 . WHO's Mental Health Gap Action Programme, which was launched in 2008, includes suicide as one of the priority conditions and provides evidence-based technical guidance to expand service provision in countries.

It is against this background that I am pleased to present Preventing suicide: a global imperative. This report builds on previous work and contributes two key elements to moving forward: a global knowledge base on suicide and suicide attempts to guide governments, policy-makers and relevant stakeholders, and actionable steps for countries based on their current resources and contexts. In addition, it represents a significant resource for developing a comprehensive multisectoral strategy that can prevent suicide effectively.

Every single life lost to suicide is one too many. The way forward is to act together, and the time to act is now. I call upon all stakeholders to make suicide prevention an imperative.

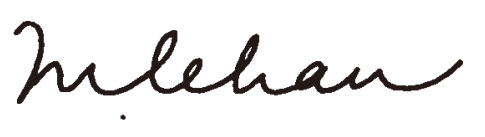

\author{
Dr Margaret Chan \\ Director-General \\ World Health Organization
}




\section{PREFACE}

Suicides are preventable. Even so, every 40 seconds a person dies by suicide somewhere in the world and many more attempt suicide. Suicides occur in all regions of the world and throughout the lifespan. Notably, among young people 15-29 years of age, suicide is the second leading cause of death globally.

Suicide impacts on the most vulnerable of the world's populations and is highly prevalent in already marginalized and discriminated groups of society. It is not just a serious public health problem in developed countries; in fact, most suicides occur in low- and middle-income countries where resources and services, if they do exist, are often scarce and limited for early identification, treatment and support of people in need. These striking facts and the lack of implemented timely interventions make suicide a global public health problem that needs to be tackled imperatively.

This report is the first $\mathrm{WHO}$ publication of its kind and brings together what is known in a convenient form so that immediate actions can be taken. The report aims to increase the awareness of the public health significance of suicide and suicide attempts and to make suicide prevention a higher priority on the global public health agenda. It aims to encourage and support countries to develop or strengthen comprehensive suicide prevention strategies in a multisectoral public health approach. For a national suicide prevention strategy, it is essential that governments assume their role of leadership, as they can bring together a multitude of stakeholders who may not otherwise collaborate. Governments are also in a unique position to develop and strengthen surveillance and to provide and disseminate data that are necessary to inform action. This report proposes practical guidance on strategic actions that governments can take on the basis of their resources and existing suicide prevention activities. In particular, there are evidence-based and low-cost interventions that are effective, even in resource-poor settings.

This publication would not have been possible without the significant contributions of experts and partners from all over the world. We would like to thank them for their important work and support.

The report is intended to be a resource that will allow policy-makers and other stakeholders to make suicide prevention an imperative. Only then can countries develop a timely and effective national response and, thus, lift the burden of suffering caused by suicide and suicide attempts from individuals, families, communities and society as a whole.

\section{Dr Shekhar Saxena}

Director

Department of Mental Health and Substance Abuse World Health Organization

Dr Etienne Krug

Director

Department of Violence and Injury Prevention and Disability World Health Organization 


\section{ACKNOWLEDGEMENTS}

\section{CONCEPTUALIZATION AND GUIDANCE}

Shekhar Saxena (WHO), Etienne Krug (WHO),

Oleg Chestnov (WHO).

\section{PROJECT COORDINATION AND EDITING}

Alexandra Fleischmann (WHO), Sutapa Howlader (Australia), Lakshmi Vijayakumar (India), Alex Butchart (WHO).

\section{TECHNICAL CONTRIBUTION AND REVIEW WORKING GROUP MEMBERS \\ Working Group 1: \\ Epidemiology of suicide and suicide attempts}

Michael Phillips (Chair, China), Vladeta Ajdacic-Gross (Switzerland), Vladimir Carli (Sweden), Paul Corcoran (Ireland), Alex Crosby (USA), Diego De Leo (Australia), David Gunnell (United Kingdom), Thomas Simon (USA).

\section{Working Group 2:}

Risk and protective factors, and related interventions Danuta Wasserman (Chair, Sweden), Alan Apter (Israel), Annette Beautrais (New Zealand), Vladimir Carli (Sweden), Gergö Hadlaczky (Sweden).

\section{Working Group 3:}

Current situation and working towards a comprehensive national response for suicide prevention

Alan Berman (Chair, USA), Ella Arensman (Ireland), Stephanie Burrows (South Africa), Brian Mishara (Canada), Vanda Scott (France), Morton Silverman (USA), Tadashi Takeshima (Japan).

\section{Working Group 4:}

\section{The way forward}

Diego De Leo (Chair, Australia), Alex Crosby (USA), Keith Hawton (United Kingdom), Merete Nordentoft (Denmark), Thomas Simon (USA).

\section{INTERNATIONAL CONTRIBUTORS}

Guilherme Borges (Mexico), Robert Bossarte (USA), Yoshinori Cho (Japan), Pamela Collins (USA), Margreet Duetz Schmucki, (Switzerland), Tony Durkee (Sweden), Maiko Fujimori (Japan), Ulrich Hegerl (Germany), Wakako Hikiji (Japan), Sebastian Hokby (Sweden), Masatoshi Inagaki (Japan), Miriam losue (Italy), Elvira Keller-Guglielmetti (Switzerland), Marla Israel (Canada), Chiaki Kawanishi (Japan), Murad Khan (Pakistan), Manami Kodaka (Japan), Takafumi Kubota (Japan), Xianyun Li (China), Shih-Cheng Liao (Chinese Taipei), Richard McKeon (USA), Winnie Mitchell (USA), Anahit Mkrtchian (Sweden), Masayuki Morikawa (Japan), Mihoko Morley (Japan), Sheila Ndyanabangi (Uganda), Etsuji Okamoto (Japan), Kotaro
Otsuka (Japan), Jong-Ik Park (Republic of Korea), Jane Pearson (USA), Alfredo Pemjean (Chile), Jane Pirkis (Australia), Beverly Pringle (USA), Yukio Saito (Japan), Marco Sarchiapone (Italy), Deborah Stone (USA), Yoshitomo Takahashi (Japan), Osamu Tanaka (Japan), Camilla Wasserman (USA), Barbara Weil (Switzerland), Takashi Yamauchi (Japan).

\section{EXPERT REVIEWERS}

Paulo Alterwain (Uruguay), Karl Andriessen (Belgium), Judit Balázs (Hungary), José M. Bertolote (Brazil), Jafar Bolhari (Iran), Eric Caine (USA), Erminia Colucci (Australia), Karen Devries (United Kingdom), Michael Dudley (Australia), Jacqueline Garrick (USA), Onja Grad (Slovenia), Ricardo Gusmão (Portugal), Christina Hoven (USA), Hiroto Ito (Japan), Jack Jordan (USA), Nav Kapur (United Kingdom), Elisabeth Kohls (Germany), Frances Law (China, Hong Kong SAR), Myf Maple (Australia), Sean McCarthy (Ireland), Roberto Mezzina (Italy), James Mugisha (Uganda), Thomas Niederkrotenthaler (Austria), Rory O`Connor (United Kingdom), George Patton (Australia), John Peters (United Kingdom), Steve Platt (United Kingdom), Jerry Reed (USA), Dan Reidenberg (USA), Karen Scavacini (Brazil), Jean-Pierre Soubrier (France), Emmanuel Streel (Belgium), Kanna Sugiura (Japan), Elizabeth Theriault (Canada), Peeter Värnik (Estonia), Paul Yip (China, Hong Kong SAR).

\section{SURVEY RESPONDENTS}

Ahmad Abdulbaghi (Iraq), Emad Abdulghani (Iraq), Francisca Trinidad Acosta (Honduras), Ahmed Al-Ansari (Bahrain), Dora Ninette Alburez de von Ahn (Guatemala), Charity Sylvia Akotia (Ghana), Atalay Alem (Ethiopia), Layachi Anser (Qatar), Alan Apter (Israel), Ella Arensman (Ireland), Tomas Baader (Chile), Hissani Abdou Bacar (Comoros), Loraine Barnaby (Jamaica), Annette Beautrais (New Zealand), Siham Benchekron (Morocco), Eleanor Bennett (Belize), Julio Bobes (Spain), José M Bertolote (Brazil), Dora Caballero (Paraguay), Mohamed Chakali (Algeria), Kin Sun Chan (China, Macao SAR), Ana-Maria Chavez-Hernandez (Mexico), Doina Cozman (Romania), Diego De Leo (Australia), Remco De Winter (Netherlands), Sounkary Doumbouya (Guinea), Kari Dyregrov (Norway), Michel Dzalamou (Congo), Rabih El Chammay (Lebanon), Félix Evangelista (El Salvador), Mohamed Chakali (Algeria), Rangiau Fariu (Cook Islands), Georg Fiedler (Germany), Gonzalo Baldomero Gonzalez Henriquez (Panama), Tobi Graafsma (Suriname), Onja Grad (Slovenia), Alenka Tancic Grum (Slovenia), Kyooseob Ha (Republic of Korea), Mitra Hefazi (Iran), Hilda Ho (Brunei Darussalam), Seyed Mohammad Hosseini (Iran), Gerard Hutchinson (Trinidad), Tekie losefa (Tokelau), Zahidul Islam (Bangladesh), Bhoomikumar Jegannathan (Cambodia), Mark Jordans (Nepal), Nusa Konec Juricic (Slovenia), Nestor Kapusta 
(Austria), Chiaki Kawanishi (Japan), Murad Khan (Pakistan), Brigitte Khoury (Lebanon), Michael Lebina (Lesotho), Filifaiésea Lilo (Tonga), Paul Links (Canada), Nasser Loza (Egypt), Daniella Malulu (Seychelles), T Maniam (Malaysia), Sabour A Mansouri (Afghanistan), Cardoso Margarida (Cape Verde), Carlos Martinez (Argentina), Lars Mehlum (Norway), Naomi Mnthali (Botswana), Alkhulaidi Mohamed (Yemen), Driss Moussaoui (Morocco), James Mugisha (Uganda), David Ndetei (Kenya), Tharcisse Niyonzigiye (Burundi), Merete Nordentoft (Denmark), Wilhelm Nordfjord (Iceland), Rory O'Connor (United Kingdom), Silvia Peláez (Uruguay), Michael Phillips (China), Alexander Pinzon (Colombia), Maurizio Pompili (Italy), Vita Postuvan (Slovenia), Toms Pulmanis (Latvia), Mbolatiana Soanirina Raharinivo (Madagascar), Lakshmi Ratnayeke (Sri Lanka), Sateesh Babu Ravulapati (India), Yury Razvodovsky (Belarus), Daniel Reidenberg (USA), Saška Roškar (Slovenia), Vsevolod Rozanov (Ukraine), Outi Ruishalme (Finland), Luis Miguel Sanchez-Loyo (Mexico), Bashir Ahmad Sarwari (Afghanistan), Lourens Schlebusch (South Africa), Armin Schmidtke (Germany), Jozef Sidlo (Slovakia), Chhit Sophal (Cambodia), Jean-Pierre Soubrier (France), Aida Sylla (Senegal), Zonda Tamás (Hungary), Alexandre Teixeira (Portugal), Prakarn Thomyangkoon (Thailand), Edgardo Juan Tolentino (Philippines), Kees Van Heeringen (Belgium), Airi Värnik (Estonia), Margda Waern (Sweden), Abdirisak Mohamed Warsame (Somalia), Barbara Weil (Switzerland), Paul Wong (China, Hong Kong SAR), Antonio Eugenio Zacarias (Mozambique), Anka Zavasnik (Slovenia).

\section{WHO HEADQUARTERS}

Katerina Ainali, Richard Brown, Somnath Chatterji, Dan Chisholm, Nicolas Clark, Natalie Drew, Tarun Dua, Jane Ferguson, Michelle Funk, Claudia Garcia Moreno, Anna Gruending, Evelyn Kortum, Doris Ma Fat, Wahyu Retno Mahanani, Colin Mathers, Mwansa Nkowane, Margaret Peden, Vladimir Poznyak, Geoffrey Reed, Dag Rekve, Leanne Riley, Florence Rusciano, Chiara Servili, Joanna Tempowski, Rebekah Thomas Bosco, Mark van Ommeren, Erica Wheeler, Taghi M Yasamy.

\section{WHO REGIONAL OFFICES}

Sebastiana Da Gama Nkomo, WHO Regional Office for Africa; Claudina Cayetano, Hugo Cohen, Devora Kestel \& Jorge Rodriguez, WHO Regional Office for the Americas; Nazneen Anwar, WHO Regional Office for South-East Asia; Matthijs Muijen, WHO Regional Office for Europe; Khalid Saeed, WHO Regional Office for the Eastern Mediterranean; Yutaro Setoya \& Xiangdong Wang, WHO Regional Office for the Western Pacific.

\section{INTERNS}

Rhett Corker, Justin Granstein, Henrik Heitmann, Eugenie $\mathrm{Ng}$, Amrita Parekh, Charlotte Phillips, Veronica Pisinger, Tahilia Rebello, Nóra Sándor.

\section{ADMINISTRATIVE SUPPORT}

Adeline Loo (WHO), Grazia Motturi (WHO), Paule Pillard (WHO).

\section{PRODUCTION TEAM}

Editing: David Bramley, Switzerland

Graphic design and layout: Yusuke Nakazawa, Japan

WHO would like to thank the International Association for Suicide Prevention (IASP); the WHO Collaborating Centre for Research and Training in Suicide Prevention, Brisbane, Australia; the WHO Collaborating Centre for Research and Training in Suicide Prevention, Beijing, China; the WHO Collaborating Centre for Research, Methods Development and Training in Suicide Prevention, Stockholm, Sweden; the Center for Suicide Prevention, Japan; the Centers for Disease Control and Prevention (CDC), USA; the Defense Suicide Prevention Office, USA; the Government of Japan; the Government of Switzerland; the National Institute of Mental Health (NIHM), USA; the Public Health Agency of Canada; the Substance Abuse and Mental Health Services Administration (SAMHSA), USA; and the Veterans Health Administration, USA for their technical contributions.

WHO would like to thank the Centers for Disease Control and Prevention (CDC), USA; the Government of Japan; the Government of Switzerland; and the National Institute of Mental Health (NIHM), USA for their financial contributions; and Syngenta, Switzerland for its contribution to printing. 
Executive summary 


\section{Introduction}

In May 2013, the Sixty-sixth World Health Assembly adopted the first-ever Mental Health Action Plan of the World Health Organization (WHO). Suicide prevention is an integral part of the plan, with the goal of reducing the rate of suicide in countries by $10 \%$ by 2020 (1). There is no single explanation of why people die by suicide. However, many suicides happen impulsively and, in such circumstances, easy access to a means of suicide - such as pesticides or firearms - can make the difference as to whether a person lives or dies.

Social, psychological, cultural and other factors can interact to lead a person to suicidal behaviour, but the stigma attached to mental disorders and suicide means that many people feel unable to seek help. Despite the evidence that many deaths are preventable, suicide is too often a low priority for governments and policy-makers. The objective of this report is to prioritize suicide prevention on the global public health and public policy agendas and to raise awareness of suicide as a public health issue. The report was developed through a global consultative process and is based on systematic reviews of data and evidence together with inputs from partners and stakeholders.

\section{Global epidemiology of suicide and suicide attempts}

An estimated 804000 suicide deaths occurred worldwide in 2012, representing an annual global age-standardized suicide rate of 11.4 per 100000 population (15.0 for males and 8.0 for females). However, since suicide is a sensitive issue, and even illegal in some countries, it is very likely that it is under-reported. In countries with good vital registration data, suicide may often be misclassified as an accident or another cause of death. Registering a suicide is a complicated procedure involving several different authorities, often including law enforcement. And in countries without reliable registration of deaths, suicides simply die uncounted.

In richer countries, three times as many men die of suicide than women do, but in low- and middle-income countries the male-to-female ratio is much lower at 1.5 men to each woman. Globally, suicides account for $50 \%$ of all violent death in men and $71 \%$ in women. With regard to age, suicide rates are highest in persons aged 70 years or over for both men and women in almost all regions of the world. In some countries, suicide rates are highest among the young, and globally suicide is the second leading cause of death in 15-29-year-olds. The ingestion of pesticide, hanging and firearms are among the most common methods of suicide globally, but many other methods are used with the choice of method often varying according to population group.

For every suicide there are many more people who attempt suicide every year. Significantly, a prior suicide attempt is the single most important risk factor for suicide in the general population. For both suicides and suicide attempts, improved availability and quality of data from vital registration, hospital-based systems and surveys are required for effective suicide prevention.

Restricting access to the means of suicide is a key element of suicide prevention efforts. However, means restriction policies (such as limiting access to pesticides and firearms or putting barriers on bridges) require an understanding of the method preferences of different groups in society and depend on cooperation and collaboration between multiple sectors. 


\section{Risk and protective factors, and related interventions}

Frequently, several risk factors act cumulatively to increase a person's vulnerability to suicidal behaviour.

Risk factors associated with the health system and society at large include difficulties in accessing health care and in receiving the care needed, easy availability of the means for suicide, inappropriate media reporting that sensationalizes suicide and increases the risk of "copycat" suicides, and stigma against people who seek help for suicidal behaviours, or for mental health and substance abuse problems.

Risks linked to the community and relationships include war and disaster, stresses of acculturation (such as among indigenous peoples or displaced persons), discrimination, a sense of isolation, abuse, violence and conflictual relationships. And risk factors at the individual level include previous suicide attempts, mental disorders, harmful use of alcohol, financial loss, chronic pain and a family history of suicide.

Strategies to counter these risk factors are of three kinds. "Universal" prevention strategies, which are designed to reach an entire population, may aim to increase access to health care, promote mental health, reduce harmful use of alcohol, limit access to the means for suicide or promote responsible media reporting. "Selective" prevention strategies target vulnerable groups such as persons who have suffered trauma or abuse, those affected by conflict or disaster, refugees and migrants, and persons bereaved by suicide, by training "gatekeepers" who assist the vulnerable and by offering helping services such as helplines. "Indicated" strategies target specific vulnerable individuals with community support, follow-up for those leaving health-care facilities, education and training for health workers, and improved identification and management of mental and substance use disorders. Prevention can also be strengthened by encouraging protective factors such as strong personal relationships, a personal belief system and positive coping strategies.

\section{The current situation in suicide prevention}

Knowledge about suicidal behaviour has increased greatly in recent decades. Research, for instance, has shown the importance of the interplay between biological, psychological, social, environmental and cultural factors in determining suicidal behaviours. At the same time, epidemiology has helped identify many risk and protective factors for suicide both in the general population and in vulnerable groups. Cultural variability in suicide risk has also become apparent, with culture having roles both in increasing risk and also in protection from suicidal behaviour.

In terms of policy, 28 countries today are known to have national suicide prevention strategies, while World Suicide Prevention Day, organized by the International Association for Suicide Prevention, is observed worldwide on 10 September each year. Additionally, many suicide research units have been set up and there are academic courses that focus on suicide and its prevention. To provide practical help, non-specialized health professionals are being used to improve assessment and management of suicidal behaviours, self-help groups of bereaved have been established in many places, and trained volunteers are helping with online and telephone counselling.

In the past half-century, many countries have decriminalized suicide, making it much easier for those with suicidal behaviours to seek help.

\section{Working towards a comprehensive response for suicide prevention}

A systematic way of developing a national response to suicide is to create a national suicide prevention strategy. A national strategy indicates a government's clear commitment to dealing with the issue of suicide. Typical national strategies comprise a range of prevention strategies such as surveillance, means restriction, media guidelines, stigma reduction and raising of public awareness as well as training for health workers, educators, police and other gatekeepers. They also usually include crisis intervention services and postvention.

Key elements in developing a national suicide prevention strategy are to make prevention a multisectoral priority that involves not only the health sector but also education, employment, social welfare, the judiciary and others. The strategy should be tailored to each country's cultural and social context, establishing best practices and evidence-based interventions in a comprehensive approach. Resources should be allocated for achieving both short-to-medium and long-term objectives, there should be effective planning, and the strategy should be regularly evaluated, with evaluation findings feeding into future planning.

In countries where a fully-developed comprehensive national strategy is not yet in place, this should not be an obstacle to implementing targeted suicide prevention programmes since 
these can contribute to a national response. Such targeted programmes aim to identify groups vulnerable to the risk of suicide and improve access to services and resources for those groups.

\section{The way forward for suicide prevention}

Ministers of health have an important role in providing leadership and bringing together stakeholders from other sectors in their country. In countries where suicide prevention activities have not yet taken place, the emphasis is on seeking out stakeholders and developing activities where there is greatest need or where resources already exist. It is also important to improve surveillance at this stage. In countries with some existing suicide prevention activities, a situation analysis can show what is already in place and indicate where there are gaps that need to be filled. Countries that already have a relatively comprehensive national response should focus on evaluation and improvement, updating their knowledge with new data and emphasizing effectiveness and efficiency.

While moving forward, two points should be considered. First, suicide prevention activities should be carried out at the same time as data collection. Second, even if it is felt that a country is not yet ready to have a national prevention strategy, the process of consulting stakeholders about a national response often generates interest and creates an environment for change. Through the process of creating the national response, stakeholders become committed, public dialogue on stigma is encouraged, vulnerable groups are identified, research priorities are fixed, and public and media awareness are increased.

Indicators that measure the strategy's progress can include:

- a percentage reduction in the suicide rate;

- the number of suicide prevention interventions successfully implemented;

- a decrease in the number of hospitalized suicide attempts.

Countries that are guided by the WHO Mental Health Action Plan 2013-2020 (1) can aim for a 10\% reduction in the suicide rate. Many countries will want to reduce the suicide rate further. In the long-term, importantly, reducing risk will go only part of the way towards reducing suicide. Furtherance of protective factors will help build for the future - a future in which community organizations provide support and appropriate referrals to those in need of assistance, families and social circles enhance resilience and intervene effectively to help loved ones, and there is a social climate where help-seeking is no longer taboo and public dialogue is encouraged.

\section{Key messages}

Suicides take a high toll. Over 800000 people die due to suicide every year and it is the second leading cause of death in 15-29-year-olds. There are indications that for each adult who died of suicide there may have been more than 20 others attempting suicide.

Suicides are preventable. For national responses to be effective, a comprehensive multisectoral suicide prevention strategy is needed.

Restricting access to the means for suicide works. An effective strategy for preventing suicides and suicide attempts is to restrict access to the most common means, including pesticides, firearms and certain medications.

Health-care services need to incorporate suicide prevention as a core component. Mental disorders and harmful use of alcohol contribute to many suicides around the world. Early identification and effective management are key to ensuring that people receive the care they need.

Communities play a critical role in suicide prevention. They can provide social support to vulnerable individuals and engage in follow-up care, fight stigma and support those bereaved by suicide. 
Introduction 
Each suicide is a personal tragedy that prematurely takes the life of an individual and has a continuing ripple effect, dramatically affecting the lives of families, friends and communities. Every year, more than 800000 people die by suicide - one person every 40 seconds. It is a public health issue that affects communities, provinces and entire countries.

Young people are among those most affected; suicide is now the second leading cause of death for those between the ages of 15 and 29 years globally. The numbers differ between countries, but it is the low- and middle-income countries that bear most of the global suicide burden, with an estimated $75 \%$ of all suicides occurring in these countries.

In May 2013, the Sixty-sixth World Health Assembly formally adopted the first-ever Mental Health Action Plan of the World Health Organization (WHO). The action plan calls on all WHO Member States to demonstrate their increased commitment to mental health by achieving specific targets. Suicide prevention is an integral component of the Mental Health Action Plan, with the goal of reducing the rate of suicide in countries by $10 \%$ by 2020 (1).

What causes suicide? Why do so many people end their lives every year? Is it because of poverty? Unemployment? The breakdown of relationships? Or is it because of depression or other serious mental disorders? Are suicides the result of an impulsive act, or are they due to the disinhibiting effects of alcohol or drugs? There are many such questions but no simple answers. No single factor is sufficient to explain why a person died by suicide: suicidal behaviour is a complex phenomenon that is influenced by several interacting factors - personal, social, psychological, cultural, biological and environmental.

While the link between suicide and mental disorders is well established, broad generalizations of risk factors are counterproductive. Increasing evidence shows that the context is imperative to understanding the risk of suicide. Many suicides occur impulsively in moments of crisis and, in these circumstances, ready access to the means of suicide such as pesticides or firearms - can determine whether a person lives or dies. Other risk factors for suicide include a breakdown in the ability to deal with acute or chronic life stresses, such as financial problems. In addition, cases of gender-based violence and child abuse are strongly associated with suicidal behaviour. Suicide rates also vary within countries, with higher rates among those who are minorities or experience discrimination.

Stigma, particularly surrounding mental disorders and suicide, means many people are prevented from seeking help. Raising community awareness and breaking down taboos are important for countries making efforts to prevent suicide.
We have solutions to a lot of these issues, and there is a strong enough knowledge base to enable us to act.

\section{Suicides are preventable}

Suicide prevention efforts require coordination and collaboration among multiple sectors of society, both public and private, including both health and non-health sectors such as education, labour, agriculture, business, justice, law, defence, politics and the media. These efforts must be comprehensive, integrated and synergistic, as no single approach can impact alone on an issue as complex as suicide.

One recognized strategy for the prevention of suicide is the assessment and management of mental disorders, as described in WHO's Mental Health Gap Action Programme (mhGAP), which identifies evidence-based individual-level strategies, including for the assessment and management of persons who attempted suicide. At the population level, mhGAP advocates restricting access to the means of suicide, developing policies to reduce the harmful use of alcohol through a range of policy options, and encouraging the media to follow responsible reporting practices on suicide.

In addition, prioritizing preventive interventions among vulnerable populations, including those who have previously attempted suicide, have also proved helpful. As a result, "postvention" has been identified as an important component of suicide prevention; bereaved families and friends of people who have died by suicide also require care and support.

Suicide prevention requires a vision, a plan and a set of strategies. These efforts must be informed by data. A guiding conceptual framework must be created in a culturally-specific manner, even though there is no universal set of strategies that will work in each and every country. Sustained leadership is essential since the goals of suicide prevention can be achieved only through sustained effort.

In order to create social change, three important factors are required: knowledge (both scientific and informed by practice), public support (political will), and a social strategy such as a national response to accomplish suicide prevention goals.

\section{Objectives of the report}

Despite the evidence that many deaths are preventable, often with low-cost interventions, suicide is too often a low 
priority for governments and policy-makers worldwide. The objective of this report is to prioritize suicide prevention on the global public health and public policy agendas and to increase overall awareness of suicide as a legitimate public health issue. Through this report, WHO presents evidence-based interventions for reducing suicides and calls on partners to increase their prevention efforts.

The report draws attention to the magnitude of the problem, describing the status and consequences of both suicide and suicide attempts worldwide by drawing on all available data. Specific sections of the report offer practical advice on public health approaches that countries can adopt to prevent suicide throughout the life course.

It is envisaged that this report will be a key resource for those engaged in suicide prevention efforts, including first and foremost ministries of health, planners and policy-makers, but also nongovernmental organizations (NGOs), researchers, health and community workers, the media and the general public.

\section{Method}

This report has been developed through a global consultative process and is based on systematic reviews of existing data and evidence as well as inputs from several different partners and stakeholders, both within and outside WHO. Sections have been conceptualized and drafted by leading suicide prevention experts who have drawn on their collective expertise to paint a global picture of suicide and create a road map for suicide prevention.

\section{Terminology}

It is important to acknowledge that during the process of putting together this report, much discussion took place with regard to definitions, with ultimate agreement on the terms below. This by no means negates the ongoing evolution of terms in this field and the use of different terms for very good reasons elsewhere in this sector. It is beyond the scope of this report to resolve issues of terminology and definitions of suicidal behaviour conclusively.

For the purpose of this report, suicide is the act of deliberately killing oneself.

For the purpose of this report, suicide attempt is used to mean any non-fatal suicidal behaviour and refers to intentional self-inflicted poisoning, injury or self-harm which may or may not have a fatal intent or outcome.

It is important to acknowledge the implications and complexities of including self-harm in the definition of "suicide attempt". This means that non-fatal self-harm without suicidal intent is included under this term, which is problematic due to the possible variations in related interventions. However, suicide intent can be difficult to assess as it may be surrounded by ambivalence or even concealment.

In addition, cases of deaths as a result of self-harm without suicidal intent, or suicide attempts with initial suicidal intent where a person no longer wishes to die but has become terminal, may be included in data on suicide deaths. Distinguishing between the two is difficult, so it is not possible to ascertain what proportions of cases are attributable to self-harm with or without suicidal intent.

Suicidal behaviour refers to a range of behaviours that include thinking about suicide (or ideation), planning for suicide, attempting suicide and suicide itself. The inclusion of ideation in suicidal behaviour is a complex issue about which there is meaningful ongoing academic dialogue. The decision to include ideation in suicidal behaviour was made for the purpose of simplicity since the diversity of research sources included in this report are not consistent in their positions on ideation.

\section{Contents of this report}

This report, the first WHO publication of its kind, presents a comprehensive overview of suicide, suicide attempts and suicide prevention efforts worldwide, and identifies evidence-based approaches to policy-making and programme development on suicide prevention that can be adapted to different settings. The report reflects the public health model for suicide prevention (Figure 1). Following these steps, suicide prevention begins with surveillance to define the problem and to understand it, followed by the identification of risk and protective factors (as well as effective interventions), and culminates in implementation, which includes evaluation and scale-up of interventions and leads to revisiting surveillance and the ensuing steps. An overarching conceptual framework - ideally a comprehensive national strategy - must be created in a culture-specific manner and informed by data in order to guide development, implementation and evaluation with vision, political will, leadership, stakeholder buy-in and, last but not least, funding for the prevention of suicide. 


\section{Surveillance}

\section{What is the problem?}

Define the problem of suicidal behaviour through systematic data collection

\section{Identify risk \& protective factors}

What are the causes \& what can buffer their impact?

Conduct research to find out why suicidal behaviour occurs and who it affects

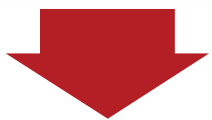

\section{Implementation \\ Scaling up effective policies \& programmes}

Scale up effective and promising interventions and evaluate their impact and effectiveness

\section{Develop \& evaluate interventions}

\section{What works \& for whom?}

Design, implement and evaluate interventions to see what works

Despite being a leading cause of death worldwide, suicide has remained a low public health priority. Suicide prevention and research on suicide have not received the financial or human investment they desperately need. It is hoped that this report will serve as a building block for the development and implementation of comprehensive suicide prevention strategies worldwide. 
Global epidemiology of suicide and suicide attempts 


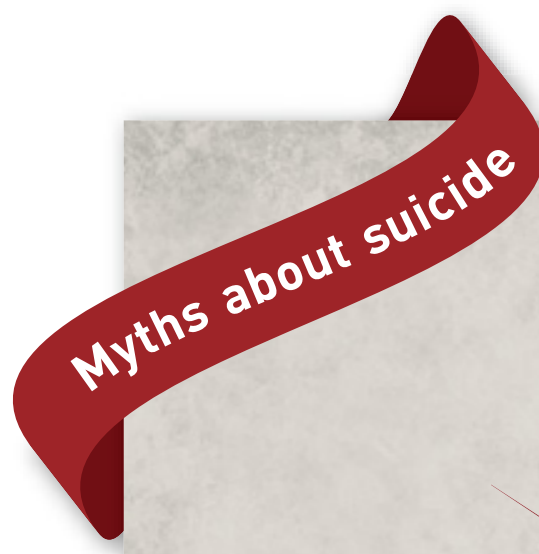

Myth:

People who talk about suicide do not mean to do it.

Fact:

People who talk about suicide may be reaching out for help or support. A significant number of people contemplating suicide are experiencing anciety, depression and hopelessness and may feel that there is no other option. 


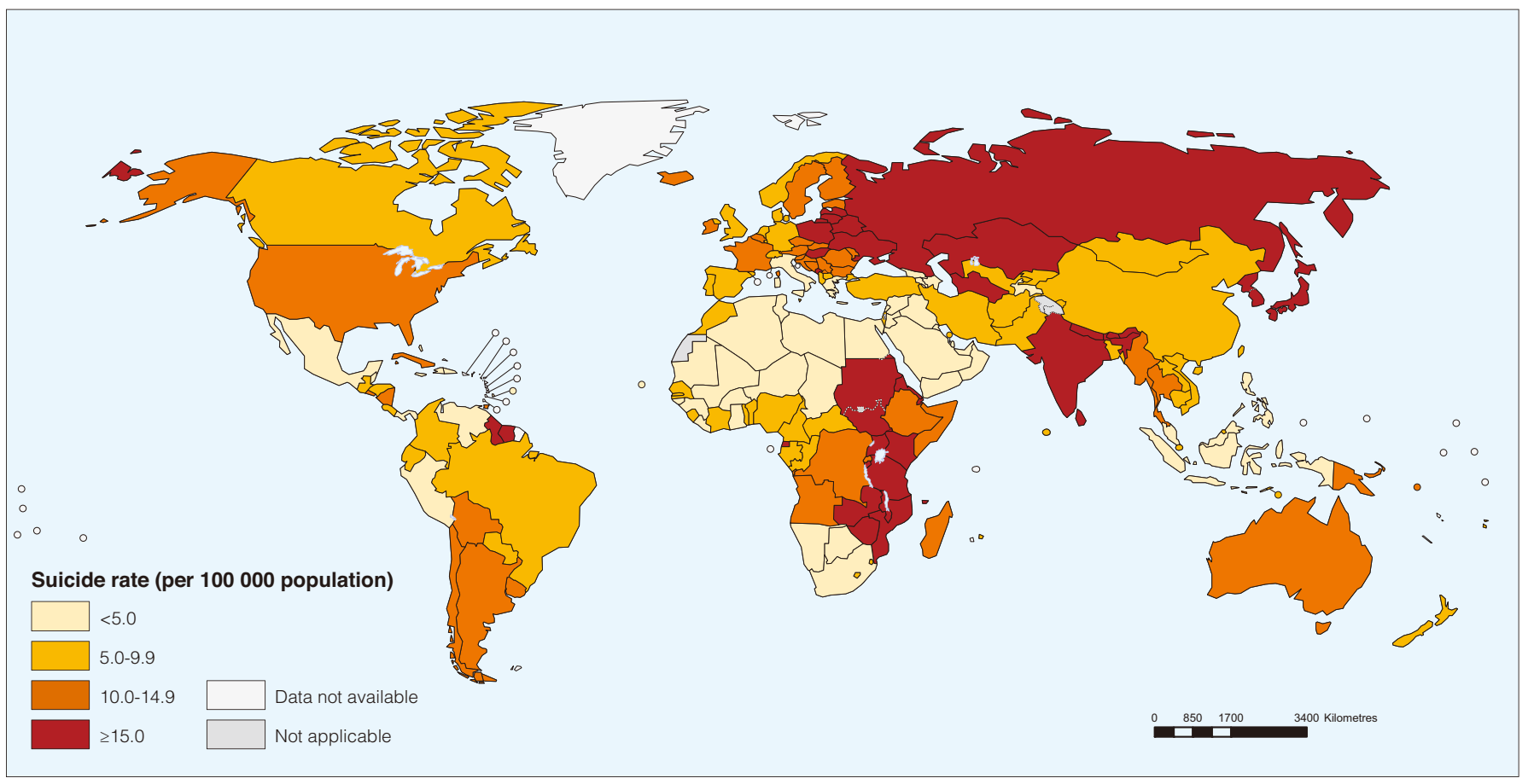

The prevalence, characteristics and methods of suicidal behaviour vary widely between different communities, in different demographic groups and over time. Consequently up-to-date surveillance of suicides and suicide attempts is an essential component of national and local suicide prevention efforts. Suicide is stigmatized (or illegal) in many countries. As a result, obtaining high-quality actionable data about suicidal behaviour is difficult, particularly in countries that do not have good vital registration systems (that register suicide deaths) or good data-collection systems on the provision of hospital services (that register medically treated suicide attempts). Developing and implementing appropriate suicide prevention programmes for a community or country requires both an understanding of the limitations of the available data and a commitment to improving data quality to more accurately reflect the effectiveness of specific interventions.

\section{Suicide mortality}

The primary data source for this chapter is the WHO Global Health Estimates. The estimates are largely based on the WHO mortality database - a global vital registration and cause-of-death registry that is created from data provided to WHO by Member States (2). A number of statistical modelling techniques are used to arrive at the estimates. The methods of generating these estimates are described in technical documents from the WHO Department of Health Statistics and Information Systems (3). This chapter presents global and regional results. In most cases the reported rates are age-standardized to the age distribution of the $\mathrm{WHO}$ World Standard Population, thus allowing for easier comparison across regions and over time. Country-specific estimates of 2012 suicide rates for 172 Member States with populations of 300000 or greater are presented in Map 1 and Annexes 1 and 2 (rates in countries with smaller populations are unstable).

\section{Global and regional suicide rates}

As shown in Table 1, there were an estimated 804000 suicide deaths worldwide in 2012. This indicates an annual global age-standardized suicide rate of 11.4 per 100000 population (15.0 for males and 8.0 for females). 
Table 1. Estimated numbers and rates of suicide by region and the world, 2012

\begin{tabular}{|c|c|c|c|c|c|c|c|}
\hline \multirow[t]{2}{*}{ Region } & \multirow[t]{2}{*}{$\begin{array}{l}\% \text { of global } \\
\text { population }\end{array}$} & \multirow{2}{*}{$\begin{array}{l}\text { Number of } \\
\text { suicides, } \\
2012 \\
\text { (thousands) }\end{array}$} & \multirow[t]{2}{*}{$\begin{array}{l}\% \text { of global } \\
\text { suicides }\end{array}$} & \multicolumn{3}{|c|}{$\begin{array}{l}\text { Age-standardized* } \\
\text { suicide rates (per } 100000 \text { ), } \\
2012\end{array}$} & \multirow{2}{*}{$\begin{array}{l}\text { Male:Female } \\
\text { ratio of age- } \\
\text { standardized } \\
\text { suicide rates, } \\
2012\end{array}$} \\
\hline & & & & $\begin{array}{l}\text { both } \\
\text { sexes }\end{array}$ & females & males & \\
\hline Global** & $100.0 \%$ & 804 & $100.0 \%$ & 11.4 & 8.0 & 15.0 & 1.9 \\
\hline $\begin{array}{l}\text { All high-income } \\
\text { Member States }\end{array}$ & $17.9 \%$ & 192 & $23.9 \%$ & 12.7 & 5.7 & 19.9 & 3.5 \\
\hline $\begin{array}{l}\text { All low- and middle-income } \\
\text { (LMIC) Member States }\end{array}$ & $81.7 \%$ & 607 & $75.5 \%$ & 11.2 & 8.7 & 13.7 & 1.6 \\
\hline LMICs in Africa & $12.6 \%$ & 61 & $7.6 \%$ & 10.0 & 5.8 & 14.4 & 2.5 \\
\hline LMICs in the Americas & $8.2 \%$ & 35 & $4.3 \%$ & 6.1 & 2.7 & 9.8 & 3.6 \\
\hline $\begin{array}{l}\text { LMICs in Eastern } \\
\text { Mediterranean }\end{array}$ & $8.0 \%$ & 30 & $3.7 \%$ & 6.4 & 5.2 & 7.5 & 1.4 \\
\hline LMICs in Europe & $3.8 \%$ & 35 & $4.3 \%$ & 12.0 & 4.9 & 20.0 & 4.1 \\
\hline LMICs in South-East Asia & $25.9 \%$ & 314 & $39.1 \%$ & 17.7 & 13.9 & 21.6 & 1.6 \\
\hline LMICs in Western Pacific & $23.1 \%$ & 131 & $16.3 \%$ & 7.5 & 7.9 & 7.2 & 0.9 \\
\hline \multicolumn{8}{|l|}{ World Bank regions** } \\
\hline High-income & $18.3 \%$ & 197 & $24.5 \%$ & 12.7 & 5.7 & 19.9 & 3.5 \\
\hline Upper-middle-income & $34.3 \%$ & 192 & $23.8 \%$ & 7.5 & 6.5 & 8.7 & 1.3 \\
\hline Lower-middle-income & $35.4 \%$ & 333 & $41.4 \%$ & 14.1 & 10.4 & 18.0 & 1.7 \\
\hline Low-income & $12.0 \%$ & 82 & $10.2 \%$ & 13.4 & 10.0 & 17.0 & 1.7 \\
\hline
\end{tabular}

LMICs = Low- and middle-income countries.

* Rates are standardized to the WHO World Standard Population, which adjusts for differences in age structure, facilitating comparisons between regions and over time.

** Includes data for three territories that are not Member States of WHO. 
The age-standardized rate of suicide is somewhat higher in high-income countries than in low- and middle-income countries (LMICs) (12.7 versus 11.2 per 100000 population). However, given the much larger proportion of the global population that resides in LMICs, $75.5 \%$ of all global suicides occur in these countries (Figure 2).
Among LMICs in the six $\mathrm{WHO}$ regions, there is an almost three-fold range in the age-standardized suicide rate, from a low of 6.1 per 100000 in the Region of the Americas to a high of 17.7 per 100000 in the South-East Asia Region. One consequence of the different suicide rates in $\mathrm{WHO}$ regions is that in 2012 the South-East Asia Region accounted for 26\% of the global population but for $39 \%$ of global suicides (Figure 3).

Figure 2. Global suicides by age and income level of country, 2012

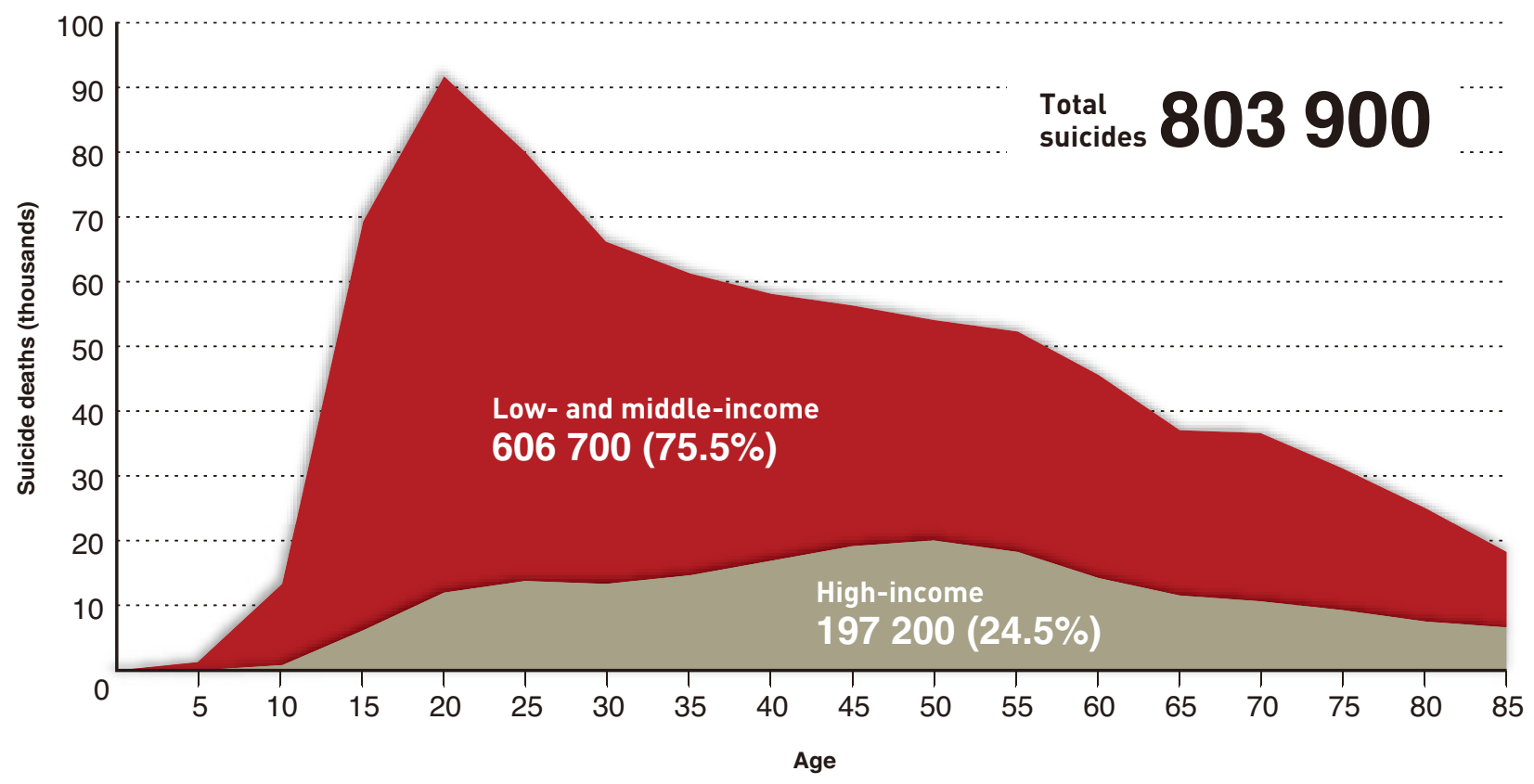

Figure 3. Regional distribution of global suicides, 2012

This difference in rates is even more pronounced when comparing country-level data. In the 172 countries with populations of over 300000 , the age-standardized suicide rates range from 0.4 to 44.2 per 100000 - a 110-fold range.

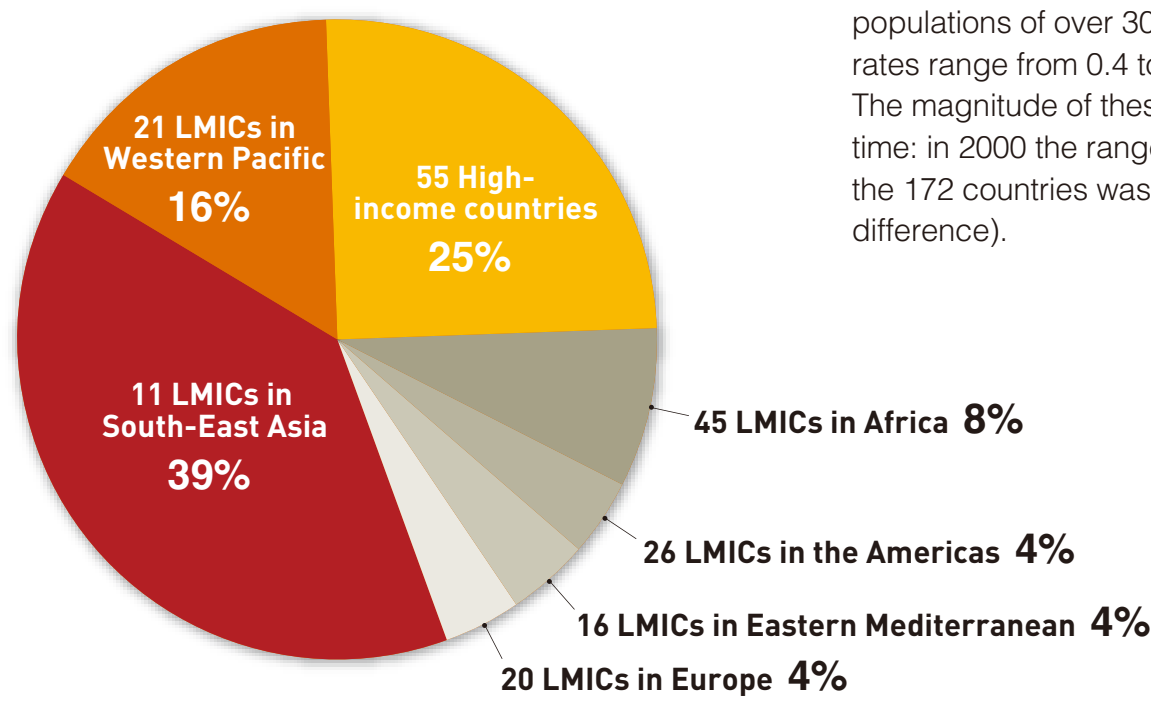

LMICs = Low- and middle-income countries. 
There are several important caveats that need to be considered when evaluating these suicide mortality data. Of the WHO 172 Member States for which estimates were made, only 60 (Map 2 and Annexes 1 and 2) have good-quality vital registration data that can be used directly to estimate suicide rates. The estimated suicide rates in the other 112 Member States (which account for about $71 \%$ of global suicides) are necessarily based on modelling methods. As might be expected, good quality vital registration systems are much more likely to be available in high-income countries. The 39 high-income countries with good vital registration data account for $95 \%$ of all estimated suicides in high-income countries, but the $21 \mathrm{LMICs}$ with good vital registration data account for only $8 \%$ of all estimated suicides in LMICs.

\section{Map 2. Quality of suicide mortality data, 2012}

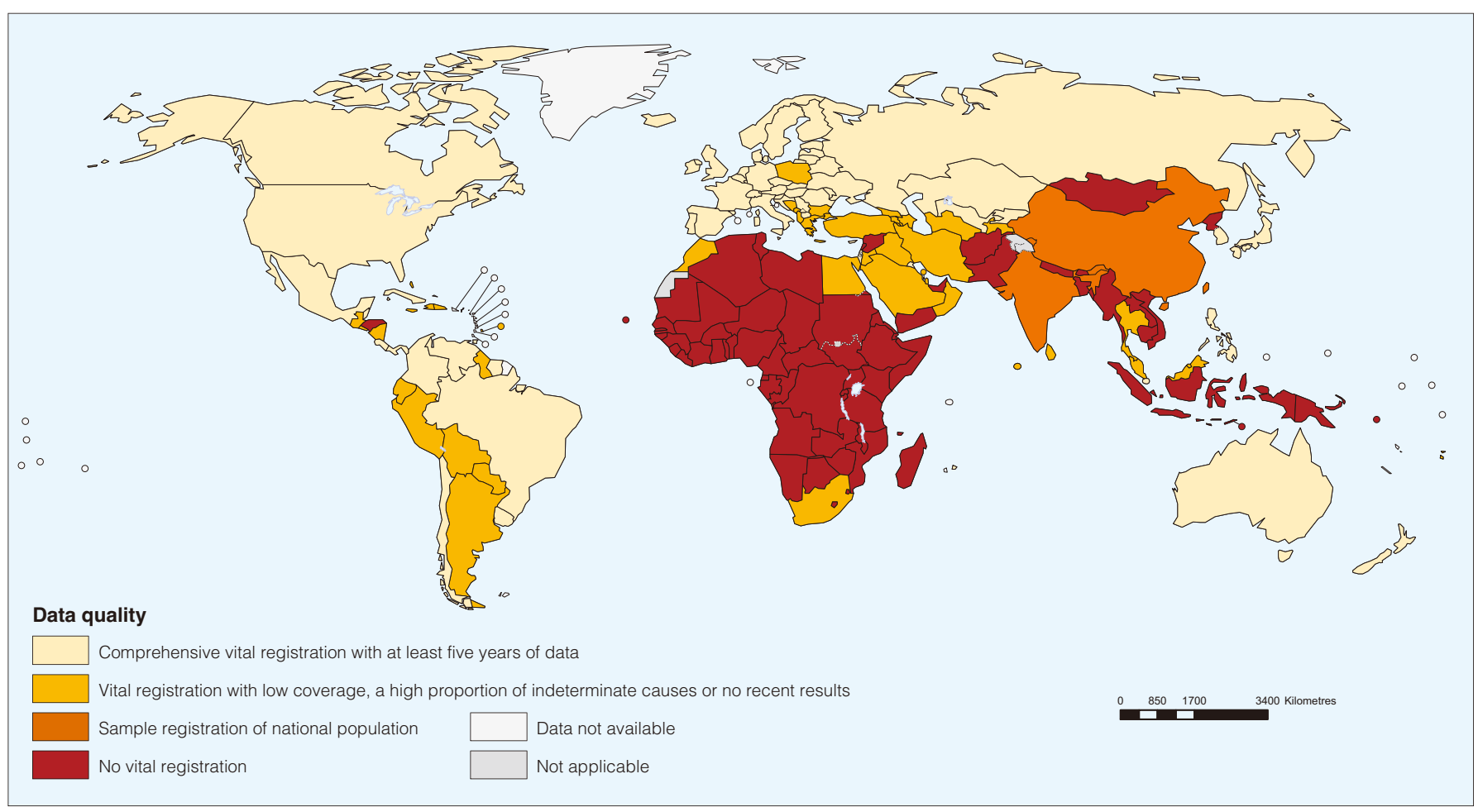

This problem of poor-quality mortality data is not unique to suicide, but given the sensitivity of suicide - and the illegality of suicidal behaviour in some countries - it is likely that under-reporting and misclassification are greater problems for suicide than for most other causes of death. Suicide registration is a complicated, multilevel procedure that includes medical and legal concerns and involves several responsible authorities that can vary from country to country. Suicides are most commonly found misclassified according to the codes of the 10th edition of the International Classification of Diseases and Related Health Conditions (ICD-10) as "deaths of undetermined intent" (ICD-10 codes Y10-Y34), and also as "accidents" (codes V01-X59), "homicides" (codes X85-Y09) and "unknown cause" (codes R95-R99) $(4,5,6)$. It is possible that the very wide range in estimated suicide rates reported for different countries and regions is an artefact of different reporting and recording practices. In the 60 countries with good vital registration systems there is a 32-fold range in national age-adjusted suicide rates for 2012 (from 0.89 to 28.85 per 100 000). Regional differences have persisted despite decades of work on improving the accuracy of country-specific mortality data. The possibility that a considerable part of these observed differences are, in fact, real differences must also be considered.

This leads to the following key questions: 1) How can countries improve monitoring of suicidal behaviour? 2) What is causing such huge differences in suicide rates across regions and between countries? 3) Among the many factors that influence suicide rates, which factors can be modified by policies or programmes? This and subsequent chapters of this report will try to answer these questions. 


\section{Suicide rates by sex}

Suicide rates vary by sex (Map 3 and Figure 4). For many years the conventional wisdom was that globally three times as many men died by suicide as did women. This high male-to-female ratio is, however, primarily a phenomenon in high-income countries where the 2012 ratio of age-standardized suicide rates is 3.5. In LMICs the male-to-female ratio is a much lower 1.6, indicating that the suicide rate is $57 \%$ (not $300 \%$ ) higher in men than in women.
Nevertheless, there are large differences between regions and between countries. As shown in Table 1, regional sex ratios in LMICs range from 0.9 in the Western Pacific Region to 4.1 in the European Region, a 4.5-fold difference. Among the 172 Member States with populations over 300 000, the mean male-to-female sex ratio is 3.2 , the median ratio is 2.8 , and the ratio ranges from 0.5 to 12.5 (i.e. a 24-fold difference).

Map 3. Male:Female ratio of age-standardized suicide rates, 2012

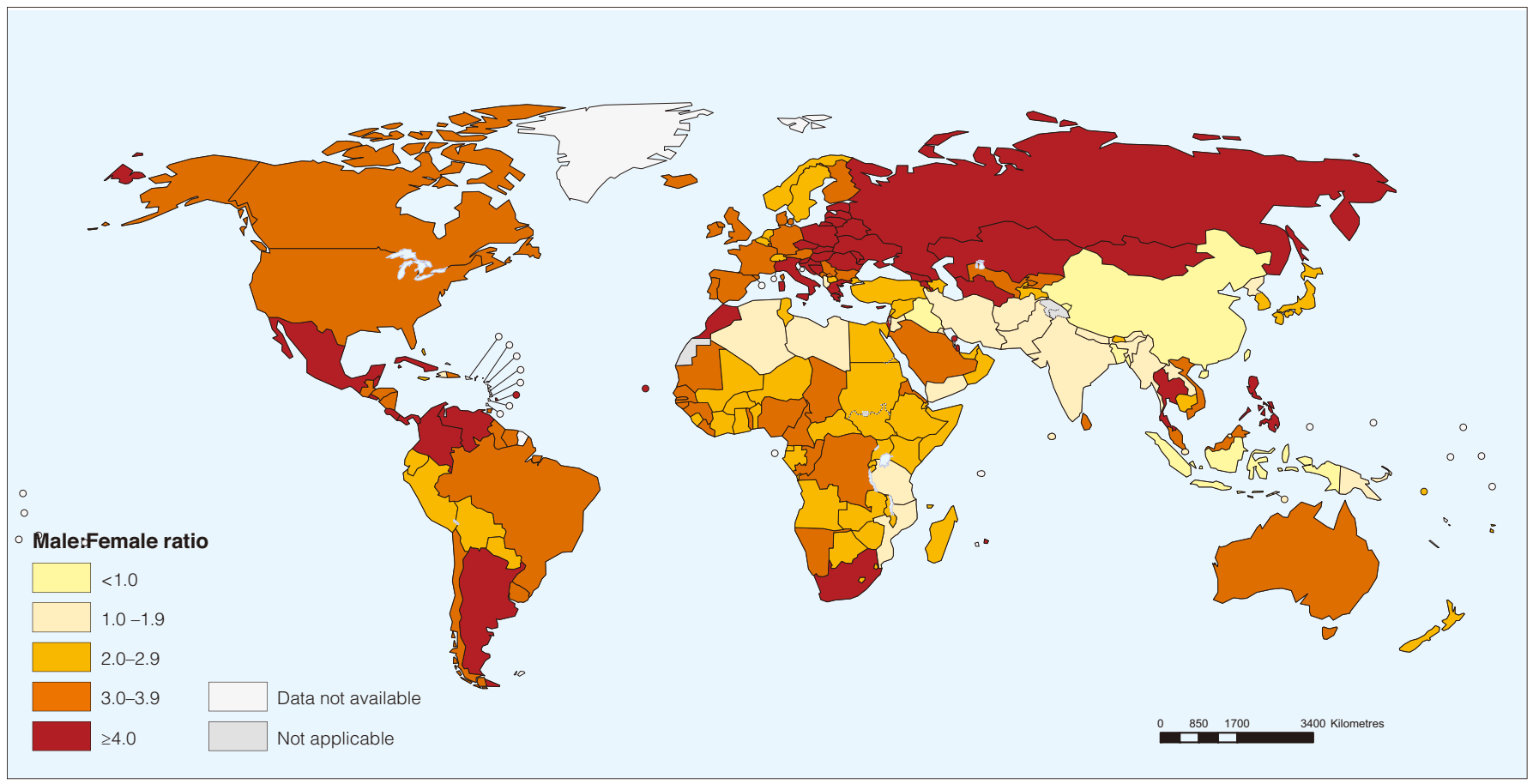

As shown in Figure 5, there are also differences in the sex ratio by age. There are many potential reasons for different suicide rates in men and women: gender equality issues, differences in socially acceptable methods of dealing with stress and conflict for men and women, availability of and preference for different means of suicide, availability and patterns of alcohol consumption, and differences in care-seeking rates for mental disorders between men and women. The very wide range in the sex ratios for suicide suggests that the relative importance of these different reasons varies greatly by country and region. 
Figure 4. Age-standardized suicide rates in different regions of the world, 2012

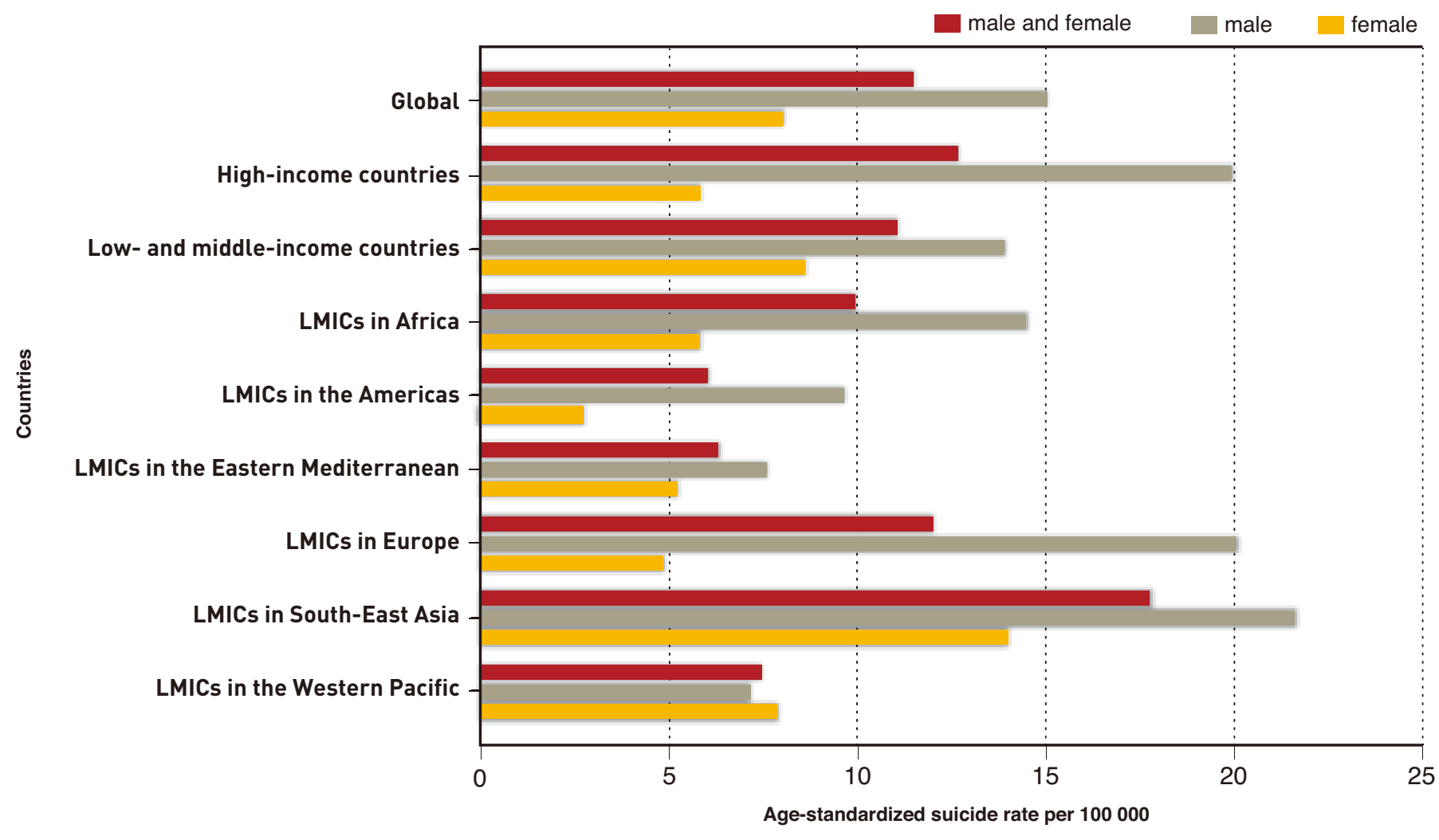

LMICS = Low- and middle-income countries

Figure 5. Male:Female ratio of suicide rates by age group and income-level of country, 2012

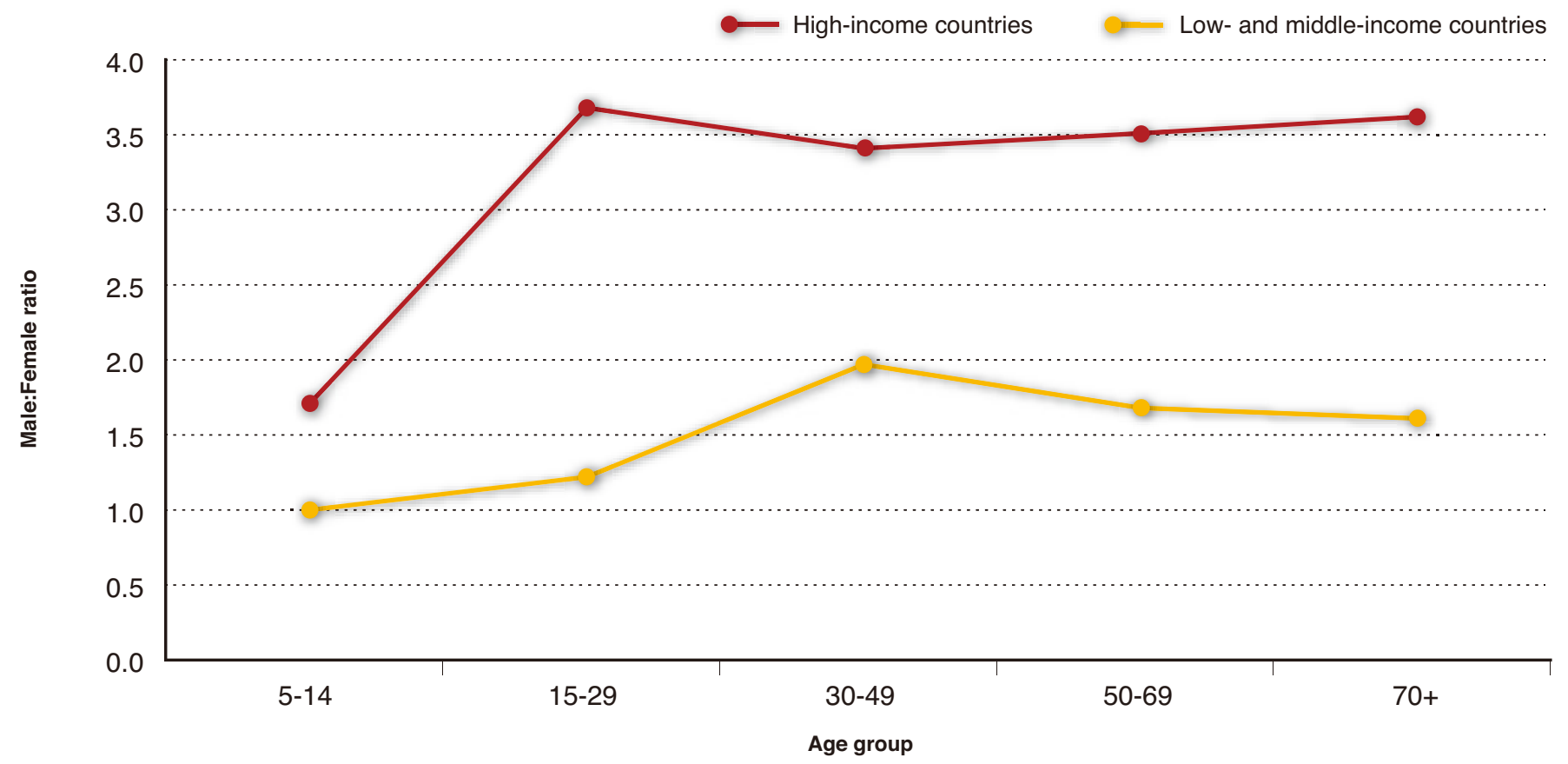




\section{Suicide rates by age}

With regard to age, suicide rates are lowest in persons under 15 years of age and highest in those aged 70 years or older for both men and women in almost all regions of the world, although the age-by-sex patterns in suicide rates between the ages of 15 and 70 years vary by region. In some regions suicide rates increase steadily with age while in others there is a peak in suicide rates in young adults that subsides in middle age. In some regions the age pattern in males and females is similar while in other regions it is quite different. The major differences between high-income countries and LMICs are that young adults and elderly women in LMICs have much higher suicide rates than their counterparts in high-income countries, while middle-aged men in high-income countries have much higher suicide rates than middle-aged men in LMICs. As is true of the overall suicide rates, the variability in suicide rates by age in different countries is even greater than the variability by region.

\section{The relative importance of suicide as a leading} cause of death

In 2012 suicide accounted for $1.4 \%$ of all deaths worldwide, making it the 15 th leading cause of death. These unexpected deaths - that predominantly occur in young and middle-aged adults - result in a huge economic, social and psychological burden for individuals, families, communities and countries. Suicide is a major public health problem in every country and every community worldwide.

In high-income countries, the proportion of all deaths due to suicide $(1.7 \%)$ is higher than the corresponding proportion in LMICs (1.4\%). This is primarily due to the higher numbers of deaths from infectious diseases and other causes in LMICs than in high-income countries. With the notable exception of LMICs in the Western Pacific Region, in all other regions of the world the proportion of all deaths due to suicide is greater in males than in females and the rank of suicide as a cause of death is higher in males than females.

The proportion of all deaths due to suicide and the rank of suicide as a cause of death vary greatly by age. Globally, among young adults 15-29 years of age suicide accounts for $8.5 \%$ of all deaths and is ranked as the second leading cause of death (after traffic accidents). Among adults aged 30-49 years it accounts for $4.1 \%$ of all deaths and is ranked the fifth leading cause of death. Remarkably, in high-income countries and in LMICs of the South-East Asia Region suicide accounts for $17.6 \%$ and $16.6 \%$ respectively of all deaths among young adults aged 15-29 years and represents the leading cause of death for both sexes.

Another method of assessing the importance of suicide as a public health problem is to assess its relative contribution to all intentional deaths, which include deaths from interpersonal violence, armed conflict and suicide (i.e. violent deaths). Figure 6 shows the proportion of all violent deaths that are due to suicide in different regions of the world. Globally, suicides account for $56 \%$ of all violent deaths $(50 \%$ in men and $71 \%$ in women). In high-income countries suicide accounts for $81 \%$ of violent deaths in both men and women, while in LMICs $44 \%$ of violent deaths in men and $70 \%$ of violent deaths in women are due to suicide. 
Figure 6. Proportion of all violent deaths that are suicides in different regions of the world, 2012

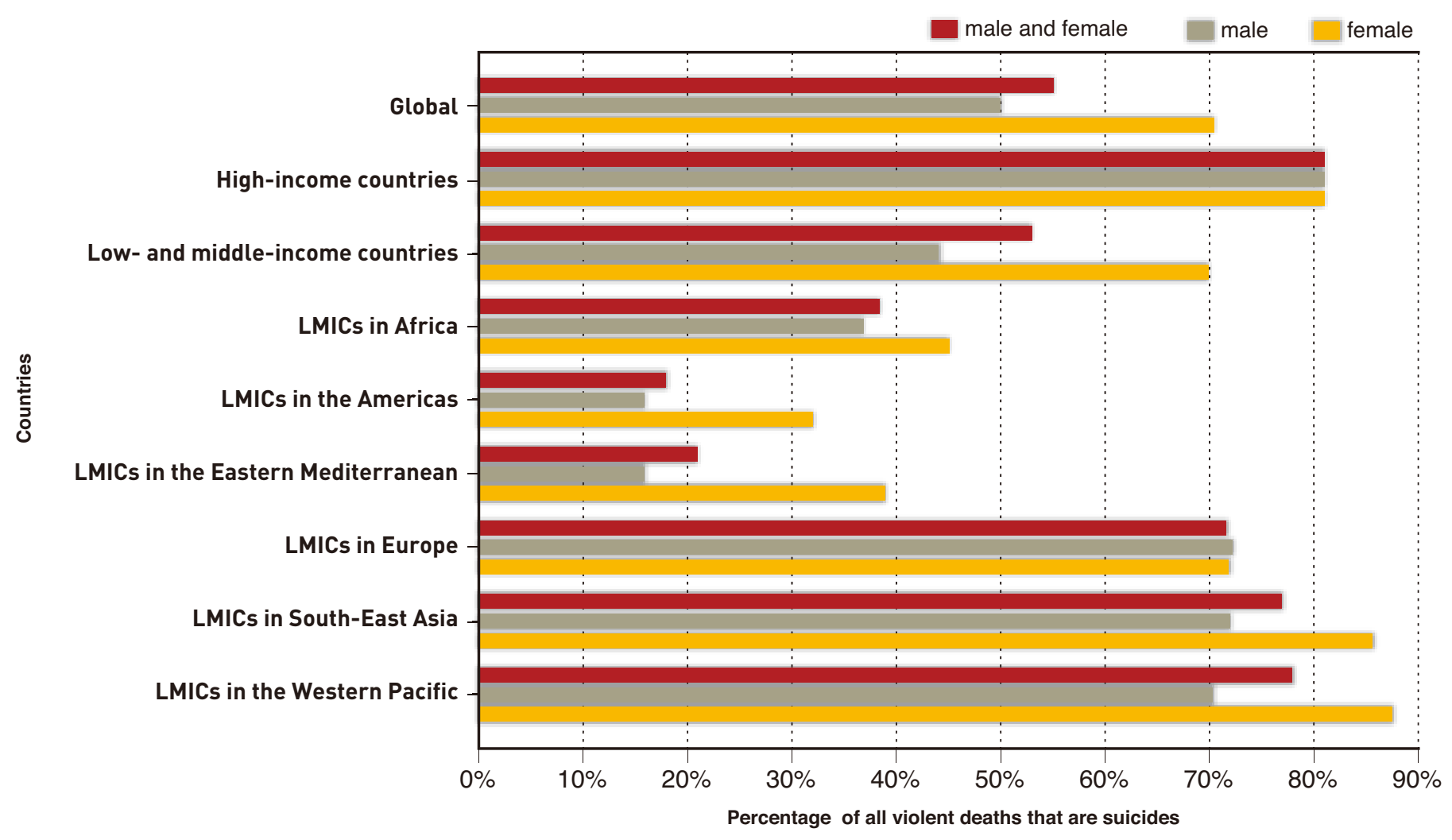

LMICs = Low- and middle-income countries.

\section{Changes in suicide rates from 2000 to 2012}

Despite the increase in the global population between 2000 and 2012, the absolute number of suicides has fallen by about 9\%, from 883000 to 804 000. However, very different patterns are seen by region: the percentage change in the total number of suicides ranges from an increase of $38 \%$ in LMICs in the African Region to a drop of $47 \%$ in LMICs in the Western Pacific Region.

The global age-standardized suicide rate (which adjusts for differences in the size and age structure of populations over time) has fallen $26 \%$ (23\% in men and $32 \%$ in women) during the 12-year period from 2000 to 2012. Age-standardized rates have fallen in all regions of the world except in LMICs in the African Region and among men in LMICs in the Eastern Mediterranean Region.

This global and regional analysis masks country-specific changes in suicide rates. Among the 172 Member States with populations of over 300000 (see Annexes 1 and 2), the 2000-2012 change in age-standardized suicide rates ranged from a decline of $69 \%$ to an increase of $270 \%$.
Among these 172 countries, 85 (49.4\%) experienced a drop in age-standardized suicide rates of over 10\%, $29(16.9 \%)$ experienced an increase of over $10 \%$, and $58(33.7 \%)$ had relatively small changes in age-standardized suicide rates over the 12-year period (from -10\% to $+10 \%$ ).

The reasons for such rapid changes in suicide rates are unknown. One possible partial explanation is the dramatic improvement in global health over the past decade. From 2000 to 2012 global age-standardized mortality for all causes dropped by $18 \%$. The drop in suicide rates has been faster than the drop in overall mortality (26\% versus $18 \%)$, but only by $8 \%$. If this trajectory can be maintained, the goal specified in the 2013-2020 WHO Mental Health Action Plan (1) of reducing suicide rates by $10 \%$ by 2020 may be achievable.

\section{Methods of suicide}

Most persons who engage in suicidal behaviour are ambivalent about wanting to die at the time of the act, and some suicidal acts are impulsive responses to acute psychosocial stressors. Means restriction (restricting access to 
the means of suicide) is a key component of suicide prevention efforts because it provides an opportunity for these individuals to reflect on what they are about to do and, hopefully, for the crisis to pass. However, devising appropriate means restriction policies (e.g. limiting access to pesticides and firearms; putting barriers on subways, bridges and iconic buildings; changing packaging regulations for medication) requires a detailed understanding of the methods of suicide used in the community and of the method preferences of different demographic groups within the community.

Unfortunately, national-level data on the methods used in suicide are quite limited. The ICD-10 includes X-codes that record the external causes of death, including the method of suicide, but many countries do not collect this information. Between 2005 and 2011 only 76 of the 194 WHO Member States reported data on methods of suicide in the $\mathrm{WHO}$ mortality database. These countries account for about $28 \%$ of all global suicides, so the methods used in $72 \%$ of global suicides are unclear. As expected, the coverage is much better for high-income countries than for LMICs. In high-income countries, hanging accounts for $50 \%$ of the suicides, and firearms are the second most common method, accounting for $18 \%$ of suicides. The relatively high proportion of suicides by firearms in high-income countries is primarily driven by high-income countries in the Americas where firearms account for $46 \%$ of all suicides; in other high-income countries firearms account for only $4.5 \%$ of all suicides.

Given the lack of national-level data about suicide methods from LMICs in the WHO mortality database, researchers need to rely on data published in the scientific literature to assess the patterns of suicide methods used in these regions (7). One of the key methods of suicide in LMICs, particularly in countries with a high proportion of rural residents engaged in small-scale agriculture, is pesticide self-poisoning. A systematic review (8) of world data for 1990-2007 estimated that around $30 \%$ (plausible range $27-37 \%$ ) of global suicides are due to pesticide self-poisoning, most of which occur in LMICs. Based on this estimate, pesticide ingestion is among the most common methods of suicide globally. If true, this would have major implications for prevention because pesticide restriction, though difficult, is often more feasible to implement than restricting the means of hanging.

Other research shows that the most prevalent method of suicide in a community can be determined by the environment, can change rapidly over time and can be disseminated from one community to another. In highly urbanized areas such as China, Hong Kong SAR and Singapore, where a majority of the population live in high-rise apartment complexes, jumping from high buildings is a common method of suicide. An epidemic in the use of barbecue charcoal to produce the highly toxic carbon monoxide gas as a means of suicide began in China, Hong Kong SAR in 1998 and rapidly spread to Taiwan, China where it became the most common method of suicide within eight years (9). Other methods that have recently become popular in some locations include mixing chemicals to produce hydrogen sulphide gas (e.g. in Japan) and the use of helium gas. These findings highlight the importance of ongoing monitoring of the methods employed in both suicide and suicide attempts in order to ensure that means restriction efforts and associated community educational efforts are responsive to the ever-changing patterns of suicide. However, many of the new emerging methods of suicide cannot be specifically identified using current ICD-10 external cause codes, so they will not be evident in mortality registry systems unless local officials promulgate the use of unique, method-specific ICD-10 sub-codes (see Box 1).

Box 1.

\section{The National Violent Death Reporting System in the USA}

The Centers for Disease Control and Prevention (CDC) in the USA has a National Violent Death Reporting System (NVDRS) which is a surveillance system that collects detailed information on violent deaths, including suicides $(10,11)$. The NVDRS serves as a data repository that links pertinent information on each incident from a variety of sources, including the victim's death certificate, toxicology and autopsy reports, and various investigative reports from law enforcement, coroner, medical examiner or death scene investigators. The NVDRS provides details on demographic characteristics of the deceased person, the mechanisms/weapons involved in the death, other incident characteristics (e.g. location and time of death), and the decedent's health and life-stress-related circumstances that were believed to have contributed to the death on the basis of findings from death scene investigations, witness testimonies, decedent disclosures and other material evidence (e.g. suicide notes). Currently the NVDRS collects data from 18 of the 50 states in the USA. States manage data collection through state health departments or subcontracted entities such as medical examiner offices. The data are gathered and coded by trained abstractors. CDC is planning to expand the NVDRS to all states in the USA as funding becomes available. 
Another important caveat regarding use of regional or country-specific data about suicide is that these data are of limited use in designing targeted suicide prevention programmes because they are insensitive to the substantial within-country variability in the rates, demographic patterns and methods of suicide. There is ample evidence of large differences in the rates and demographic characteristics of suicide between different locations within countries - e.g. between urban and rural areas of China (12) and between different states in India (13). In this situation, national data do not help to determine the geographical regions or the

\section{Suicide attempts}

Suicide attempts result in a significant social and economic burden for communities due to the utilization of health services to treat the injury, the psychological and social impact of the behaviour on the individual and his/her associates and, occasionally, the long-term disability due to the injury. More importantly, a prior suicide attempt is the single most important predictor of death by suicide in the general population: individuals who have made prior suicide attempts are at much higher risk of dying by suicide than individuals who have not made prior suicide attempts. Identifying these high-risk individuals and providing them with follow-up care and support should be a key component of all comprehensive suicide prevention strategies.

Monitoring the prevalence, demographic patterns and methods used in suicide attempts in a community provides important information that can assist in the development and evaluation of suicide prevention strategies. When combined with information on suicide deaths, data on the rates and methods of suicide attempts can be used to estimate the case fatality rate of suicidal behaviour (i.e. the proportion of all suicidal acts that result in death) by sex, age and method. This information helps in identifying the high-risk groups in the community that should be the target of selective psychosocial interventions and the high-risk methods that should be the target of means restriction interventions.

There are two primary methods for obtaining information about national or regional rates of suicide attempts: from demographic groups that should be prioritized for intervention efforts. National estimates of the proportions of all suicides by different methods provide a focus for national means restriction efforts, but these efforts often need to be adapted for different regions in each country. For instance, pesticide-ingestion suicides primarily occur in rural areas, so pesticide restriction measures would probably not be a primary focus of suicide prevention programmes in urban areas of countries that may have a high proportion of pesticide-ingestion suicides nationally.

self-reports of suicidal behaviour in surveys of representative samples of community residents, and from medical records about treatment for self-harm in representative samples of health-care institutions (usually hospitals) in the community. WHO does not routinely collect data on suicide attempts, but it has supported the activities of the WHO World Mental Health Surveys (14) which collect information about suicide attempts. Moreover, the WHO STEPwise approach to chronic disease risk factor surveillance (STEPS) includes questions intended to collect data on suicide attempts (15). Additionally, WHO has released a resource booklet, in addition to one on suicide case registration (16), about establishing hospital-based case registries for medically treated suicide attempts (17).

\section{Self-reports of suicidal behaviour from surveys}

Many community surveys about psychosocial issues include self-report questions about suicidal behaviour. When the same survey is administered to the same population over time, reasonable conclusions can be drawn about changing trends in self-reported suicidal behaviour. One example of this is the biannual Youth Risk Behavior Surveillance System (YRBSS) in the USA (18). However, it is much more difficult to interpret results when different survey instruments are employed or when the same survey is administered to different populations (particularly if it uses different languages). Beyond the standard methodological problems associated with community surveys (such as ensuring that the survey sample is truly representative of the target population), there 
are several potential confounding factors that can affect self-report rates of suicidal ideation and suicide attempts. Such factors include the literacy level of the population, the specific wording used in the questionnaire, the length of the questionnaire, the interpretation (i.e. the exact meaning and implications) of the wording in the local language, the time frame considered, and - most importantly - the extent to which respondents are willing to reveal this information.

Willingness to report prior suicidal behaviour may vary by age, sex, religion, ethnicity and other factors, so one must be cautious when comparing self-reported rates of suicidal behaviour in different demographic or cultural groups. Comparison of self-reported rates of suicidal ideation across groups is particularly problematic because suicidal ideation is often a fleeting, fluctuating experience that is not observable by others. Moreover, comparison of self-reported lifetime rates of suicidal ideation and suicide attempts which may be of limited value in assessing the current risk of suicide - are also confounded by the different ages of respondents and by recall biases in remembering long-distant events. Thus, the most useful, and arguably the most reliable, measure generated by community-based self-report surveys is the occurrence of suicide attempts (that result in some level of physical injury) in the prior year.

The WHO World Mental Health Surveys (14) use the WHO Composite International Diagnostic Interview (CIDI) that includes a series of standardized questions about the occurrence, timing, method(s) and medical treatment (if any) of suicide attempts. The available report on the 12-month prevalence of suicide attempts among individuals 18 years of age and older (collected in studies conducted from 2001 to 2007) is based on data from 10 high-income countries (nine used nationally representative samples) with a combined sample of 52484 individuals, six middle-income countries (four used nationally representative samples) with a combined sample of 25666 individuals, and five low-income countries (one used a nationally representative sample) with a combined sample of 31227 individuals (19). The reported prevalence of having made one or more suicide attempts in the prior year was 3 per 1000 individuals (i.e. 0.3\%) in both males and females from high-income countries, 3 per 1000 in males and 6 per 1000 in females from middle-income countries, and 4 per 1000 in both males and females from low-income countries. Applying the prevalence in high-income, middle-income and low-income countries to the adult populations (i.e. 18 years and above) of all countries in each of these World Bank income strata, the estimated global annual prevalence of self-reported suicide attempt is approximately 4 per 1000 adults. Given the estimated 2012 global suicide rate of 15.4 per 100000 adults of 18 years and over, this would indicate that for each adult who died of suicide there were likely to be more than 20 others who made one or more suicide attempts. However, as is the case for the rates of suicide and suicide attempts, there is wide variation in the attempt-to-death ratio and in the case fatality rate of suicidal behaviour by region, sex, age and method.

\section{Hospital-based data on medically treated suicide attempts}

The other sources of information about the rates of suicide attempts are records of medical treatment for self-injury from emergency and outpatient departments of hospitals and from other health facilities. Unlike the recording of deaths, there are no internationally accepted methods for standardizing the collection of information about suicide attempts, so a number of methodological issues need to be considered when comparing rates across different jurisdictions.

Estimates of the rates of medically treated suicide attempts based on hospital reports may be inaccurate if the selected hospitals are not representative of all hospitals in the community or if a substantial proportion of suicide attempts are treated only by local clinics and therefore do not reach a hospital. Moreover, the reported rates of medically treated suicide attempts are heavily influenced by the recording processes in hospital settings. These may not be fully reliable because they:

- may not distinguish individuals from treatment episodes (so individuals with multiple suicide attempts in a year are duplicated);

- may not exclude those who die in the hospital during treatment for the suicidal act or are discharged so they can die at home (and thus are not suicide attempts);

- may not distinguish those with non-suicidal self-injury from those with suicidal self-injury;

- may not include individuals treated in hospital emergency departments who are subsequently discharged before formal inpatient hospital admission;

- may not include individuals directly admitted to hospital wards without going through the emergency department;

- may not record the method of the suicide attempt (which makes it impossible to assess method-specific case-fatality rates); and most importantly

- may systematically record suicide attempts as "accidents" because of stigma, lack of insurance coverage for suicidal behaviour or concern about potential legal complications. 
Standardizing these recording processes within countries, and subsequently between countries, is one of the basic tasks needed in countries' efforts to understand and eventually reduce suicides (see Box 2).

Box 2.

\section{The National Registry of Deliberate Self-Harm in Ireland}

The National Registry of Deliberate Self-Harm (NRDSH) in Ireland is a national system of population monitoring for occurrence of deliberate self-harm. The registry was established at the request of the Department of Health and Children by the National Suicide Research Foundation and is funded by the Health Service Executive's National Office for Suicide Prevention. The purpose of this national registry is to determine and monitor the incidence and repetition of self-harm presentations to hospital emergency departments with the aim of identifying high-incidence groups and areas, and informing services and practitioners concerned with the prevention of suicidal behaviour $(20,21)$.
Only some suicide attempts result in injuries that receive medical treatment, so case-fatality estimates based on medically treated suicide attempts will necessarily be higher than those based on self-reported rates of suicide attempts from community surveys. Very few countries have developed national or nationally representative registry systems of medically treated suicide attempts so it is only rarely possible to integrate hospital-level data with national suicide rates. Case-fatality measures can be computed when nationally representative data about medically treated suicide attempts are available. Unfortunately, there are no examples available from LMICs so examples are limited to four high-income countries: the Flanders region of Belgium (22), Ireland (20), Sweden (23), and the USA (24). There was a four-fold range in the overall case fatality of "medically serious suicidal behaviour" (operationally defined as suicidal behaviour that results in medical treatment or death) in the four countries from $4.2 \%$ in Ireland to $17.8 \%$ in Flanders. The pattern of case fatality by sex and age is identical across the four countries: medically serious suicidal behaviour is much more likely to be fatal in men than in women and there is a clear stepwise increase in the case fatality of medically serious suicidal behaviour by age. This finding is consistent with previous subnational reports of the case fatality of medically serious suicidal behaviour $(25,26)$.

Another potentially useful measure - which is also available for specific locations in several LMICs - is the in-hospital case fatality for specific methods (i.e. the number of in-hospital deaths from a method divided by the number of persons treated in hospitals who used the method to attempt suicide). Determination of method-specific in-hospital case fatality can identify highly lethal methods that should be a focus of both community-based means restriction preventive efforts and hospital-based efforts to improve the medical management of self-harm behaviours. For example, the medical management of pesticide-ingestion suicide attempts is often technically difficult and may require advanced equipment that is not available in rural hospitals of many LMICs. In these settings, providing training and equipment to local medical personnel is an essential component of the suicide prevention effort (27). Data on the in-hospital case fatality of different pesticides - which can range from $0 \%$ to $42 \%$ - is essential in determining the type of training and equipment that is most needed (28). 
Risk and protective factors, and related interventions 


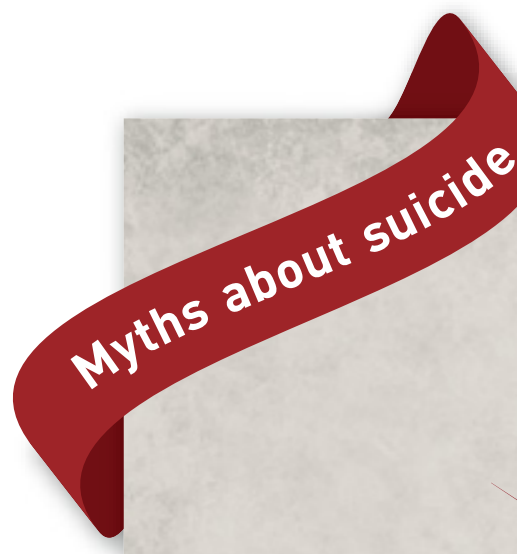

Myth:

Most suicides happen suddenly without worning.

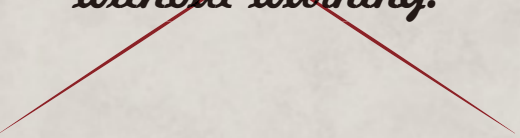

\section{Fact:}

The majority of suicides have been preceded by warning signs, whether verbal or behavioural. Of course there are some suicides that occur without warning. But it is important to understand what the warning signs are and look out for them. 
The foundation of any effective response in suicide prevention is the identification of suicide risk factors that are relevant to the context and their alleviation by implementing appropriate interventions. Suicidal behaviours are complex. There are multiple contributing factors and causal pathways to suicide and a range of options for its prevention. Usually no single cause or stressor is sufficient to explain a suicidal act. Most commonly, several risk factors act cumulatively to increase an individual's vulnerability to suicidal behaviour. At the same time, the presence of risk factors does not necessarily lead to suicidal behaviour; not everyone with a mental disorder, for instance, dies from suicide. Effective interventions are imperative as they can mitigate the risk factors identified. Protective factors are equally important and have been identified as improving resilience. Therefore, enhancing protective factors is also an important aim of any comprehensive suicide prevention response.

\section{Risk factors}

A wide spectrum of risk factors has been recognized and key ones are illustrated in Figure 7. The diagram includes a wide range of factors. For the ease of navigation they have been grouped into areas that span across systemic, societal, community, relationship (social connectedness to immediate family and friends) and individual risk factors that are reflective of an ecological model.

It is important to note firstly that the risk factors listed are far from exhaustive. Many others exist that may be classified and categorized differently. The importance of each risk factor and the way it is classified will depend on each context. These factors can contribute to suicidal behaviours directly but can also contribute indirectly by influencing individual susceptibility to mental disorders. It would be a mistake to assign a clear distinction between the areas identified. Just as each individual risk factor interrelates with others, the areas are not mutually exclusive. It is far more useful to view the areas as moving from systemic through to individual. Specific risk factors could actually sit within more than one of the areas simultaneously. For instance, loss of a job or financial support could influence a person individually and could lead to the deterioration of immediate relationships, but it could also be linked to an economic recession at systemic level. The groups assigned help to simplify the exhaustive risk factors that exist and to identify relevant interventions more easily.

\section{Interventions}

Evidence-based interventions for suicide prevention are organized in a theoretical framework that distinguishes between universal, selective and indicated interventions (29, 30). Figure 7 links these interventions to corresponding risk factors. These linkages are not finite, and in reality should be context-driven. The interventions are of three kinds:

1. Universal prevention strategies (Universal) are designed to reach an entire population in an effort to maximize health and minimize suicide risk by removing barriers to care and increasing access to help, strengthening protective processes such as social support and altering the physical environment.

2. Selective prevention strategies (Selective) target vulnerable groups within a population based on characteristics such as age, sex, occupational status or family history. While individuals may not currently express suicidal behaviours, they may be at an elevated level of biological, psychological or socioeconomic risk.

3. Indicated prevention strategies (Indicated) target specific vulnerable individuals within the population - e.g. those displaying early signs of suicide potential or who have made a suicide attempt.

Given the multiple factors involved and the many pathways that lead to suicidal behaviour, suicide prevention efforts require a broad multisectoral approach that addresses the various population and risk groups and contexts throughout the life course. 


\section{Figure 7. Key risk factors for suicide aligned with relevant interventions}

(Lines reflect the relative importance of interventions at different levels for different areas of risk factors)

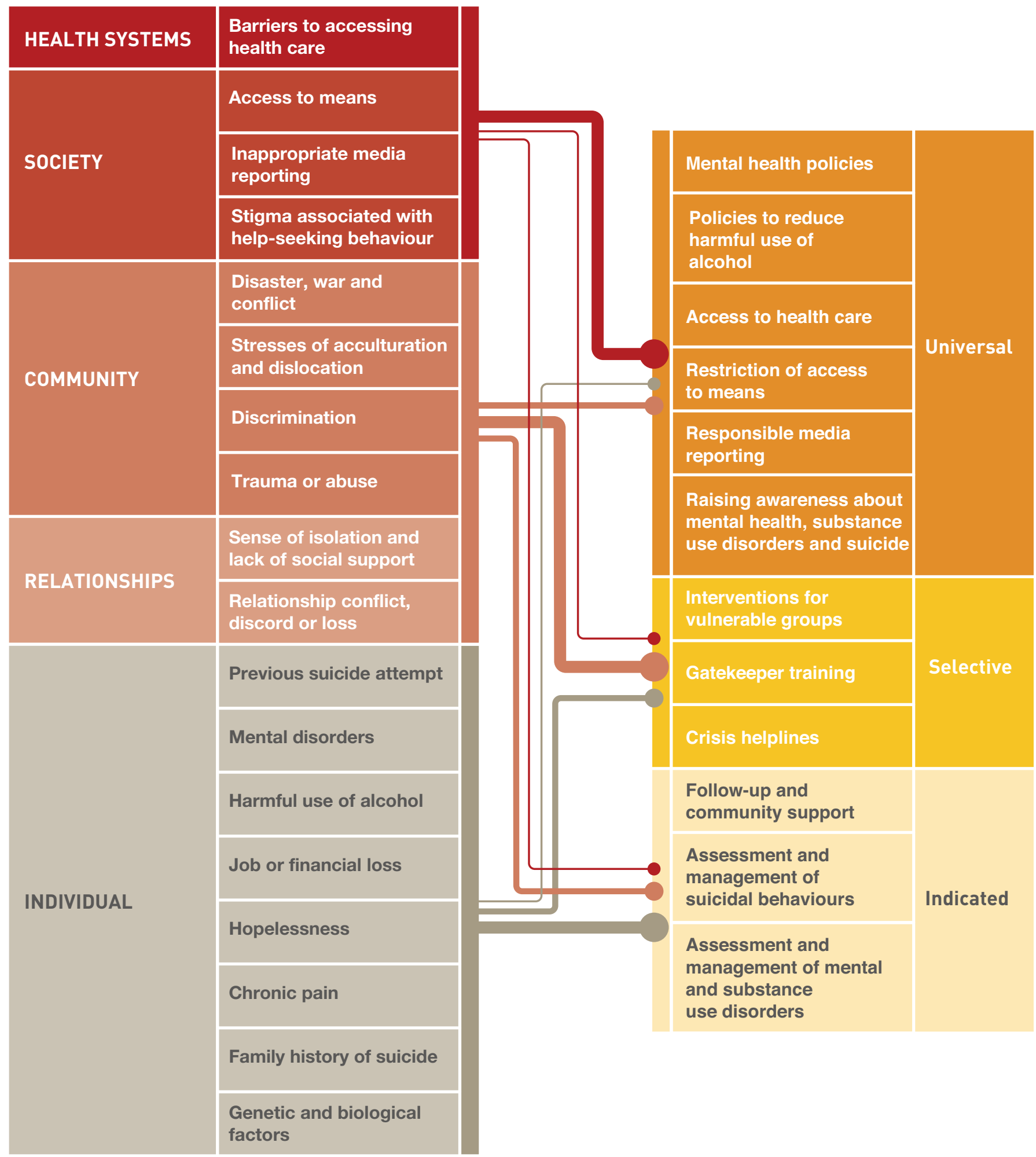




\section{Health system and societal risk factors}

Taboo, stigma, shame and guilt obscure suicidal behaviour. By proactively addressing these, supportive health systems and societies can help prevent suicide. Some of the key risk factors related to the areas of health systems and society are presented below.

\section{Barriers to accessing health care}

Suicide risk increases significantly with comorbidity, so timely and effective access to health care is essential to reducing the risk of suicide (37). However, health systems in many countries are complex or limited in resources; navigating these systems is a challenge for people with low health literacy in general and low mental health literacy in particular (38). Stigma associated with seeking help for suicide attempts and mental disorders further compounds the difficulty, leading to inappropriate access to care and to higher suicide risk.

\section{Access to means}

Access to the means of suicide is a major risk factor for suicide. Direct access or proximity to means (including pesticides, firearms, heights, railway tracks, poisons, medications, sources of carbon monoxide such as car exhausts or charcoal, and other hypoxic and poisonous gases) increases the risk of suicide. The availability of and preference for specific means of suicide also depend on geographical and cultural contexts (39).

\section{Inappropriate media reporting and social media use}

Inappropriate media reporting practices can sensationalize and glamourize suicide and increase the risk of "copycat" suicides (imitation of suicides) among vulnerable people. Media practices are inappropriate when they gratuitously cover celebrity suicides, report unusual methods of suicide or suicide clusters, show pictures or information about the method used, or normalize suicide as an acceptable response to crisis or adversity.

Exposure to models of suicide has been shown to increase the risk of suicidal behaviour in vulnerable individuals (31, $32,33)$. There are increasing concerns about the supplementary role that the Internet and social media are playing in suicide communications. The Internet is now a leading source of information about suicide and contains readily accessible sites that can be inappropriate in their portrayal of suicide (34). Internet sites and social media have been implicated in both inciting and facilitating suicidal behaviour. Private individuals can also readily broadcast uncensored suicidal acts and information which can be easily accessed through both media.

\section{Stigma associated with help-seeking behaviour}

Stigma against seeking help for suicidal behaviours, problems of mental health or substance abuse, or other emotional stressors continues to exist in many societies and can be a substantial barrier to people receiving help that they need. Stigma can also discourage the friends and families of vulnerable people from providing them with the support they might need or even from acknowledging their situation. Stigma plays a key role in the resistance to change and implementation of suicide prevention responses. 


\section{Relevant interventions for health system and societal risk factors}

\section{Mental health policies}

In 2013, WHO launched the comprehensive Mental Health Action Plan 2013-2020 (1). The plan encourages countries to work towards their own mental health policies with a focus on four key objectives:

1. Strengthen effective leadership and governance for mental health.

2. Provide comprehensive, integrated and responsive mental health and social care services in community-based settings.

3. Implement strategies for promotion and prevention in mental health.

4. Strengthen information systems, evidence and research for mental health.

The suicide rate is an indicator and its decrease is a target in the action plan.

\section{Policies to reduce harmful use of alcohol}

Policy options and interventions to reduce harmful use of alcohol have been published in WHO's Global strategy to reduce the harmful use of alcohol (35). At the same time, these offer measures for effective suicide prevention and include the following:

1. Leadership, awareness and commitment.

2. Health services' response.

3. Community action.

4. Drink-driving policies and countermeasures.

5. Availability of alcohol.

6. Marketing of alcoholic beverages.

7. Pricing policies.

8. Reducing the negative consequences of drinking and alcohol intoxication.

9. Reducing the public health impact of illicit alcohol and informally produced alcohol.

10. Monitoring and surveillance.

In populations with a lower prevalence of heavy drinking, strategies such as awareness-raising can be implemented through general media campaigns, school health promotion activities or information targeted at vulnerable individuals through health professionals (36). The alcohol culture of specific regions should be considered carefully before strategies are selected in order to ensure that the strategies are effective in the context. A functioning legal system is also a prerequisite for enforcing these strategies effectively.

\section{Access to health care}

Adequate, prompt and accessible treatment for mental and substance use disorders can reduce the risk of suicidal behaviour (37) (see also Box 6). Implementing health literacy policies and practices throughout health systems and institutions, and especially at community health centres, is a key way to improve access to health-care services in general and mental health care in particular. Practices include clear messaging to users on available services, appropriate use of language by health-care providers, and clearer pathways for patients through the system. In particular, mental health literacy should be included in health literacy strategies and policies (38).

\section{Restriction of access to means}

The most common means of suicide worldwide are self-poisoning with pesticides, hanging and jumping $(39,40)$. Restricting access to the means of suicide is effective in preventing suicide - particularly impulsive suicide - as it gives those contemplating suicide more time to reconsider (41). Implementation of strategies to restrict means can occur both at national level, through laws and regulations, and at local level, for instance by securing risk environments (42).

The key interventions in restricting access to the means of suicide include the following:

\section{- Access to pesticides}

Pesticides account for an estimated one third of the world's suicides (8). Suicide by intentional pesticide ingestion primarily occurs in rural areas of low- and middle-income countries in Africa, Central America, South-East Asia and the Western Pacific. Measures proposed to prevent suicide by pesticides include: ratifying, implementing and enforcing relevant international conventions on hazardous chemicals and wastes; legislating to remove locally problematic pesticides from agricultural practice; enforcing regulations on the sale of pesticides; reducing access to pesticides through safer storage and disposal by individuals or communities; and reducing the toxicity of pesticides $(43,44)$. In addition, the medical management of those who attempt suicide by self-ingestion of pesticides should be optimized. Specific information can be found in three WHO booklets regarding the prevention of suicide by pesticides $(27,45,46)$. 
Relevant interventions for health system and societal risk factors contd.

\section{- Access to firearms}

Suicide by firearms is a highly lethal method, accounting for the majority of suicides in some countries, such as the USA (47). Available data show a close correlation between the proportions of households owning firearms and the proportion of firearm suicides (48).

Legislation restricting firearm ownership has been associated with a reduction in firearm suicide rates in many countries, including Australia, Canada, New Zealand, Norway and the United Kingdom. Possible legislative and regulatory action to reduce firearm-related suicide includes tightening of rules on availability of firearms in private households and of procedures for obtaining licenses and registration; limiting personal gun ownership to hand guns; extending the waiting period for purchases; enforcing safe storage requirements; decreeing a minimum age for firearm purchase; and implementing criminal and psychiatric background checks for firearm purchases. Community education on regulations is also imperative in countries where guns are a familiar element in society (49).

\section{- Bridges, buildings and railroads}

Suicide by jumping - from bridges, high buildings or in front of trains - is a common method of suicide in view of its easy accessibility. Structural interventions to restrict access are effective in preventing suicides (50).

\section{- Accessibility of poisonous gases}

Historically, intentional carbon monoxide poisoning has been one of the most common methods of suicide. Legislative and pragmatic changes to domestic gas at national and regional levels have substantially reduced suicide by this method (51). Collectively, evidence indicates that reducing the lethality of carbon monoxide has a direct effect on decreasing overall suicide rates.

Charcoal-burning poisoning is a recent method of suicide by toxic gas that has rapidly become a common method in some Asian countries (9). Removing charcoal packs from open shelves into a controlled area in major store outlets in China, Hong Kong SAR has significantly reduced charcoal-related suicide deaths (52).

\section{- Access to pharmacological agents}

In most European countries, self-poisoning with medication is the second or third most common method of suicide and suicide attempts (53). Restricting access to and availability of medications that are commonly used in suicide has been shown to be an effective preventive measure (54). Health-care providers can play a critical role by restricting the amount of medication dispensed, informing patients and their families about the risks of treatment with medicines, and stressing the importance of adhering to prescribed dosages and disposal of excess unused tablets.

\section{Figure 8. Suicide deaths prevented by proposed interventions approximating a $20 \%$ reduction in 2010 suicide deaths in the USA (55)}

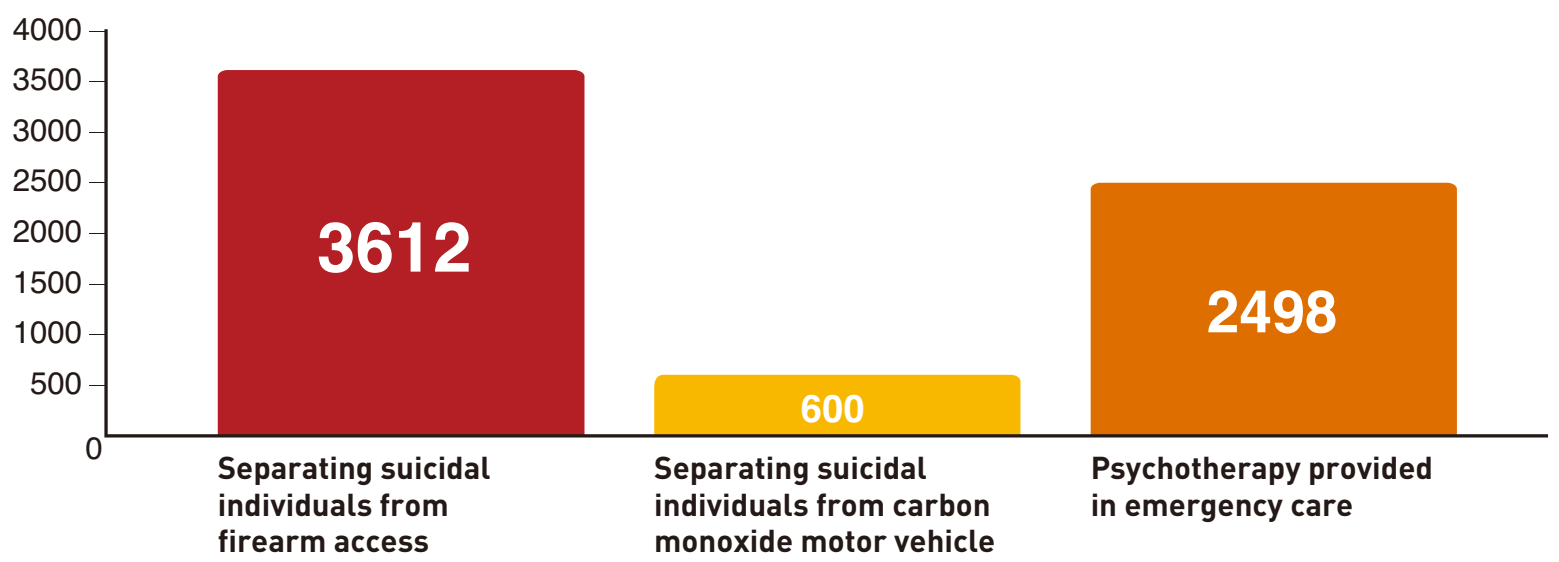

Figure 8 displays a combination of three approaches that, if fully implemented, could save many thousands of lives in just one year in the USA. However, it is important to note that the figure comes from modelling of optimal implementation of just a few approaches (55). 


\section{Responsible media reporting}

Responsible reporting of suicide in the media has been shown to decrease suicide rates (40). Important aspects of responsible reporting include: avoiding detailed descriptions of suicidal acts, avoiding sensationalism and glamorization, using responsible language, minimizing the prominence of suicide reports, avoiding oversimplifications, educating the public about suicide and available treatments, and providing information on where to seek help (56). Media collaboration and participation in the development, dissemination and training of responsible reporting practices are also essential for successfully improving the reporting of suicide and reducing suicide imitation (57). These improvements were demonstrated in Australia and Austria following active media involvement in the dissemination of media guidelines (58)

Use of the Internet and social media has a potential role as a universal suicide prevention strategy. Some websites that promote mental health are already showing promising results in promoting help-seeking behaviours, but there is little evidence of effectiveness in preventing suicides (59). The best examples of online suicide prevention strategies are online chats with professionals for suicidal people, self-help programmes and online therapy (60). A website in the United Kingdom has clips of young people speaking about suicide attempts. These allow young people to feel empathy with others in similar situations (61). Alternatives, when computers are not available, include text messaging and the growing use of social media services on mobile devices for individual support and therapy.

\section{Raising awareness about mental health, substance use disorders and suicide}

Stigma and negative attitudes surround mental disorders and help-seeking among the public. Awareness campaigns (see also Boxes 3 and 6) aim to reduce the stigma related to mental disorders and help-seeking for suicide, and to increase access to care. There is little evidence linking awareness campaigns to a reduction in suicide, but they have had a positive impact on community attitudes, thus increasing the opportunity for public dialogue on these issues. Effective mental health awareness campaigns focus on only one or two disorders, using different types of exposure (e.g. television, print media, Internet, social media, posters) in order to reinforce the messages, appropriately adapting messages, combining several strategies, and organizing programmes at local level by targeting specific populations $(62,63)$.

Box 3.

\section{The Saving and Empowering Young Lives in Europe study}

A multicomponent mental health awareness programme for young people was developed and tested in the Saving and Empowering Young Lives in Europe (SEYLE) project. SEYLE is a preventive programme which was tested in 11 European countries and which aims to promote mental health among school-based adolescents in European schools (64). Each country performed a randomized controlled trial consisting of three active interventions and one minimal intervention which served as a control. The active interventions comprised gatekeeper training, a mental health awareness programme, and professional screening for at-risk adolescents (65).

Compared to those in the minimal intervention, adolescents who took part in the mental health awareness programme had significantly lower rates of both severe suicidal ideation/plans and suicide attempts at 12-month follow-up. For optimal implementation of awareness programmes it is important to consider the help and support of local politicians, schools, teachers and other stakeholders (66). 


\section{Community and relationship risk factors}

The communities that people live in have an important association with suicide risk factors. Worldwide, different cultural, religious, legal and historical factors have shaped the status and understanding of suicide, leading to the identification of a wide range of community factors that influence suicide risk. A person`s immediate relationships with family, close friends and significant others can also have an impact on suicidal behaviours. Some of the key factors related to these areas are described below.

\section{Disaster, war and conflict}

Experiences of natural disaster, war and civil conflict can increase the risk of suicide because of the destructive impacts they have on social well-being, health, housing, employment and financial security. Paradoxically, suicide rates may decline during and immediately after a disaster or conflict, but this varies between different groups of people. The immediate decline may be due to the emergent needs for intensified social cohesion. Overall, there seems to be no clear direction in suicide mortality following natural disasters as different studies show different patterns (67).

\section{Stresses of acculturation and dislocation}

The stresses of acculturation and dislocation represent a significant suicide risk that has an impact on a number of vulnerable groups, including indigenous peoples, asylum-seekers, refugees, persons in detention centres, internally displaced people, and newly arrived migrants.

Suicide is prevalent among indigenous peoples: native American Indians in the USA, First Nations and Inuits in Canada, Australian aboriginals, and aboriginal Maori in New Zealand all have rates of suicide that are much higher than those of the rest of the population $(68,69)$. This is especially true for young people, and young males in particular, who constitute some of the most vulnerable groups in the world (70). Suicidal behaviour is also increased among native and aboriginal communities undergoing transition (71). Among indigenous groups, territorial, political and economic autonomy are often infringed and native culture and language negated. These circumstances can generate feelings of depression, isolation and discrimination, accompanied by resentment and mistrust of state-affiliated social and health-care services, especially if these services are not delivered in culturally appropriate ways.

\section{Discrimination}

Discrimination against subgroups within the population may be ongoing, endemic and systemic. This can lead to the continued experience of stressful life events such as loss of freedom, rejection, stigmatization and violence that may evoke suicidal behaviour.

Some examples of linkages between discrimination and suicide include:

- people who are imprisoned or detained (72);

- people who identify themselves as lesbian, gay, bisexual, transgender and intersex (73);

- people who are affected by bullying, cyberbullying and peer victimization (74);

- refugees, asylum-seekers and migrants (75).

\section{Trauma or abuse}

Trauma or abuse increases emotional stresses and may trigger depression and suicidal behaviours in people who are already vulnerable. Psychosocial stressors associated with suicide can arise from different types of trauma (including torture, particularly in asylum-seekers and refugees), disciplinary or legal crises, financial problems, academic or work-related problems, and bullying (76). In addition, young people who have experienced childhood and family adversity (physical violence, sexual or emotional abuse, neglect, maltreatment, family violence, parental separation or divorce, institutional or welfare care) have a much higher risk of suicide than others (77). The effects of adverse childhood factors tend to be interrelated and correlated, and act cumulatively to increase risks of mental disorder and suicide (78).

\section{Sense of isolation and lack of social support}

Isolation occurs when a person feels disconnected from his or her closest social circle: partners, family members, peers, friends and significant others. Isolation is often coupled with depression and feelings of loneliness and despair. A sense of isolation can often occur when a person has a negative life event or other psychological stress and fails to share this with someone close. Compounded with other factors, this can lead to an increase in risk for suicidal behaviour particularly for older persons living alone since social isolation and loneliness are important contributing factors for suicide (71).

Suicidal behaviour often occurs as a response to personal psychological stress in a social context where sources of support are lacking and may reflect a wider absence of well-being and cohesion. Social cohesion is the fabric that binds people at multiple levels in a society - individuals, 
families, schools, neighbourhoods, local communities, cultural groups and society as a whole. People who share close, personal and enduring relationships and values typically have a sense of purpose, security and connectedness $(134,135)$.

\section{Relationship conflict, discord or loss}

Relationship conflict (e.g. separation), discord (e.g. child custody disputes) or loss (e.g. death of a partner) can cause grief and situational psychological stress, and are all associated with increased risk of suicide (79). Unhealthy relationships can also be a risk factor. Violence, including sexual violence, against women is a common occurrence and is often committed by an intimate partner. Intimate partner violence is associated with an increase in suicide attempts and suicide risk. Globally $35 \%$ of women have experienced physical and/or sexual violence by an intimate partner or sexual violence by a non-partner $(80,81)$.

\section{Relevant interventions for community and relationship risk factors}

\section{Interventions for vulnerable groups}

A number of vulnerable groups (see also Boxes 4 and 6) have been identified as having a higher risk of suicide. While rigorous evaluation is lacking, some examples of targeted interventions are included below.

- Persons who have experienced abuse, trauma, conflict or disaster: On the basis of evidence from studies that have investigated these relationships, interventions should be targeted at groups that are most vulnerable following conflict or a severe natural disaster. Policy-makers should encourage preservation of existing social ties in affected communities $(82,83)$.

- Refugees and migrants: Risk factors vary between groups, so it may be more effective to develop interventions tailored to specific cultural groups rather than treating all immigrants as if they are the same (84).

- Indigenous peoples: A review of intervention strategies in Australia, Canada, New Zealand and the USA found that community prevention initiatives, gatekeeper training (see next page) and culturally tailored educational interventions were effective in reducing feelings of hopelessness and suicidal vulnerability. Most effective were interventions with high levels of local control and involvement of the indigenous community to ensure that the interventions were culturally relevant (85).
- Prisoners: A review of risk factors among prisoners in Australia, Europe, New Zealand and the USA showed that prevention interventions should aim to improve mental health, decrease alcohol and substance abuse, and avoid placing vulnerable individuals in isolated accommodation. All individuals should also be screened for current or past suicidal behaviours (86)

- Lesbian, gay, bisexual, transgender and intersex (LGBTI) persons: Efforts to reduce the suicide risk among LGBTI persons should focus on addressing risk factors such as mental disorders, substance abuse, stigma, prejudice, and individual and institutional discrimination (87).

- Postvention support for those bereaved or affected by suicide: Intervention efforts for individuals bereaved or affected by suicide are implemented in order to support the grieving process and reduce the possibility of imitative suicidal behaviour. These interventions may comprise school-based, family-focused or community-based postventions. Outreach to family and friends after a suicide has led to an increase in the use of support groups and bereavement support groups, reducing immediate emotional distress such as depression, anxiety and despair (88). 
Relevant interventions for community and relationship risk factors contd.

Box 4.

\section{Interventions among military and veteran populations}

There is mounting evidence that risk of suicide is elevated among some military and veteran populations (89). Epidemiological studies such as the Army Study To Assess Risk and Resilience in Service members (Army STARRS), conducted in the USA, have identified several factors, including diagnosis with a mental illness, rank and gender (90, 91), as factors that increase the risk of suicide among persons currently serving in the military and those with a history of military service.

\section{In 2007, the USA's Department of Veterans Affairs} implemented a national toll-free hotline, the Veterans Crisis Line, for United States military veterans and their families. In 2009, the crisis line service was extended to further encompass the military community.

In recent years, the Department of Veterans Affairs and the United States' Department of Defense have contributed considerable resources to identify characteristics associated with increased risk of suicide and with implementation of interventions designed to reduce risk among vulnerable populations. These efforts have identified several factors associated with increased risk of suicide as well as strategies for identifying and engaging those at risk. Examples of these activities include strategies for enhanced case management, promotion of resilience, peer support, and patient-led planning designed to increase safety outside of clinical settings.

Current activities include efforts to identify individual and population characteristics associated with increased suicide risk that may be more prevalent among persons who volunteer for United States military service, methods for engaging at-risk persons in evidence-based treatment for underlying disorders, and management of periods of increased risk - particularly when associated with periods of transition (92).

\section{Gatekeeper training}

Individuals at risk of suicide rarely seek help. Nevertheless, they may exhibit risk factors and behaviours that identify them as vulnerable. A "gatekeeper" is anyone who is in a position to identify whether someone may be contemplating suicide. Key potential gatekeepers include (93) :

- primary, mental and emergency health providers;

- teachers and other school staff;

- community leaders;

- police officers, firefighters and other first responders;

- military officers;

- social welfare workers;

- spiritual and religious leaders or traditional healers;

- human resource staff and managers.
Gatekeeper training programmes aim to develop participants' knowledge, attitudes and skills for identifying individuals at risk, determining the level of risk, and then referring at-risk individuals for treatment (see also Box 6). All training content should be culturally adapted and should include local information about accessibility to health care. Adapted programmes have shown promising results when tailored to specific populations, such as Aboriginal groups (85). Studies show that $25-50 \%$ of women who display suicidal behaviour saw a health-care provider in the preceding four weeks; therefore gatekeeper training provides an opportunity to begin interventions with these individuals (94).

Gatekeeper training is a best practice for which no conclusive link has so far been made with reduced rates of suicide or suicide attempts (95). See also Box 5 for a programme targeted to gatekeepers and their own health. 
Box 5.

\section{A workplace suicide prevention programme that decreased suicide}

A multifaceted comprehensive police suicide prevention programme in Montreal, Canada, led to a significant decrease of $79 \%$ in suicide rates among police in Montreal. The programme consisted of half-day training on suicide for all officers in the police force, focusing on risk identification and how to help. Supervisors and union representatives received a full day of training on risk assessment and providing help. A volunteer police telephone helpline manned by specially trained officers was established and there was a publicity campaign on resources for help and on the importance of working together in suicide prevention (96).

Comprehensive suicide prevention programmes tailored to the culture of the work environment may be effective in improving attitudes, knowledge and behaviours and may significantly affect suicide rates.

\section{Crisis helplines}

Crisis helplines are public call centres which people can turn to when other social support or professional care is unavailable or not preferred. Helplines can be in place for the wider population or may target certain vulnerable groups. The latter can be advantageous if peer support is likely to be helpful.

Helplines in the USA have been shown to be effective in engaging seriously suicidal individuals and in reducing suicide risk among callers during the call session and subsequent weeks (97). A study of telephone and chat helpline services in Belgium suggests that these strategies might also be cost-effective for suicide prevention (98). Helplines have proved to be a useful and widely implemented best practice. However, despite reducing suicide risk, the lack of evaluation means that there is no conclusive association with reducing suicide rates. 


\section{Individual risk factors}

Risk of suicide can be influenced by individual vulnerability or resilience. Individual risk factors relate to the likelihood of a person developing suicidal behaviours.

\section{Previous suicide attempt}

By far the strongest indicator for future suicide risk is one or more prior suicide attempts (99). Even one year after a suicide attempt, risk of suicide and premature death from other causes remains high (100).

\section{Mental disorders}

In high-income countries, mental disorders are present in up to $90 \%$ of people who die by suicide (101), and among the $10 \%$ without clear diagnoses, psychiatric symptoms resemble those of people who die by suicide. However, mental disorders seem to be less prevalent (around 60\%) among those who die by suicide in some Asian countries, as shown in studies from China and India $(12,102)$.

This risk factor should be approached with some caution. Depression, substance use disorders and antisocial behaviours are relatively common and most people suffering from them will not display suicidal behaviour. However, people dying by suicide or making suicide attempts may have a significant psychiatric comorbidity. Suicide risk varies with the type of disorder, and the most common disorders associated with suicidal behaviour are depression and alcohol use disorders. The lifetime risk of suicide is estimated to be $4 \%$ in patients with mood disorders (103), $7 \%$ in people with alcohol dependence (104), 8\% in people with bipolar disorder $(105,106)$, and $5 \%$ in people with schizophrenia (107). Importantly, the risk of suicidal behaviour increases with comorbidity; individuals with more than one mental disorder have significantly higher risks (101).

\section{Harmful use of alcohol and other substances}

All substance use disorders increase the risk of suicide (108). Alcohol and other substance use disorders are found in $25-50 \%$ of all suicides (104), and suicide risk is further increased if alcohol or substance use is comorbid with other psychiatric disorders. Of all deaths from suicide, $22 \%$ can be attributed to the use of alcohol, which means that every fifth suicide would not occur if alcohol were not consumed in the population (109). Dependence on other substances, including cannabis, heroin or nicotine, is also a risk factor for suicide (110).

\section{Job or financial loss}

Losing a job, home foreclosure and financial uncertainty lead to an increase in the risk of suicide through comorbidity with other risk factors such as depression, anxiety, violence and the harmful use of alcohol (111). Consequently economic recessions, as they relate to cases of individual adversity through job or financial loss, can be associated with individual suicide risk (112).

\section{Hopelessness}

Hopelessness, as a cognitive aspect of psychological functioning, has often been used as an indicator of suicidal risk when coupled with mental disorders or prior suicide attempts (113). The three major aspects of hopelessness relate to a person's feelings about the future, loss of motivation and expectations. Hopelessness can often be understood by the presence of thoughts such as "things will never get better" and "I do not see things improving", and in most cases is accompanied by depression (114).

\section{Chronic pain and illness}

Chronic pain and illness are important risk factors for suicidal behaviour. Suicidal behaviour has been found to be 2-3 times higher in those with chronic pain compared to the general population (115). All illnesses that are associated with pain, physical disability, neurodevelopmental impairment and distress increase the risk of suicide (116). These include cancer, diabetes and HIV/AIDS.

\section{Family history of suicide}

Suicide by a family or community member can be a particularly disruptive influence on a person`s life. Losing someone close to you is devastating for most people; in addition to grief, the nature of the death can cause stress, guilt, shame, anger, anxiety and distress to family members and loved ones. Family dynamics may change, usual sources of support may be disrupted, and stigma can hinder help-seeking and inhibit others from offering support (117). Suicide of a family member or loved one may lower the threshold of suicide for someone grieving (118). For all these reasons, those who are affected or bereaved by suicide have themselves an increased risk of suicide or mental disorder (119). 


\section{Genetic and biological factors}

Genetic or developmental alterations in a number of neurobiological systems are associated with suicidal behaviour. For instance, low levels of serotonin are associated with serious suicide attempts in patients with mood disorders, schizophrenia and personality disorders. A family history of suicide is a strong risk factor for suicide and suicide attempt (120).

\section{Relevant interventions for individual risk factors}

\section{Follow-up and community support}

Recently discharged patients often lack social support and can feel isolated once they leave care. Follow-up and community support have been effective in reducing suicide deaths and attempts among patients who have been recently discharged (121). Repeated follow-ups are a recommended low-cost intervention that is easy to implement; existing treatment staff, including trained non-specialized health workers, can implement the intervention and require few resources to do so (122). This is particularly useful in low- and middle-income countries. The intervention can involve the use of postcards, telephone calls or brief in-person visits (informal or formal) to make contact and encourage continued contact $(123,124)$. Involving available community support - such as family, friends, colleagues, crisis centres or local mental health centres - in aftercare is important as these can regularly monitor people and encourage treatment adherence (122).

\section{Assessment and management of suicidal behaviours}

It is important to develop effective strategies for the assessment and management of suicidal behaviours. WHO's mhGAP Intervention Guide recommends assessing comprehensively everyone presenting with thoughts, plans or acts of self-harm/suicide. The guide also recommends asking any person over 10 years of age who experiences any of the other priority conditions, chronic pain or acute emotional distress, about his or her thoughts, plans or acts of self-harm/suicide (122). A careful assessment should be carried out through clinical interviews and should be corroborated by collateral information (125).

Education and training of health workers, with a focus on emergency care staff, is needed to ensure that psychosocial support is provided to those in need and that there is systematic follow-up and community support. In addition to contributing to the management of individual risk factors, assessment and management of suicidal behaviours also addresses risk factors in relationships.

\section{Assessment and management of mental and substance use disorders}

Training health workers in the assessment and management of mental and substance use disorders is a key way forward in suicide prevention. A large number of those who die by suicide have had contact with primary health care providers within the month prior to the suicide (126). Educating primary health care workers to recognize depression and other mental and substance use disorders and performing detailed evaluations of suicide risk are important for preventing suicide. Training should take place continuously or repeatedly over years and should involve the majority of health workers in a region or country (42). It is important to consider local risk factors and to tailor the training programme to these in order for the programme to be successful within countries and cultures.

The WHO mhGAP Intervention Guide, which is directed primarily at the training of non-specialized health workers, provides guidance on the assessment and management of the following priority conditions: depression, psychosis, epilepsy/seizures, developmental disorders, behavioural disorders, dementia, alcohol use disorders, drug use disorders and self-harm/suicide (122).

It is important, however, to take into consideration the fact that multiple factors are related to the poor assessment and management skills of health workers - such as low mental health literacy and experience, stigma, lack of cooperation with psychiatrists and poor interviewing skills. Addressing these issues, for instance through education curricula and training, may therefore be important for improving assessment and management. 


\section{Box 6.}

\section{Multicomponent interventions}

There are multiple causes and pathways for suicide. Interventions that contain more than one prevention strategy might therefore be particularly useful for preventing suicide. Indeed, research suggests that multicomponent programme strategies are associated with successful reductions in suicide rates.

For example, the United States Air Force programme, consisting of 11 community and health-care components with accountability and protocols, was shown to be highly effective in preventing suicides in the Air Force (127).

A multicomponent programme targeting depressive disorders in Nuremberg, Germany, significantly reduced suicide and attempted suicide rates (128). The programme consisted of four different interventions: a public relations campaign targeting the general public; training of community facilitators such as teachers, journalists and police; training of general practitioners; and supporting patients and their families. This multifaceted intervention has now been applied by the European Alliance against Depression, which comprises partners from 17 countries (129).
Multicomponent interventions for high-risk individuals also appear to be effective. A United Kingdom study examined the effect of nine components of health-service reform on suicide outcomes (130), showing that health trusts that implemented more service reforms showed larger reductions in suicides. Three programmes were particularly associated with suicide reductions: a 24-hour crisis response, dual diagnosis policies, and a multidisciplinary review after a suicide death. These studies collectively demonstrate that there may be additive and synergistic effects of integrating multiple interventions. 


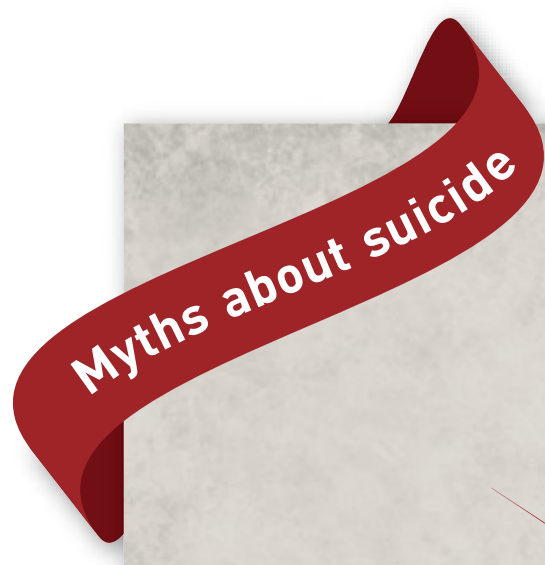

Myth:

Someone who is suicidal is determined to die.

Fact:

Fact: On the contrary, suicidal people are often ambivalent about living or dying. Someone may act impulsively by drinking pesticides, for instance, and die a few days later, even though they would have liked to live on. Access to emotional support at the right time can prevent suicide. 


\section{What protects people from the risks of suicide?}

In contrast to risk factors, protective factors guard people against the risk of suicide. While many interventions are geared towards the reduction of risk factors in suicide prevention, it is equally important to consider and strengthen factors that have been shown to increase resilience and connectedness and that protect against suicidal behaviour. Resilience has a buffering effect on suicide risk; for persons who are highly resilient the association between the risk of suicide and suicidal behaviour is diminished (131). Some protective factors counter specific risk factors while others protect individuals against a number of different suicide risk factors.

\section{Strong personal relationships}

The risk of suicidal behaviour increases when people suffer from relationship conflict, loss or discord. Conversely, the cultivation and maintenance of healthy close relationships can increase individual resilience and act as a protective factor against the risk of suicide. The individual's closest social circle - partners, family members, peers, friends and significant others - have the most influence and can be supportive in times of crisis. Friends and family can be a significant source of social, emotional and financial support, and can buffer the impact of external stressors. In particular, resilience gained from this support mitigates the suicide risk associated with childhood trauma (51). Relationships are especially protective for adolescents and the elderly, who have a higher level of dependency.

\section{Religious or spiritual beliefs}

When considering religious or spiritual beliefs as conferring protection against suicide, it is important to be cautious. Faith itself may be a protective factor since it typically provides a structured belief system and can advocate for behaviour that can be considered physically and mentally beneficial (132). However, many religious and cultural beliefs and behaviours may have also contributed towards stigma related to suicide due to their moral stances on suicide which can discourage help-seeking behaviours. The protective value of religion and spirituality may arise from providing access to a socially cohesive and supportive community with a shared set of values. Many religious groups also prohibit suicide risk factors such as alcohol use. However, the social practices of certain religions have also encouraged self-immolation by fire among specific groups such as South Asian women who have lost their husbands (133). Therefore, while religion and spiritual beliefs may offer some protection against suicide, this depends on specific cultural and contextual practices and interpretations.

\section{Lifestyle practice of positive coping strategies and well-being}

Subjective personal well-being and effective positive coping strategies protect against suicide (134). Well-being is shaped in part by personality traits which determine vulnerability for and resilience against stress and trauma. Emotional stability, an optimistic outlook and a developed self-identity assist in coping with life's difficulties. Good self-esteem, self-efficacy and effective problem solving-skills, which include the ability to seek help when needed, can mitigate the impact of stressors and childhood adversities (135). Willingness to seek help for mental health problems may in particular be determined by personal attitudes. As mental disorders are widely stigmatized, people (and especially males) may be reluctant to seek help. People who are unlikely to seek help can compound their mental health problems, increasing the risk of suicide that may otherwise have been effectively prevented through early intervention. Healthy lifestyle choices which promote mental and physical well-being include regular exercise and sport, adequate sleep and diet, consideration of the impact on health of alcohol and drugs, healthy relationships and social contact, and effective management of stress $(136,137)$.

Use of "upstream approaches" such as addressing risk and protective factors early in the life course has the potential to "shift the odds in favour of more adaptive outcomes" over time. Moreover, upstream approaches may simultaneously impact a wide range of health and societal outcomes such as suicide, substance abuse, violence and crime (138) (see Box 7). 
Box 7.

\section{Theoretically valid upstream prevention approaches}

Childhood adversity (e.g. child maltreatment, exposure to domestic violence, parent mental disorder) and other risk factors appearing early in life (e.g. bullying, delinquency) have been linked to later morbidity and mortality, including suicide (139). Similarly, protective factors (e.g. connectedness) acquired in childhood may reduce later suicide risk. While effective upstream strategies exist, they remain largely unevaluated with regard to their impact on suicide and attempted suicide; however, they are theoretically valid and provide promising directions for future suicide prevention and evaluation.
Examples of upstream strategies include:

- Early childhood home visits to provide education by trained staff (e.g. nurses) to low-income expectant/new mothers $(140,141)$.

- Mentoring programmes to enhance connectedness between vulnerable young people and supportive, stable and nurturing adults (142).

- Community-wide prevention systems to empower entire communities to address adolescent health and behaviour problems through a collaborative process of engagement (143).

- School-based violence prevention and skill-building programmes to engage teachers/staff, students and parents in fostering social responsibility and social-emotional skills-building (e.g. coping, problem-solving skills, help-seeking) (144). 


\section{The current situation in suicide prevention}




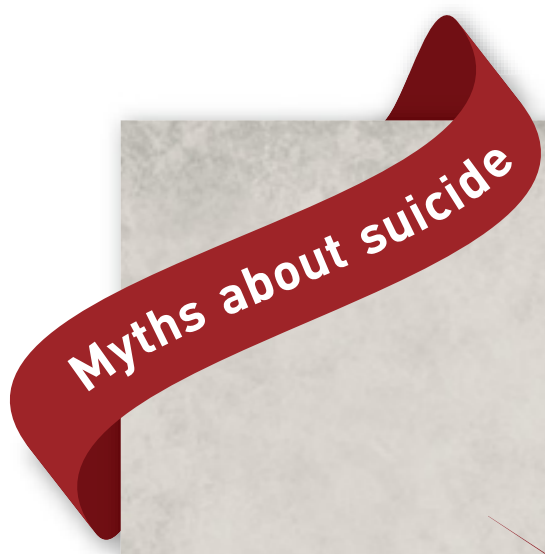

Myth:

Once someone is suicidal, he or she will always remain suicidal

Fact:

Heightened suicide risk is often short term and situation specific. While suicidal thoughts may return, they are not permanent and an individual with previously suicidal thoughts and attempts can go on to live a long life. 
Suicide is a major public health problem worldwide but it is preventable. It is imperative that more governments through their health, social and other relevant sectors invest human and financial resources in suicide prevention (145). Health ministries play a central role in government efforts to reduce suicide. However, reducing suicide nationally must be a multisectoral effort in order to be effective. Thus, health ministries have a responsibility to lead the engagement of other ministries, as well as stakeholders beyond the government sector, as part of a comprehensive national effort.

\section{What is known and what has been achieved}

Knowledge about suicidal behaviour has grown enormously in the past few decades. It is worth examining some achievements in suicide research, policy and practice.

\section{Research achievements}

1. Recognition of multicausality: The interplay of biological, psychological, social, environmental and cultural factors in the determinism of suicidal behaviours is now well recognized. The contribution of comorbidity (e.g. mood and alcohol use disorders) in increasing the risk of suicide has become evident to researchers and clinicians alike.

\section{Identification of risk and protective factors: Many risk} and protective factors for suicidal behaviours have been identified through epidemiological research both in the general population and in vulnerable groups (146). There has been an increase in knowledge about psychological factors and several cognitive mechanisms related to suicidal behaviour, such as feelings of hopelessness, cognitive rigidity, feelings of entrapment, impaired decision-making, impulsivity and the protective role of social support and good coping skills.

3. Recognition of cultural differences: Cultural variability in suicide risk factors has become apparent. This is especially evident in the less relevant role of mental disorders in countries such as China (12) and India (13). There is increasing recognition that psychosocial and cultural/traditional factors can play a very important role in suicide. However, culture can also be a protective factor; for instance, cultural continuity (i.e. the preservation of traditional identities) has been established as an important protective factor among First Nations and indigenous communities in North America (147).

\section{Policy achievements}

1. National suicide prevention strategies: In recent decades, and particularly since 2000 , a number of national suicide prevention strategies have been developed. There are 28 countries known to have national strategies demonstrating commitments to suicide prevention.

2. World Suicide Prevention Day: International recognition of suicide as a major public health problem culminated in the creation of World Suicide Prevention Day on 10 September 2003. This observance - held on the same date every year is organized by the International Association for Suicide Prevention (IASP) and has been cosponsored by WHO. This day has spurred campaigns both nationally and locally and has contributed to raising awareness and reducing stigma around the world.

3. Education about suicide and its prevention: At the academic level, many suicide research units have been created, as well as graduate and postgraduate courses. During the past 15 years the delivery of training packages on suicide prevention has also become widespread, with specific modules for different settings such as schools, military environments and prisons.

\section{Practice achievements}

\section{Utilization of non-specialized health professionals:} Guidelines have been developed that expand the capacity of the primary health care sector to improve management and assessment of suicidal behaviours by involving non-specialized health workers. This has been an important factor in lowand middle-income countries where resources are limited $(122,148)$.

2. Self-help groups: Establishment of self-help groups for survivors, both of suicide attempts and for those bereaved by suicide, has substantially increased since 2000 (149).

3. Trained volunteers: Trained volunteers who provide online and telephone counselling are a valuable source of emotional help for individuals in crisis (150). Crisis helplines, in particular, have gained international recognition for their important contribution in supporting people during suicidal crises (151). 


\section{What are countries doing about suicide prevention now?}

In 2013, IASP and the Department of Mental Health and Substance Abuse of WHO initiated the IASP-WHO global survey on suicide prevention to ascertain what information exists on national strategies and activities in this area. Questionnaires were sent predominantly to members of IASP in 157 countries, with 90 countries responding (a global response rate of $57 \%$ ). According to $\mathrm{WHO}$ regions, responses were received from 18 countries in the African Region, 17 in the Region of the Americas, 11 in the Eastern Mediterranean Region, 26 in the European Region, 7 in the South-East Asia Region and 11 in the Western Pacific Region. Caution should be exercised when interpreting the findings as they cannot be generalized to all countries.

\section{National responses to suicide}

In $55(61 \%)$ of the responding countries, suicide was perceived to be a significant public health concern. Within the different $\mathrm{WHO}$ regions, this varied from $20(77 \%)$ in the European Region to 2 (29\%) in the South-East Asia Region.

In $28(31 \%)$ of the responding countries a comprehensive national strategy or action plan was adopted by the government (Table 2). In the vast majority of countries, this has developed since 2000 .

Table 2. Numbers of responding countries with a national strategy on suicide prevention adopted or under development

\begin{tabular}{|l|c|c|}
\hline & $\begin{array}{l}\text { Number of countries with } \\
\text { a national strategy or action plan }\end{array}$ & $\begin{array}{l}\text { Number of countries where } \\
\text { a national strategy or action plan } \\
\text { is under development }\end{array}$ \\
\hline African Region & 0 & 3 \\
\hline Region of the Americas & 8 & 2 \\
\hline Eastern Mediterranean Region & 0 & 5 \\
\hline European Region & 13 & 0 \\
\hline South-East Asia Region & 2 & 2 \\
\hline Western Pacific Region & 5 & 13 \\
\hline Total number of countries & 28 & 5 \\
\hline
\end{tabular}


In 48 countries (53\%) an NGO was noted as specifically dedicated to the prevention of suicide. Within the regions this ranged from 22 in the European Region to 1 in the Eastern Mediterranean Region. In 20 (22\%) of the responding countries there was a national centre or institute dedicated to suicide research and/or prevention. National centres were most prevalent in the European Region (10) and least prevalent in the African and Eastern Mediterranean regions (1 each).
Among the countries that did not have a national strategy, a number of suicide prevention activities were carried out in the 47 countries (52\%) which provided a response to this specific question (Table 3).

\section{Table 3. Activities of responding countries without a national strategy on suicide prevention}

\begin{tabular}{|c|c|c|}
\hline Type of programme & Characteristics & Number of countries \\
\hline National programme & $\begin{array}{l}\text { A programme or initiative which addresses one or } \\
\text { more of the key areas for suicide prevention at } \\
\text { national level with leadership from an NGO or } \\
\text { academic institution. }\end{array}$ & 7 \\
\hline Setting-specific programme & $\begin{array}{l}\text { One or more comprehensive, multifaceted suicide } \\
\text { prevention initiatives managed by an institution, } \\
\text { the private sector, or other. }\end{array}$ & 9 \\
\hline Scattered programmes & $\begin{array}{l}\text { Isolated/scattered programmes or activities } \\
\text { addressing one or more key suicide prevention } \\
\text { areas at subnational level with leadership from } \\
\text { state, regional or local authorities. }\end{array}$ & 26 \\
\hline Integrated programme & $\begin{array}{l}\text { No specific stand-alone strategy or programme, } \\
\text { but suicide prevention is integrated into health } \\
\text { policies as a sub-item in another area (e.g. mental } \\
\text { health, alcohol, noncommunicable diseases). }\end{array}$ & 8 \\
\hline
\end{tabular}




\section{Training on suicide risk assessment and intervention}

In 34 (38\%) of the responding countries, training in suicide assessment and intervention was widely available for mental health professionals. Availability ranged from 14 countries in the European Region to 3 countries in the African Region.

Training for general practitioners was available in 23 (26\%) of the responding countries. Within the regions this ranged from 9 countries in the European Region to 1 country each in the African and Western Pacific regions.

Suicide prevention training for non-health professionals such as first responders, teachers or journalists - was available in 33 (37\%) of the responding countries. Within the regions this ranged from 15 in the European Region to none in the African Region.

\section{Support groups for people bereaved by suicide}

In 38 (42\%) of the 90 countries responding, self-help groups were available for people bereaved by suicide. Availability ranged from 20 countries in the European Region to none in the Eastern Mediterranean Region. In 25 (66\%) of the 38 countries, some, but not all, of the support groups were led by accredited professionals, and in $9(24 \%)$ of the 38 countries all support groups were led by accredited professionals.

\section{Current legal status of suicide around the world and perspectives for change}

At the beginning of the nineteenth century, most countries around the world had laws that provided for punishment, including jail sentences, for persons who attempted suicide. However, in the last 50 years the situation has changed significantly. Most, but not all, countries have decriminalized suicide.

Of 192 independent countries and states investigated (152), 25 currently have specific laws and punishments for attempted suicide. An additional 10 countries follow Sharia law and in these countries people who have attempted suicide may be punished. Penalties stipulated in the laws range from a small fine or short period of imprisonment to life imprisonment. However, many of the countries with laws stipulating punishments do not actually prosecute people who attempt suicide. The complexities of the situation are illustrated by the following examples that exist in different countries:

- People who have attempted suicide are consistently arrested, but they are generally not prosecuted at the first attempt and leave the police station with a severe warning of the consequences of a repeated attempt. After a second attempt, a jail sentence is usually given.

- People who attempt suicide are consistently jailed; a group of volunteer lawyers work to provide them with counsel, help to obtain their release and refer them for treatment.

- Police occasionally arrest people who have attempted suicide, but judges release them afterwards.

\section{What are the effects of decriminalization?}

No data or case-reports indicate that decriminalization increases suicides; in fact, suicide rates tend to decline in countries after decriminalization. It is possible that decriminalization will increase the reporting of suicides once fear of legal recriminations is eliminated. This allows for more accurate estimates of the true extent of the issue. When suicide is considered a criminal act, suicide attempts are often hidden and suicide deaths are unreported, thus giving the false impression that suicidal behaviours are less prevalent. All countries should review their legal provisions in relation to suicide to ensure they do not deter people from seeking help. 
Working towards

a comprehensive national

response for suicide prevention 


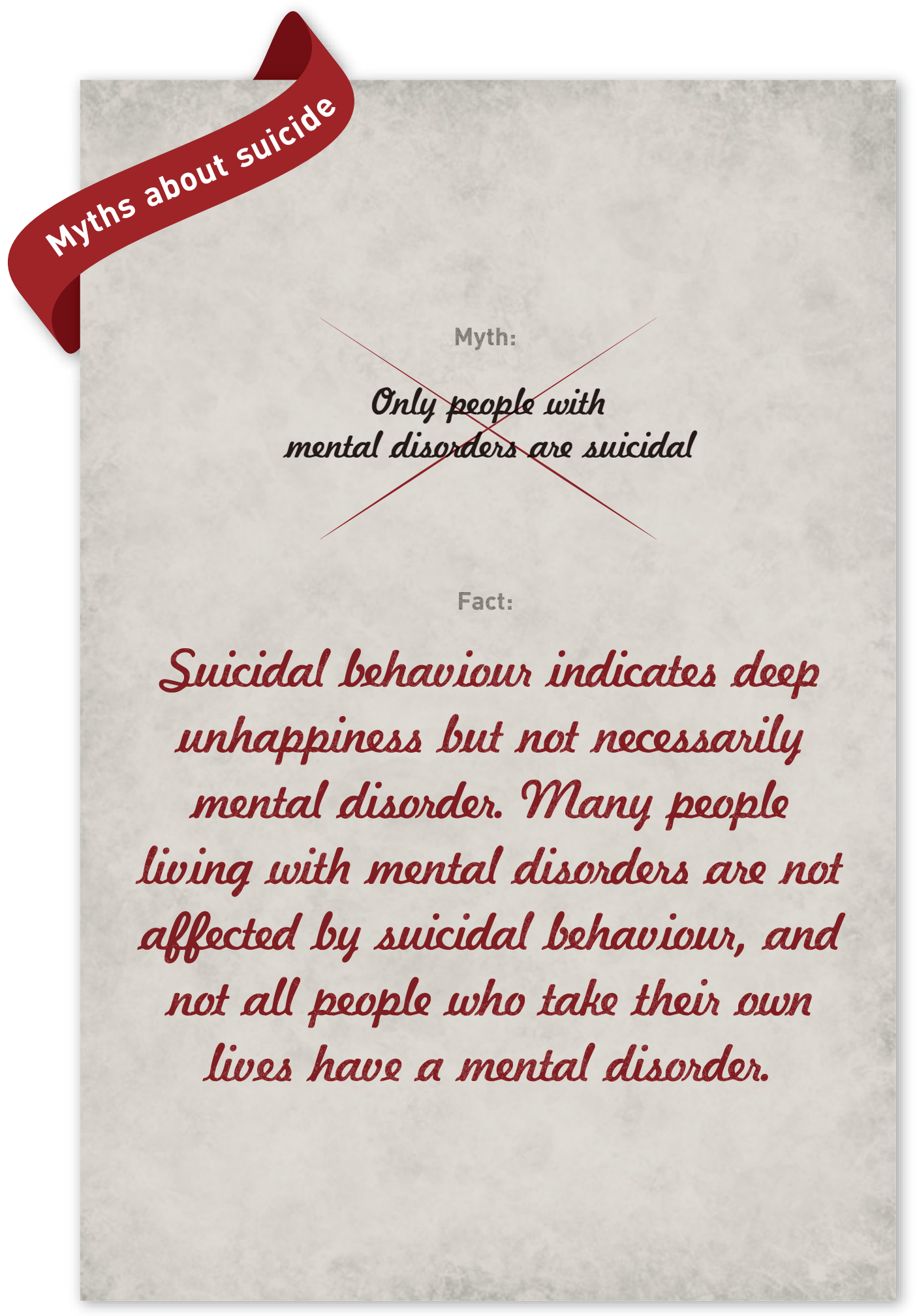


Establishing a country's national response to suicide prevention presents an opportunity to tackle the task of preventing suicides across the world in a way that is meaningful to a country's context. Regardless of where a country currently stands in terms of commitment to and resources for suicide prevention, the process of establishing a national response itself can improve prevention. The creation of a national response provides a rallying point for bringing together a diversity of stakeholders in suicide prevention and for building on their expertise through a participatory approach. The result is a convergence of stakeholders from government, NGOs, and health and non-health sectors that can contribute to country-specific, national long-term strategies that follow a public health model. Many stakeholders, from survivors' support groups to advocacy groups for vulnerable populations, are already active in suicide prevention activities within countries. Ministries of health and national policy-makers play an integral role in coordinating this process since strong leadership ensures well-defined and measurable aims and goals.

To be effective, national suicide prevention objectives could be designed to:

- enhance surveillance and research;

- identify and target vulnerable groups;

- improve the assessment and management of suicidal behaviour;

- promote environmental and individual protective factors;

- increase awareness through public education;

- improve societal attitudes and beliefs and eliminate stigma towards people with mental disorders or who exhibit suicidal behaviours;

- reduce access to means of suicide;

- encourage the media to adopt better policies and practices toward reporting suicide; and

- support individuals bereaved by suicide.
In addition, all countries should review their legal provisions in relation to suicide to ensure they do not act as a barrier to seeking help.

The lack of a fully-developed comprehensive national strategy should not be an obstacle to implementing targeted suicide prevention programmes since these can contribute to a national response. Such programmes firstly aim to identify groups vulnerable to the risk of suicide, and secondly they improve access to services and resources for the identified groups. The programmes are designed to promote mental well-being and reduce suicide risk. When designing targeted suicide prevention programmes it is important to account for cultural diversity, utilize advances in technology and incorporate prevention training and education for groups (153).

Evaluation of an overall national response is important and needs to be implemented into all targeted prevention programmes and interventions, but it continues to be a challenge (154). Resources and skills in programme evaluation are limited in all service systems involved in suicide prevention. Establishing the training and education infrastructure to address this is a priority, as are creation and support of opportunities for sharing information on evaluation methods. 


\section{Case example: Japan - suicide prevention in the face of socioeconomic change}

\section{Context}

In 1998, the number of suicides in Japan rose remarkably to 32863 from 24391 the previous year. In the period 1978-1997 the annual suicide number had averaged approximately 25000 . Most people considered this rapid increase to have arisen from the country's socioeconomic problems. The increase in suicide rates was found in all age groups, but particularly among middle-aged men. Despite the commonly recognized risk factors, suicide remained a social taboo in Japan. It was considered a personal problem and was not widely or publicly discussed.

\section{Drivers of change}

In 2000, the situation began to change when children who had lost their parents to suicide began to break the taboo by speaking out in the media about their experiences. In 2002, the Ministry of Health, Labour and Welfare held an "expert roundtable on suicide prevention measures". The ensuing report outlined that a suicide prevention policy must not only address mental health issues correctly but must also include a multifaceted examination of psychological, social, cultural and economic factors. However, this report was treated simply as recommendations from experts and it was not fully reflected in any actual policies.
Suicide began to be viewed as a "social problem" in Japan around 2005-2006 and this triggered concrete actions. In May 2005, the NGO LIFELINK collaborated with a member of the parliament to bring about the first forum on suicide. At the forum, LIFELINK and other NGOs submitted urgent proposals for comprehensive suicide prevention. The Minister of Health, Labour and Welfare, who attended the forum, vowed on behalf of the government to tackle the issue of suicide. This vow was widely reported in the media.

\section{Legislation}

Subsequently, a bipartisan parliamentary group was formed in 2006 in support of the formation of a suicide prevention policy. Buoyed by a petition with more than 100000 signatories calling for suicide prevention legislation, Japan's Basic Act for Suicide Prevention was signed into law in June 2006. Following this, the driving force for suicide prevention shifted from the Ministry of Health, Labour and Welfare to the Cabinet Office, and suicide prevention became an overarching government policy that was not limited to a single ministry. In 2007, the "General principles of suicide prevention" policy was enacted, aimed at preventing suicide and providing support to survivors. Underlying it was the philosophy that a suicide prevention policy would help build a society in which citizens live purposeful lives, and various responsibilities were attributed to the state. The principles of the Basic Act reflect the idea that suicide prevention activities should take account of the complexity of suicide-related factors and should not only focus on mental disorders. Thus, suicide prevention activities should include prevention, intervention and postvention, with close cooperation between stakeholders.
Following the global economic crisis in 2008, the Japanese government secured funding in 2009 through the "Regional comprehensive suicide prevention emergency strengthening fund", or Regional Fund. The Regional Fund was mainly directed at reinforcing local suicide prevention activities, including intensive public awareness campaigns during the crucial month of March - a time when it was recognized that the rate of suicide increased. In 2010, the government designated March as National Suicide Prevention Month. It also introduced reforms to data collection, mandating the National Police Agency to release detailed municipal-level suicide statistics monthly. This facilitated the promotion of suicide prevention measures aligned with local needs.

In 2012, the "General principles of suicide prevention" policy was revised to emphasize support for young people and for those who had previously attempted suicide.

\section{Results}

Following a gradual decrease beginning in 2009, the number of suicides in Japan fell below 30000 in 2012 for the first time since 1998. Most of this decrease occurred in urban areas. The suicide rate for young people continued to rise, signalling the need for new targeted interventions. However, the rates of suicide among middle-aged and older persons had decreased, resulting in the overall decline. Data from the National Police Agency also showed a marked decrease in suicides related to economic and livelihood issues. 


\section{How can countries create a comprehensive national strategy and why is it useful?}

One systematic way of developing a national response is through the creation of a national suicide prevention strategy. A national strategy indicates a clear commitment of a government to prioritizing and dealing with the issue of suicide. It also provides leadership and guidance regarding what the key evidence-based suicide prevention activities are and what should be prioritized. A strategy allows for the transparent identification of stakeholders who are accountable for specific tasks, and outlines ways to coordinate between them effectively (145).

The explicit inclusion and mainstreaming of suicide prevention within other priority health programmes and partnerships (such as HIV/AIDS, women's and children's health, noncommunicable diseases, and the Global Health Workforce Alliance), as well as within other relevant sectors' policies and laws (such as those dealing with education, employment, disability, the judicial system, human rights protection, social protection, poverty reduction and development), are important means of meeting the multidimensional requirements of a suicide prevention strategy and of ensuring sustainability.

A national strategy does not need to be the starting point for suicide prevention. Many countries have existing activities and responses already in place. However, a national strategy can assist in providing a broad plan. Regions within a country can then implement the plan at the relevant level.

\section{Guiding principles for the development and implementation of national strategies}

After consultations with a variety of experts and with technical support from WHO, the United Nations published Prevention of suicide: guidelines for the formulation and implementation of national strategies (155). This seminal document emphasized the need for intersectoral collaboration, multidisciplinary approaches, and continued evaluation and review.

The United Nations document highlighted some activities and approaches for attaining the goals of national strategies. Since then, a number of typical components of national suicide prevention strategies have evolved (Table 4).

When the United Nations guidelines were initially prepared, only Finland had a government-sponsored systematic initiative for developing a national framework and programme for suicide prevention. Fifteen years later, more than 25 countries - in the high-, middle- and low-income categories - have adopted national (or in some cases regional) strategies for the prevention of suicidal behaviours. Most of these countries acknowledge the importance of the United Nations guidelines in the development of their national strategies. 
Table 4. Typical components of national strategies

\begin{tabular}{|c|c|}
\hline Component & Goals and objectives \\
\hline Surveillance & $\begin{array}{l}\text { Increase the quality and timeliness of national data on suicide and suicide attempts. Support the } \\
\text { establishment of an integrated data collection system which serves to identify vulnerable groups, } \\
\text { individuals and situations. }\end{array}$ \\
\hline Means restriction & $\begin{array}{l}\text { Reduce the availability, accessibility and attractiveness of the means to suicide (e.g. pesticides, firearms, } \\
\text { high places). Reduce toxicity/lethality of available means. }\end{array}$ \\
\hline Media & $\begin{array}{l}\text { Promote implementation of media guidelines to support responsible reporting of suicide in print, } \\
\text { broadcasting and social media. }\end{array}$ \\
\hline Access to services & $\begin{array}{l}\text { Promote increased access to comprehensive services for those vulnerable to suicidal behaviours. } \\
\text { Remove barriers to care. }\end{array}$ \\
\hline Training and education & $\begin{array}{l}\text { Maintain comprehensive training programmes for identified gatekeepers (e.g. health workers, educators, } \\
\text { police). Improve the competencies of mental health and primary care providers in the recognition and } \\
\text { treatment of vulnerable persons. }\end{array}$ \\
\hline Treatment & $\begin{array}{l}\text { Improve the quality of clinical care and evidence-based clinical interventions, especially for individuals who } \\
\text { present to hospital following a suicide attempt. Improve research and evaluation of effective interventions. }\end{array}$ \\
\hline Crisis intervention & $\begin{array}{l}\text { Ensure that communities have the capacity to respond to crises with appropriate interventions and that } \\
\text { individuals in a crisis situation have access to emergency mental health care, including through telephone } \\
\text { helplines or the Internet. }\end{array}$ \\
\hline Postvention & $\begin{array}{l}\text { Improve response to and caring for those affected by suicide and suicide attempts. Provide supportive } \\
\text { and rehabilitative services to persons affected by suicide attempts. }\end{array}$ \\
\hline Awareness & $\begin{array}{l}\text { Establish public information campaigns to support the understanding that suicides are preventable. } \\
\text { Increase public and professional access to information about all aspects of preventing suicidal } \\
\text { behaviour. }\end{array}$ \\
\hline Stigma reduction & $\begin{array}{l}\text { Promote the use of mental health services, and services for the prevention of substance abuse and } \\
\text { suicide. Reduce discrimination against people using these services. }\end{array}$ \\
\hline $\begin{array}{l}\text { Oversight and } \\
\text { coordination }\end{array}$ & $\begin{array}{l}\text { Establish institutions or agencies to promote and coordinate research, training and service delivery in } \\
\text { respect of suicidal behaviours. Strengthen the health and social system response to suicidal behaviours. }\end{array}$ \\
\hline
\end{tabular}


Key elements to keep in mind when creating a national strategy are as follows:

\section{a) Make suicide prevention a multisectoral priority, regardless of resources}

The overarching aim of a national suicide prevention strategy is to promote, coordinate and support appropriate intersectoral action plans and programmes for the prevention of suicidal behaviours at national, regional and local levels. Partnerships are required with multiple public sectors (such as health, education, employment, judiciary, housing, social welfare) and other sectors, including the private sector, as appropriate to the country.

\section{b) Tailor for diversity}

Although existing national strategies have similar components, no two national strategies are identical, in part because the problem of suicide is different in each country. Suicide depends on a number of factors, and its expression is influenced by social and cultural contexts. While common risk factors have been identified globally, the goals, objectives and interventions must be tailored to the specific context.

\section{c) Establish best practices}

A closer look at the components of existing national strategies indicates that they are compilations of individual evidence-based interventions and best practices that, taken together, represent a comprehensive approach to addressing a broad range of risk and protective factors that are common to a specific country. Developing, implementing and evaluating pilot projects, targeted programmes and action steps is an essential basis for developing a suicide prevention strategy.

\section{d) Allocation of resources (finances, time, staff)}

In order for a suicide prevention strategy to be coordinated and comprehensive, it should have specified financial and human resources, a time frame for implementation, and short-to-medium and long-term objectives. Developing a national suicide prevention strategy requires having a financially sustainable model in order to accomplish desired goals. A logical framework is one of many programme planning and evaluation tools that can be used to help display the connections between the problem to be addressed, the activities to be implemented and the expected results.

\section{e) Effective planning and collaboration}

Regardless of what tools countries choose to employ, their planning and evaluation should be done collaboratively. Creation of a national planning group allows stakeholders to address their underlying assumptions, identify the resources and inputs needed, and plan the activities that will lead to desired outcomes.

\section{f) Use of evaluation findings and sharing lessons learned}

The suicide prevention strategy and its components should be evaluated, and the findings and lessons learned should be shared with relevant stakeholders. Evaluation findings are likely to be better used if they are tailored to specific audiences with appropriate recommendations. All those involved in the evaluation should receive feedback and should be supported in implementing change after receiving the evaluation results. Dissemination involves sharing the results and lessons learned from the evaluation with relevant audiences in a timely, unbiased and consistent manner. The reporting strategy should consider the intended users and other stakeholders, and the information provided (e.g. style, tone, format) should be appropriate to the audience. 
Case example: Chile the start of a new system

\section{Context}

Suicide rates have been growing quite rapidly in Chile in the last 20 years, and particularly since 2000. Rates are highest among older males and have increased most among young people. To respond to these trends, several steps have been taken:

1. Access to mental health care has improved significantly with the new legislation "Universal guarantees in health care" which was enacted in 2005. The legislation improves access to health care and covers four mental disorders - each a significant risk factor for suicide.

2. A National Suicide Prevention Plan, first designed in 2007 and recently officially approved, includes evidence-based prevention strategies proposed by WHO, namely:

- regional and national surveillance of all cases of suicide and suicide attempts in order to define regional risk profiles and monitor health-care provision;

- 15 regional, intersectoral prevention plans coordinated by the regional health authority;

- training of health-care personnel, particularly primary health care and emergency room staff;

- preventive programmes in schools, focused on social-environmental protection, training in self-esteem, life skills, coping with crisis situations and decision-making competencies;

- a crisis help system, including a helpline, Internet webpage and an intervention programme in each of the 29 general health services in the country; and

- a media education programme designed to reduce inappropriate reporting and to promote awareness of the protective role the media may play.

\section{Future goals}

Chile's National Strategy on Health 2011-2020 has a goal of achieving a $10 \%$ decrease in the youth suicide rate.

Source: Communication from the Ministry of Health, Chile.

\section{Implementation of a national suicide prevention strategy}

When implementing a national suicide prevention strategy it is important to be clear of the inputs, outputs and related outcomes in order to determine how to move forward. Depending on the focus of the strategy, it may be nationally led but put into action locally. Examples of these first three elements (i.e. inputs, outputs and outcomes) of a logical framework are provided below. Evaluation of the outputs, outcomes and impacts are considered in more detail in the next section.

\section{Inputs}

The resources, contributions and investments that are needed to carry out activities, such as:

- a funding source and sustained funding;

- sufficient numbers of trained personnel, or capacity-building;

- sustained leadership and collaboration;

- culturally-relevant evidence-based prevention programmes;

- access to data;

- identified implementation partners; and

- political will.

\section{Outputs}

The activities, products and services that reach the intended audiences, such as:

- training programmes for gatekeepers;

- public education campaigns;

- access to care;

- community programmes and helplines;

- treatment and continuity-of-care programmes;

- postvention;

- interventions to restrict access to means;

- media guidelines; and

- policy implementation. 


\section{Outcomes}

The changes, results and benefits achieved for individuals, groups, agencies, communities and/or systems due to the activities and other outputs. Specific outcomes should be categorized as short-term, intermediate or long-term and should be measurable, such as:

- numbers of suicides and suicide attempts;

- numbers trained or otherwise influenced by individual activities;

- hours of accessible services;

- numbers treated;

- measures reflecting a decrease in perceived stigma regarding help-seeking;

- improvement in provision of mental health services;

- mental health, well-being or connectedness;

- measures reflecting cost-effectiveness; and

- reduced rates of hospitalizations due to suicide attempts, or deaths by suicide.

\section{The importance of data}

When implementing a national response, the problem to be solved, reduced, changed or prevented must first be understood. Surveillance refers to the systematic collection of outcome-specific data (most importantly on suicides and suicide attempts) "...for use in the planning, implementation, and evaluation of public health practice" (156). Many countries have no or, at best only very basic, systems of surveillance that provide routine suicide data that is collected systematically and that can inform both programmatic targets for interventions and the development of policy initiatives. Significantly, many countries do not know the key methods used for suicide or the proportion of all suicides who have previously made attempts. Measuring the success, or lack thereof, of efforts to reduce suicides, suicide attempts or the impact of suicide on society at large requires access to reliable and valid data (see also Box 9). Quality improvement depends on having data that point to where the needs for improvement exist.

\section{Adapting programmes for implementation}

Often there are programmes in place that can be expanded or adapted to address the populations targeted and the outcomes identified in a national strategy. On other occasions new programmes need to be developed and implemented. The context of each country and its approach to suicide prevention will need to be considered. For example, if the data reflect high youth suicide among specific cultural groups within a country, the national suicide strategy will need to be implemented with a focus on youth in mind. There is no one-size-fits-all approach to suicide; interventions that work in one country or region cannot be expected to work effectively in another without consideration of the context and adaptation of the intervention to ensure it is fit for purpose.

\section{Prioritization}

Given the fiscal realities in most countries, multicomponent strategies for preventing suicide will probably need to be phased in one by one. It is important to define a country's priorities in order to make the most of limited resources, including staff and funding. A situation analysis of sectors' needs in terms of personnel, leadership and/or collaboration is imperative for implementing a strategy. Particularly for countries with strained resources, it is vital to identify the greatest opportunities for immediate action based on existing programmes or on those that can easily be adapted.

Countries that have achieved short-term goals in suicide prevention may have the resources to begin focusing on longer-term systemic change.

\section{Challenges to implementation}

The implementation of a national suicide prevention strategy often requires change in the way individuals and their organizations operate. Challenges in achieving the changes depend on the context but may include (157):

- limited knowledge of stakeholders about how to change the way they work to align with evidence;

- personal beliefs, attitudes and perceptions regarding the change, and perceived risks and benefits;

- individual skills and capacities to carry out the change in practice;

- poor leadership and collaboration;

- practical barriers, including lack of resources, equipment or staffing;

- the political or social environment.

Potential barriers need to be identified and addressed. A participatory, consultative approach with buy-in from, and feedback to, stakeholders will reduce barriers at individual level. Training in new skills and competencies should be an essential part of any national strategy. 
Case example: Switzerland responding to diversity

\section{Background}

Suicide rates in Switzerland are in the middle range compared to other European countries: 1034 persons died by suicide in Switzerland in 2011.

Switzerland has a federal structure, with the Swiss Federal Office of Public Health taking care of overarching issues such as health insurance and health information. The 26 cantons are primarily responsible for suicide prevention, making the coordination of an overall national response a challenge. Despite this, suicide prevention activities, such as the Suicide Prevention Strategy 2010-2015 of the canton of Zug, have met with success at the cantonal level. Examples of progress in suicide prevention in the Swiss cantons include:

- means reduction projects;

- media monitoring;

- surveillance;

- short-term interventions and follow-up of people who have attempted suicide;

- gatekeeper training;

- World Suicide Prevention Day awareness-raising activities:

- self-help groups for the bereaved;

- crisis helplines.

\section{Challenges of a federated country}

Despite the success of suicide prevention activities and the responses at local level, the lack of national coordination remains a challenge for the cantons. This can result in:

- a lack of opportunities for cantons to share best practices and learn from each other;

- a lack of national coordination in resource allocation and surveillance;

- an imbalance between cantons as they may not have the same resources and activities because suicide prevention interventions are driven by the motivation of each canton.

\section{The way forward}

Since 2011 the political pressure to become active in suicide prevention has increased at national level. A motion was accepted by the Parliament requesting the Federation (the Swiss Federal Office of Public Health respectively) to develop an action plan for suicide prevention. All stakeholders (cantons, NGOs, etc.) need to be involved in this process and the legal basis needs to be established.

\section{How can progress be tracked when evaluating a national suicide prevention strategy?}

Evaluation is an integral component of any national suicide prevention strategy and adds value in the following ways:

Knowledge production: Evaluation provides stakeholder groups with important information on the strategy's progress and on its strengths and weaknesses. This information can be used to monitor the success of the strategy in achieving short-term, intermediate and long-term outcomes and is a basis for making modifications as needed and for guiding future planning and resource allocation (158).

Planning and management: Evaluation offers ways to improve how the national strategy and its component activities are planned and managed. It enables the development of clear outcome-oriented plans and inclusive partnerships, as well as systems for data-gathering and feedback that encourage learning and ongoing improvement (154).

Accountability: Evaluation is a tool for demonstrating accountability to funders, legislators and the general public. It helps ensure that the most effective approaches are maintained and that resources are not wasted on ineffective programmes (158).

Many national strategies cover a defined time frame of 5-10 years and include multiple objectives, actions and targets. In the course of those years, certain planned and intended interventions may not be implemented or sustained. If reduction in suicidal behaviours, mitigation of risk factors and strengthening of protective factors are not achieved by a national strategy, it is critical to know whether this was due to lack of implementation.

While increasing numbers of countries develop and implement national suicide prevention strategies, systematic and comprehensive evaluations are limited $(159,160,161)$. Evaluations of the effectiveness of national suicide prevention strategies reveal inconsistent outcomes, with some countries showing significant reductions in suicide rates for the total population (e.g. Finland, Scotland), but with limited effects in others (e.g. Australia, Norway, Sweden) (159, 162). However, caution is advised in interpreting the evaluation outcomes as the quality of information regarding the implementation of actions is limited. Analyses of changes in suicide rates or risk and protective factors also vary across countries, making comparisons difficult. 
Case example: Scotland a comprehensive multisectoral strategy

\section{Initiative}

In 2002, a national strategy and action plan to prevent suicide, called Choose Life, was launched with the aim of reducing the suicide rate in Scotland by 20\% by 2013. Scotland had seen an increasing rate of suicide, particularly among men, which was 27 per 100000 in 2001 (the rate for women being 9 per 100 000). Choose Life was developed and implemented within a national public mental health programme, which is part of broader Scottish policy commitments to improve population health, promote social justice and tackle inequalities. This allows suicide prevention work to be undertaken within a wider framework of policy objectives and initiatives that share the overarching goal of improving population mental health.

A national network was formed with representatives of local councils, police, ambulance, accident and emergency services, prison services and key NGOs, and a national training and capacity-building programme was established. An implementation plan was developed, concentrating on 32 local council areas, with each local plan focusing on three key objectives:

- Achieve coordinated action for suicide prevention across health-care services, social- care services, education, housing, police, welfare and employment services.

- Develop multi-professional training programmes to build capacity for supporting the prevention of suicide.

- Provide financial support for local community and neighbourhood interventions.

Between 2002 and 2006, the Scottish Government invested $£ 20.4$ million in implementation of the Choose Life strategy.

\section{Results}

In 2006, an independent process evaluation and assessment of intermediate outcomes was conducted of the first phase of the strategy implementation. The evaluation indicated that considerable progress had been made in achieving many milestones but that there was a need to put more emphasis on sustainability by continuing to incorporate Choose Life objectives into other national policy streams. The evaluation also underlined the need for targeted action such as improved integration of clinical services, including substance misuse treatment services, at national level.

Over the period 2000-2002 to 2010-2012 the suicide rate in Scotland fell by $18 \%$. An evaluation of Choose Life was completed in 2012; however, it is difficult to determine if the decline can be attributed to the programme as a whole or to any particular elements of it.

\section{Challenges in evaluation}

The evaluation of a national suicide prevention strategy does not occur in a vacuum but is influenced by real-world constraints (158). Evaluations need to be practical and feasible, and they have to be conducted within the limits of resources, time and the political, social and economic context of a country. There is no such thing as the right evaluation but, over the course of a strategy, any number of evaluations may be appropriate. Comparisons of regional variations in suicide prevention efforts across states/territories and local communities can provide valuable lessons on the types of delivery structures that are most efficient and effective (163). In countries where suicidal behaviour is still considered illegal, and socially and religiously is not accepted, both the implementation and the evaluation of suicide prevention strategies will be complicated by high levels of stigma around suicide and the lack of accurate suicide mortality data $(164,165)$.

A major design concern of any evaluation plan is the difficulty in attributing observed outcomes or impacts to the prevention strategy since many other factors could exert an influence on suicide rates and other indicators (166). For example, increased awareness and improved data may result in greater disclosure and more accurate information about suicides that would previously have been missed. This could result in apparently higher rates $(159,167)$. Also, major changes such as economic crises can adversely affect population health and suicide by, for instance, reducing the financial capacity to respond to these issues. Consequently, understanding a strategy's context (history, organization, and broader political and social setting) is essential and will improve how evaluations are conceived and conducted (154).

There is a gap in the rigorous evaluation of promising suicide prevention strategies. While many new and innovative interventions have been noted and implemented internationally, they are yet to be evaluated. This is an issue particularly for low-income countries that may have learned valuable lessons in the implementation of suicide prevention that are lost due to a lack of data. The result is a bias towards interventions and recommendations from countries with an active academic sector. An increase in evaluations, particularly in low-income countries, could remedy this crucial gap. 


\section{The cost and cost-effectiveness of suicide prevention efforts}

It is important to build into evaluation an assessment of the costs and resources required to implement interventions in different settings, cultures and contexts, and to include qualitative information on both success and the obstacles to implementation (168). Economic evaluations which take issues of context and implementation into account can help to determine whether interventions that are both effective and cost-effective in one country are feasible in others. In countries with limited resources, assessing cost-effectiveness can help determine where resources will be best allocated.

In addition to evidence on the effect or impact of suicide prevention strategies, health planners and decision-makers require information on the expected costs of implementation and also on cost-effectiveness in order to ensure that such strategies represent good value for money. For instance, an economic study of self-poisoning in Sri Lanka was able to estimate that resource needs for treatment in the country would amount to US\$ 866000 in 2004 (each treated case costing an average of US\$32) (169).

Globally there is a lack of robust economic studies to inform planners and policy-makers of the budgetary requirements and return on investment associated with efforts to prevent suicide (168). A recent WHO review of suicide prevention strategies that included cost as a parameter of interest showed that two thirds of the strategies assessed as being effective or promising were categorized as low-cost and that low cost was also closely associated with universal or selective (as opposed to indicated) prevention approaches (40).
The inclusion of an economic component in funded clinical trials in some countries has resulted in some evidence on the cost-effectiveness of certain strategies, such as online self-help to reduce suicidal ideation in the Netherlands (170) or cognitive behavioural therapy for persons with a history of self-harm in the United Kingdom (171). Other economic studies have employed a modelling approach to assess expected costs and benefits over time, such as Australia's Assessing Cost-Effectiveness (ACE) in Prevention project which assessed the comparative cost-effectiveness of a number of interventions, including (172):

- reducing access to means of suicide through revised legislation on gun ownership (at a cost of more than 50000 Australian dollars gained for each additional healthy life year);

- guidelines for more responsible media reporting (27 000 Australian dollars per healthy life year gained so long as at least one suicide is averted)'.

Such studies provide good examples of how economic analyses can be carried out and how they can inform national suicide prevention strategies.

\footnotetext{
A healthy life year can be thought of as one year spent alive in full health, free of disability or morbidity.
} 


\section{The way forward for suicide prevention}




\section{Myth:}

Jalking about suicide is a bad idea and can bo interpreted as encouragement.

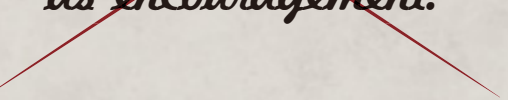

\section{Fact:}

Given the widespread stigma around suicide, most people who are contemplating suicide do not know who to speak to. Rather than encouraging suicidal behaviour, talking openly can give an individual other options or the time to rethink his/her decision, thereby preventing suicide. 


\section{What can be done and who needs to be involved?}

Action is needed to make prevention possible. Suicide prevention approaches have evolved as communities and countries have changed their attitudes and beliefs regarding suicide. Stigma against seeking help for suicide has been reduced in many contexts. Now the challenge for policy-makers and other stakeholders is to embrace the increase in public dialogue about suicide and take advantage of the environment to implement a response. For many countries there is still a long way to go, and significant obstacles to implementing suicide prevention strategies remain. This section of the report offers countries pathways for moving forward, regardless of where they are on their way forward to suicide prevention.

\section{Forging a way forward}

Ministers of health have a critical role to play in providing leadership and in bringing together stakeholders from other sectors in their country. They can help coordinate across sectors - including education, public media, justice, labour, social welfare, religion, transportation and agriculture - to effectively engage them in suicide prevention activities that use the current knowledge base about prevention. This involvement can then be built on.

The steps a country should take next will depend on where the country is on the way towards suicide prevention. Table 5 lists examples of strategic actions that countries can take to advance suicide prevention on the basis of the best available evidence described throughout this report. The table shows the range of current activities and options for preventive actions that can be considered in a number of strategic areas.

\section{Countries that have no current activity}

In countries where suicide prevention activities have not yet taken place, the emphasis is on action. These countries can seek out stakeholders and develop activities opportunistically where there is greatest need or where resources already exist. They may find in the course of doing so and analysing the situation that some community groups have already been working on small-scale activities for suicide prevention. Such groups will often require further support in order to increase in scale or scope, and this can be achieved through further collaboration. In addition, it is important to improve surveillance at this stage, though countries can do this concurrently with, and not at the expense of, initiating relevant suicide prevention interventions.

\section{Countries that have some activity}

In countries that have some existing suicide prevention activities, it may be productive to focus first on consolidation by conducting a situation analysis. These countries can identify gaps in services and can work towards a comprehensive national response by identifying and mapping all stakeholders and by delegating roles and responsibilities within the national response. Particular attention can be given to the context and to vulnerable groups, with risk factors prioritized accordingly.

\section{Countries that have a national response}

For countries that already have a fairly comprehensive national response the emphasis can be on evaluation and improvement. While evaluation is equally important for continuous improvement at earlier stages, at this stage resources may often be more readily available for in-depth evaluations. The emphasis for these countries is on the timely inclusion of new data and ensuring that the national response improves in effectiveness and efficiency.

Effective suicide prevention will require a continuous cycle of learning and doing. Ministers of health and other suicide prevention leaders can benefit from regular efforts to reflect on progress and consider next steps. A SWOT analysis or another situational analysis tool can be used to measure progress (see Box 8). Well conducted situational analyses can be used to identify strengths to be enhanced, weaknesses to be corrected, opportunities to be pursued, and threats to be addressed. 
Box 8.

\section{Conducting a situation analysis: SWOT example}

Continuous progress on suicide prevention requires commitment and ongoing consideration of past accomplishments and potential next steps. Ministers of health and leaders in suicide prevention from other sectors can benefit from completing periodic situational analyses of the status of suicide prevention efforts in the country. There are several models for conducting situational analyses and it will be important to choose one that is familiar and is considered appropriate for local needs. One relatively straightforward approach is the SWOT analysis, a planning tool that can be used to set objectives and determine the steps necessary to reach those objectives. The SWOT analysis involves answering questions to determine Strengths, Weaknesses, Opportunities and Threats relating to suicide prevention. When conducting situational analyses using SWOT or other models, it is important to consider existing resources, political will, policy and legislative opportunities, and partnerships across sectors.

\section{Example of a SWOT analysis for surveillance:}

\begin{tabular}{|l|l|l|l|}
\hline Strengths & Weaknesses & Opportunities & Threats \\
\hline $\begin{array}{l}\text { Currently have national } \\
\text { data on suicide } \\
\text { mortality. }\end{array}$ & $\begin{array}{l}\text { Lack of data on suicide } \\
\text { attempts. }\end{array}$ & $\begin{array}{l}\text { Education minister } \\
\text { proposes to add } \\
\text { questions on suicidal } \\
\text { behaviour to next } \\
\text { national survey of high } \\
\text { school students' drug } \\
\text { use. }\end{array}$ & $\begin{array}{l}\text { Resources needed for } \\
\text { analysis and dissemina- } \\
\text { tion of the results. } \\
\text { Partnerships with } \\
\text { researchers and the } \\
\text { media are limited. }\end{array}$ \\
\hline
\end{tabular}

Table 5 presents areas for strategic action. These cover the engagement of appropriate stakeholders who can work within their own sector or across sectors to reduce suicide; efforts to reduce access to the means of suicide; improvement of the systematic collection of surveillance data to understand trends in suicide; monitoring of the effects of prevention efforts over time; efforts to correct myths and to raise awareness that suicide is a preventable public health problem; and mobilizing the health system.

The columns in the table contain suggestions for steps towards each strategic action regardless of where the country is in its progress towards implementing a successful suicide prevention strategy. The intention is that partners will use this information to consider what strategic actions they need to implement. Stakeholders are suggested as possible leaders for each strategic action and can use the list to help identify additional actions that will complement current activities and fill gaps in the national approach to suicide prevention.
The foundational work of engaging key stakeholders is critical to ensuring the participation of different sectors. This table can be used both to consider how each sector is currently contributing to suicide prevention and to identify opportunities to expand or leverage the contributions of these sectors to engage other partners and to facilitate progress on other suicide prevention actions. 
Table 5. Proposed strategic actions for suicide prevention (categorized by current implementation levels)

\begin{tabular}{|c|c|c|c|c|}
\hline $\begin{array}{l}\text { Areas of strategic } \\
\text { action }\end{array}$ & Lead stakeholders & $\begin{array}{l}\text { No activity } \\
\text { (currently there is } \\
\text { no suicide prevention } \\
\text { response at national } \\
\text { or local level] }\end{array}$ & $\begin{array}{l}\text { Some activity } \\
\text { [some work has begun } \\
\text { in suicide prevention } \\
\text { in priority areas at either } \\
\text { national or local level] }\end{array}$ & $\begin{array}{l}\text { Established suicide } \\
\text { prevention strategy } \\
\text { exists at national level }\end{array}$ \\
\hline $\begin{array}{l}\text { Engage key } \\
\text { stakeholders }\end{array}$ & $\begin{array}{l}\text { Ministry of Health as } \\
\text { lead, or other } \\
\text { coordinating health } \\
\text { body }\end{array}$ & $\begin{array}{l}\text { Initiate identification of } \\
\text { and engagement with } \\
\text { key stakeholders on } \\
\text { country priorities, or } \\
\text { where activities already } \\
\text { exist. }\end{array}$ & $\begin{array}{l}\text { Identify all key } \\
\text { stakeholders across } \\
\text { sectors and engage } \\
\text { them comprehensively } \\
\text { in suicide prevention } \\
\text { activities. Assign } \\
\text { responsibilities. }\end{array}$ & $\begin{array}{l}\text { Assess the roles, } \\
\text { responsibilities, and } \\
\text { activities of all key } \\
\text { stakeholders on a } \\
\text { regular basis. Use the } \\
\text { results to expand sector } \\
\text { participation and } \\
\text { increase stakeholder } \\
\text { involvement. }\end{array}$ \\
\hline $\begin{array}{l}\text { Reduce access to } \\
\text { means }\end{array}$ & $\begin{array}{l}\text { Legal and judicial } \\
\text { system, policy-makers, } \\
\text { agriculture, transporta- } \\
\text { tion }\end{array}$ & $\begin{array}{l}\text { Begin efforts to reduce } \\
\text { access to means of } \\
\text { suicide through } \\
\text { community } \\
\text { interventions. }\end{array}$ & $\begin{array}{l}\text { Coordinate and expand } \\
\text { existing efforts to } \\
\text { reduce access to the } \\
\text { means of suicide } \\
\text { (including laws, policies } \\
\text { and practices at } \\
\text { national level). }\end{array}$ & $\begin{array}{l}\text { Evaluate efforts to } \\
\text { reduce access to the } \\
\text { means of suicide. Use } \\
\text { the evaluation results to } \\
\text { make improvements. }\end{array}$ \\
\hline $\begin{array}{l}\text { Conduct surveillance } \\
\text { and improve data } \\
\text { quality }\end{array}$ & $\begin{array}{l}\text { Ministry of Health, } \\
\text { Bureau of Statistics, all } \\
\text { other stakeholders, and } \\
\text { particularly the formal } \\
\text { and informal health } \\
\text { systems to collect data }\end{array}$ & $\begin{array}{l}\text { Begin surveillance, } \\
\text { prioritizing mortality } \\
\text { data, with core } \\
\text { information on age, sex } \\
\text { and methods of suicide. } \\
\text { Begin identification of } \\
\text { representative locations } \\
\text { for development of } \\
\text { models. }\end{array}$ & $\begin{array}{l}\text { Put a surveillance system } \\
\text { in place to monitor suicide } \\
\text { and suicide attempts at } \\
\text { national level (including } \\
\text { additional disaggregation) } \\
\text { and ensure the data is } \\
\text { reliable, valid and publicly } \\
\text { available. Establish } \\
\text { feasible data models that } \\
\text { are effective and can be } \\
\text { scaled up. }\end{array}$ & $\begin{array}{l}\text { Monitor key attributes such } \\
\text { as quality, representative- } \\
\text { ness, timeliness, } \\
\text { usefulness and costs of the } \\
\text { surveillance system in a } \\
\text { timely manner. Use the } \\
\text { results to improve the } \\
\text { system. Scale up effective } \\
\text { models for comprehensive } \\
\text { data coverage and quality. }\end{array}$ \\
\hline Raise awareness & $\begin{array}{l}\text { All sectors, with } \\
\text { leadership from the } \\
\text { Ministry of Health and } \\
\text { the media }\end{array}$ & $\begin{array}{l}\text { Organize activities to } \\
\text { raise awareness that } \\
\text { suicides are preventable. } \\
\text { Ensure that messages } \\
\text { reach some of the regions } \\
\text { or populations targeted } \\
\text { and are delivered through } \\
\text { at least one widely } \\
\text { accessed channel. }\end{array}$ & $\begin{array}{l}\text { Develop strategic public } \\
\text { awareness campaigns } \\
\text { and implement them } \\
\text { using evidence-based } \\
\text { information at national } \\
\text { level. Use methods and } \\
\text { messages that are } \\
\text { tailored to target } \\
\text { populations. }\end{array}$ & $\begin{array}{l}\text { Evaluate the } \\
\text { effectiveness of public } \\
\text { awareness campaign } \\
\text { (s). Use the results to } \\
\text { improve future } \\
\text { campaigns. }\end{array}$ \\
\hline Engage the media & $\begin{array}{l}\text { Media and Ministry of } \\
\text { Health in partnership }\end{array}$ & $\begin{array}{l}\text { Begin dialogue with the } \\
\text { media on responsible } \\
\text { reporting of suicide. }\end{array}$ & $\begin{array}{l}\text { Approach major media } \\
\text { organizations within the } \\
\text { country to support the } \\
\text { development of their own } \\
\text { standards and practices to } \\
\text { ensure responsible } \\
\text { reporting on suicide. Work } \\
\text { with media stakeholders to } \\
\text { promote prevention } \\
\text { resources and appropriate } \\
\text { referrals. }\end{array}$ & $\begin{array}{l}\text { Evaluate media } \\
\text { reporting of suicide } \\
\text { events. Engage and } \\
\text { train all media about } \\
\text { responsible reporting. } \\
\text { Establish timely training } \\
\text { for new workers in the } \\
\text { media. }\end{array}$ \\
\hline $\begin{array}{l}\text { Mobilize the health } \\
\text { system and train } \\
\text { health workers }\end{array}$ & $\begin{array}{l}\text { Formal and informal } \\
\text { health systems, } \\
\text { education sector }\end{array}$ & $\begin{array}{l}\text { Begin planning and } \\
\text { implementing care for } \\
\text { people who attempt } \\
\text { suicide, and train health } \\
\text { workers. }\end{array}$ & $\begin{array}{l}\text { Provide accessible } \\
\text { evidence-based crisis } \\
\text { care, clinical care and } \\
\text { postvention services at } \\
\text { national level. Provide } \\
\text { refresher training to } \\
\text { health workers. Adapt } \\
\text { curricula for health } \\
\text { workers. }\end{array}$ & $\begin{array}{l}\text { Implement regular } \\
\text { monitoring and } \\
\text { evaluation of existing } \\
\text { services. Use the results } \\
\text { to improve ongoing } \\
\text { care. }\end{array}$ \\
\hline
\end{tabular}




\begin{tabular}{|c|c|c|c|c|}
\hline $\begin{array}{l}\text { Areas of strategic } \\
\text { action }\end{array}$ & Lead stakeholders & $\begin{array}{l}\text { No activity } \\
\text { [currently there is } \\
\text { no suicide prevention } \\
\text { response at national } \\
\text { or local level] }\end{array}$ & $\begin{array}{l}\text { Some activity } \\
\text { [some work has begun } \\
\text { in suicide prevention } \\
\text { in priority areas at either } \\
\text { national or local level] }\end{array}$ & $\begin{array}{l}\text { Established suicide } \\
\text { prevention strategy } \\
\text { exists at national level }\end{array}$ \\
\hline $\begin{array}{l}\text { Change attitudes and } \\
\text { beliefs }\end{array}$ & $\begin{array}{l}\text { Media, health services } \\
\text { sector, education } \\
\text { sector, community } \\
\text { organizations }\end{array}$ & $\begin{array}{l}\text { Begin implementation of } \\
\text { activities to reduce } \\
\text { stigma associated with } \\
\text { seeking help for suicide. } \\
\text { Increase help-seeking } \\
\text { behaviour. }\end{array}$ & $\begin{array}{l}\text { Change attitudes } \\
\text { towards the use of } \\
\text { mental health services, } \\
\text { and reduce discrimina- } \\
\text { tion against users of } \\
\text { these services. }\end{array}$ & $\begin{array}{l}\text { Conduct periodic } \\
\text { evaluations to monitor } \\
\text { changes in public } \\
\text { attitudes and beliefs } \\
\text { about suicide, mental } \\
\text { and substance use } \\
\text { disorders and } \\
\text { help-seeking. }\end{array}$ \\
\hline $\begin{array}{l}\text { Conduct evaluation } \\
\text { and research }\end{array}$ & $\begin{array}{l}\text { Relevant community } \\
\text { health services, } \\
\text { education sector and } \\
\text { Ministry of Health }\end{array}$ & $\begin{array}{l}\text { Begin planning and } \\
\text { prioritizing the required } \\
\text { suicide prevention } \\
\text { research, and collate } \\
\text { the existing data (e.g. } \\
\text { suicide deaths). }\end{array}$ & $\begin{array}{l}\text { Expand existing } \\
\text { research, assigning } \\
\text { resources to inform and } \\
\text { evaluate efforts to } \\
\text { prevent suicide at } \\
\text { regional and/or national } \\
\text { level. }\end{array}$ & $\begin{array}{l}\text { Conduct periodic } \\
\text { assessment of the } \\
\text { portfolio of research to } \\
\text { monitor scientific } \\
\text { progress and identify } \\
\text { knowledge gaps. } \\
\text { Redirect resources on } \\
\text { the basis of the } \\
\text { evaluation. }\end{array}$ \\
\hline $\begin{array}{l}\text { Develop and } \\
\text { implement a } \\
\text { comprehensive } \\
\text { national suicide } \\
\text { prevention strategy }\end{array}$ & Ministry of Health & $\begin{array}{l}\text { Begin to develop a } \\
\text { national suicide } \\
\text { prevention strategy to } \\
\text { serve as a rallying point, } \\
\text { even if data and } \\
\text { resources are not yet } \\
\text { available. }\end{array}$ & $\begin{array}{l}\text { Continue to develop the } \\
\text { national strategy to } \\
\text { ensure it is comprehen- } \\
\text { sive, multisectoral and } \\
\text { covers all gaps in } \\
\text { service and } \\
\text { implementation. }\end{array}$ & $\begin{array}{l}\text { Evaluate and monitor } \\
\text { strategy implementation } \\
\text { and outcomes in order } \\
\text { to identify the most } \\
\text { effective components. } \\
\text { Use the results to } \\
\text { update the strategy } \\
\text { continuously. }\end{array}$ \\
\hline
\end{tabular}

Table 5 is by no means exhaustive and is intended to encourage continuous improvement and to offer ideas for actions that can be pursued. The cells of the table include examples of strategic actions or ways to think about progress. The table is not intended to provide a formula or prescription for suicide prevention.

While moving forward, there are two key points to consider. First, suicide prevention activities should be implemented simultaneously with data collection (see Box 9). The collection and collation of accurate data on suicide and suicide attempts are important and have been a major challenge in most countries; however, waiting for a perfect surveillance system is not the answer. Improvements to surveillance should be made as the country moves forward in implementing suicide prevention interventions, with changes being made in response to the data as necessary.
Second, some countries may feel that for various reasons they are not ready to have a national response to suicide prevention. However, the process of consulting stakeholders about a national response often creates an environment for change. Through the process of creating a national response to suicide, stakeholders become engaged, public dialogue on issues of stigma is encouraged, vulnerable target groups are identified, research priorities are set, and both public and media awareness are increased. Consequently, rather than seeing the creation of a national response as an end-result, it is more accurate to view the development of a national response as one important element on the path towards effective suicide prevention. 
Box 9.

\section{Key actions in surveillance}

Improved surveillance and monitoring of suicide and suicide attempts are required for effective suicide prevention. As there are limited resources available for suicide prevention, administrators, public health agencies and other stakeholders must decide what proportion of the funds and resources available for suicide prevention should be allocated to monitoring and how they should be distributed between the various types of monitoring activities. The situation varies greatly between countries, so there is no one-size-fits-all manual for making these decisions. There are, however, some general principles for key actions that may be useful across most jurisdictions:

- Establish a permanent task force that is specifically responsible for monitoring and improving the quality of suicide-related data as an integral component of the overall suicide prevention effort.

Improving the quality of suicide-related information is such an essential component of suicide prevention efforts and of every national suicide prevention strategy that a dedicated group (task force) should be assigned to focus on this activity. After a situation analysis of the current status of suicide-related data has been conducted, a plan to improve data availability, comprehensiveness and quality would be developed, its implementation monitored and the plan periodically updated.

\section{- Conduct periodic assessments about the availabili- ty, comprehensiveness and quality of data about suicides and suicide attempts.}

Periodic assessment and improvement of the quality of data is important for each of the three main data sources:

- Improve the quality of vital registration data on suicide. The activities needed to establish or improve recording of deaths by suicide will vary according to the current status of the vital registration system in the country.

- Improve the quality of data about medical treatment for suicide attempts. Development of a hospital-based monitoring system is a complicated process but a start can be made by developing a feasible method of data collection in a few representative locations and subsequently scaling it up to the whole country.

- Improve the quality of community surveys about suicidal behaviour. This must take into account the fact that the sample size should be large enough to be representative of the community or country. Standardized questions should be used, the most important and useful being about suicide attempts in the previous year.
- Give preference to having high-quality data from several representative locations over poor-quality data that covers the entire nation.

In most low- and middle-income countries and some high-income countries, financial, personnel or technical limitations make it unfeasible to develop national monitoring systems for suicides and suicide attempts or to conduct national surveys regularly. In this situation it is better to identify several representative target sites and then scale up to the national level.

- Integrate the suicide monitoring effort with other activities whenever possible rather than establishing stand-alone activities.

Suicide deaths are usually collected as part of the overall death registration system and not in a stand-alone monitoring system. The monitoring of suicide attempts treated in emergency departments is best organized as part of an overall monitoring system for injuries. Community surveys about suicidal behaviour can easily be integrated into other community surveys about physical or mental health.

- Include stigma-reducing efforts in the overall plan to improve data quality.

Perhaps the greatest barrier to good-quality data about suicide is the stigma associated with suicidal behaviour. Working with the media to change public perceptions and with medical and nursing schools to change medical professionals' attitudes (e.g. by framing suicide as a major treatable public health problem) are important steps towards achieving the long-term goal of reducing the stigma associated with suicide.

- Find a balance between the need for national data and the need for community-specific data.

National data can be of limited use in devising and monitoring local prevention strategies because there may be substantial demographic, economic or cultural differences between different regions of the country. It is important to determine the extent to which the local profile of suicide diverges from the national profile.

- Ensure that the monitoring system is used to assist in the development and assessment of suicide prevention activities.

All large government-sponsored suicide prevention studies should require the use of suicide or suicide attempt as the key outcome measures and should allocate an adequate portion of the budget to the monitoring of these outcomes. 


\section{What does success look like?}

In addition to helping countries plan their inputs and actions, a logical framework such as the one shown in Figure 9 can be used with other monitoring and evaluation tools to track progress and measure success. After exploring possible inputs, outputs and activities for planning and implementing a national suicide prevention strategy, it is important to revisit the outcomes and to look further at the impacts that are achieved in order to move ahead with evaluation.

Figure 9. The logical framework applied to suicide prevention

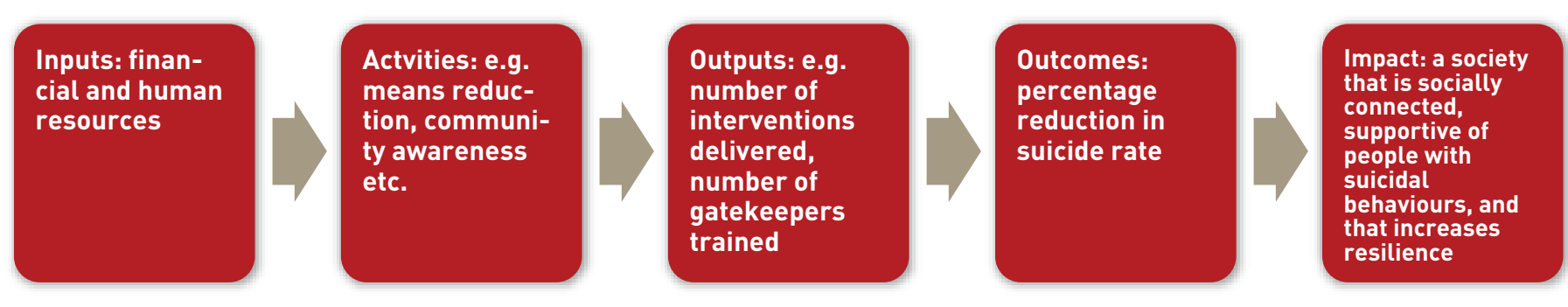

\section{Outcomes}

Quantitative indicators that measure the principal outcomes of a national strategy are useful indicators of progress. These can include:

- a percentage reduction in the suicide rate;

- the number of suicide prevention interventions successfully implemented;

- a decrease in the number of hospitalized suicide attempts.

Countries that are guided by the Mental Health Action Plan 2013-2020 (1) can aim for a 10\% reduction in the suicide rate. Some countries may go further; for instance, England in its previous national health strategy Saving lives: our healthier nation, 1999 (173) set a target in the area of mental health to reduce the death rate from suicide and undetermined injury by at least $20 \%$ by 2010 . This target was successfully met by 2008 (174). Quantitative indicators attached to key activities provide important milestones for the coordinated national response across all sectors.

\section{Impacts}

While the main target outcomes are important and may show progress, they may miss other important qualitative information. Sometimes suicide rates do not decline due to an increase in the reporting of suicide, or due to other contextual factors. Countries should look beyond the principal outputs and outcomes towards broader impacts in order to obtain a complete understanding of progress and success. Measures of broader impact may include quantitative and qualitative indicators such as:

- communities where organizations (schools, religious organizations, workplaces, etc.) are providing support to the population and are connected sufficiently to provide appropriate referrals for those needing assistance;

- families and social circles that provide social support, enhance resilience, recognize risk factors for suicide, and intervene effectively to help loved ones;

- a social climate in which help-seeking for suicidal behaviour is no longer taboo and public dialogue on the issue is encouraged.

These indicators are often more difficult to measure but are important because they can signal significant progress in suicide prevention and should be considered equally important when a country assesses the progress made and what success will look like. 
Key messages 
Suicides take a high toll. Over $\mathbf{8 0 0} 000$ people die due to suicide every year and it is the second leading cause of death in 15-29-year-olds. There are indications that for each adult who died of suicide there may have been more than 20 others attempting suicide.

Suicide is a global phenomenon. All countries are affected. Despite preconceptions that suicide is more prevalent in high-income countries, in reality $75 \%$ of suicides occur in low- and middle-income countries. Suicide is an important cause of death across the lifespan. In addition to the impact on individuals who attempt and die from suicide, the powerful ripple effect that suicide has on families, friends, communities and countries is far-reaching.

Suicides are preventable. For national responses to be effective, a comprehensive multisectoral suicide prevention strategy is needed.

To ensure that it is effective, the national strategy should include collaboration between health and non-health sectors at governmental and nongovernmental levels. It should involve communities and also the media to encourage responsible reporting of suicide. The strategy should improve surveillance as well as policies relating to mental health and alcohol in particular. Early prevention should be a core component of any strategy developed.

Restricting access to the means for suicide works. An effective strategy for preventing suicides and suicide attempts is to restrict access to the most common means, including pesticides, firearms and certain medications.

Restriction of access to means plays an important role in suicide prevention, particularly in the case of suicides that are impulsive. Implementation of effective policies coupled with community interventions has been instrumental in reducing suicide through means restriction.
Health-care services need to incorporate suicide prevention as a core component. Mental disorders and harmful use of alcohol contribute to many suicides around the world. Early identification and effective management are key to ensuring that people receive the care they need.

Improving the quality of care for people seeking help can ensure that early interventions are effective. Improved quality of care is the key to reducing suicides that arise as a result of mental and alcohol use disorders and other risk factors. Mental health and alcohol policies should prioritize care, promote its successful integration into overall health-care services, and support sufficient funding for the improvement of these services.

Communities play a critical role in suicide prevention. They can provide social support to vulnerable individuals and engage in follow-up care, fight stigma and support those bereaved by suicide.

In all countries, particularly those with limited resources, the importance of communities and their support programmes in suicide prevention cannot be overstated. Effective social support within communities and individual resilience can help protect vulnerable persons from suicide by building and improving social connectedness and skills to cope with difficulties. Specifically, the community can provide help in crisis situations, keep in regular contact with people who have attempted suicide, and support persons bereaved by suicide. 
1. Mental health action plan 2013-2020. Geneva: World Health Organization; 2013

(http://apps.who.int/iris/bitstream/10665/89966/1/9789241506 021_eng.pdf, accessed 23 April 2014).

2. WHO mortality database documentation: 1 May 2013 update. Geneva: World Health Organization; 2013

(http://www.who.int/healthinfo/statistics/mortality_rawdata/en/, accessed 19 May 2014).

3. WHO methods and data sources for global causes of death 2000-2012. Global Health Estimates Technical Paper WHO/HIS/HSI/GHE/2014.7. Geneva: World Health Organization; 2014.

4. Värnik P, Sisask M, Värnik A, Yur'Yev A, Kõlves K, Leppik $L$ et al. Massive increase in injury deaths of undetermined intent in ex-USSR Baltic and Slavic countries: Hidden suicides? Scand J Public Health. 2010;38(4):395-403.

5. Värnik P, Sisask M, Värnik A, Arensman E, Van Audenhove $\mathrm{C}$, van der Feltz-Cornelis CM et al. Validity of suicide statistics in Europe in relation to undetermined deaths: developing the 2-20 benchmark. Inj Prev. 2012;18(5):321-5. 6. Höfer P, Rockett IR, Värnik P, Etzersdorfer E, Kapusta ND. Forty years of increasing suicide mortality in Poland: undercounting amidst a hanging epidemic? BMC Public Health. 2012;11(12):644.

7. Wu KCC, Chen YY, Yip PSF. Suicide methods in Asia: implications in suicide prevention. Int J Environ Res Public Health. 2012;9(4):1135-58.

8. Gunnell D, Eddleston M, Phillips MR, Konradsen F. The global distribution of fatal pesticide self-poisoning: systematic review. BMC public health. 2007a;7:357. doi:10.1186/1471-2458-7-357.

9. Chang SS, Chen YY, Yip PSF, Lee WJ, Hagihara A, Gunnell D. Regional changes in charcoal-burning suicide rates in East/Southeast Asia from 1995 to 2011: a time trend analysis. PLoS Medicine. 2014;11(4):e1001622.

10. National Violent Death Reporting System (NVDRS)

Coding manual, version 3. Atlanta (GA): Centers for Disease Control and Prevention; 2014.

(http://www.cdc.gov/violenceprevention/pdf/NVDRS_Coding_ Manual_Version_3-a.pdf, accessed on 15 May 2014.)

11. Paulozzi LJ, Mercy J, Frazier L Jr., Annest JL. CDC's National Violent Death Reporting System: background and methodology. Inj Prev. 2004;10(1):47-52.

12. Phillips MR, Yang G, Zhang Y, Wang L, Ji H, Zhou M. Risk factors for suicide in China: a national case-control psychological autopsy study. Lancet. 2002;360:1728-36. 13. Patel V, Ramasundarahettige C, Vijayakumar L, Thakur J S, Gajalakshmi V, Gururaj G et al. Suicide mortality in India: a nationally representative survey. Lancet. 2012;379

(9834):2343-51.

14. Kessler R, Ustun TB, editors. The WHO World Mental Health Surveys. New York (NY): Cambridge University Press; 2008.

15. STEPS optional module: mental health/suicide. Geneva: World Health Organization; 2014

(http://www.who.int/chp/steps/riskfactor/modules/en/, accessed 15 May 2014).
16. Preventing suicide: a resource for suicide case registration. Geneva: World Health Organization; 2011 (http://whqlibdoc.who.int/publications/2011/9789241502665_ eng. pdf?ua=1, accessed 5 May 2014).

17. Preventing suicide: a resource for non-fatal suicidal behaviour case registration. Geneva: World Health

Organization; 2014

(http://apps.who.int/iris/bitstream/10665/112852/1/978924150 6717_eng.pdf?ua=1, accessed 7 June 2014).

18. Methodology of the youth risk behavior surveillance system - 2013. MMWR Morb Mortal Wkly Rep. 62:1-20. 19. Borges G, Haro JM, Chiu WT, Hwang I, de Girolamo G, Medina-Mora ME et al. Prevalence and identification of groups at risk for 12-month suicidal behavior in the WHO World Mental Health Surveys. In: Nock MK, Borges G, Ono Y, editors. Suicidality in the WHO World Mental Health Surveys. New York (NY): Cambridge University Press; 2012:185-98. 20. Perry IJ, Corcoran P, Fitzgerald AP, Keeley HS, Reulbach $U$, Arensman $E$. The incidence and repetition of hospital-treated deliberate self-harm: findings from the world's first registry. PLoS ONE. 2012;7(2):1-7.

21. Arensman E, Larkin C, Corcoran P, Reulbach U, Perry IJ. Factors associated with self-cutting as a method of self-harm: findings from the Irish National Registry of Deliberate Self-Harm. Eur J Public Health. 2013;1-6. 22. Wittouck C, De Munck S, Portzky G, Van Rijsselberghe L, Van Autreve S, van Heeringen K. A comparative follow-up study of aftercare and compliance of suicide attempters following standardized psychosocial assessment. Arch Suicide Res. 2010;14(2):135-45.

23. Ludvigsson JF, Andersson E, Ekbom A, Feychting M, Kim $\mathrm{JL}$, Reuterwall $\mathrm{C}$ et al. External review and validation of the Swedish national inpatient register. BMC Public Health. 2011;11:450. doi:10.1186/1471-2458-11-450.

24. Web-based injury statistics query and reporting system. Atlanta (GA): Centers for Disease Control and Prevention; 2014 (http://www.cdc.gov/injury/wisqars/index.html, accessed 15 May 2014).

25. Jansen E, Buster MCA, Zuur AL, Das C. Fatality of suicide attempts in Amsterdam 1996-2005. Crisis. 2009;30 (4):180-5.

26. Miller M, Azraek D, Hemenway D. The epidemiology of case fatality rates for suicide in the Northeast. Inj Prev Res. 2004;43(6):723-30.

27. Clinical management of acute pesticide intoxication: prevention of suicidal behaviours. Geneva: World Health Organization; 2008

(http://whqlibdoc.who.int/publications/2008/9789241597456_e ng.pdf, accessed 23 April 2014).

28. Dawson AH, Eddleston M, Senarathna L, Mohamed F, Gawarammana I, Bowe SJ et al. Acute human toxicity of agricultural pesticides: a prospective cohort study. PLoS Medicine. 2010;7(10):e1000357.

doi:10.1371/journal.pmed.1000357.

29. Mrazek PB, Haggerty RJ, editors. Reducing risks for mental disorders: frontiers for preventive intervention research. Washington (DC): National Academies Press; 1994. 
30. Gordon, RSJ. An operational classification of disease prevention. Public Health Rep. 1983;98(2):107-9.

31. Niederkrotenthaler T, Fu KW, Yip PS, Fong DY, Stack S, Cheng $Q$ et al. Changes in suicide rates following media reports on celebrity suicide: a meta-analysis. J Epidemiol Community Health. 2012;66(11):1037-42.

32. Sisask M, Värnik A. Media roles in suicide prevention: a systematic review. Int J Environ Res Public Health.

2012;9:123-38.

33. Daine K, Hawton K, Singaravelu V, Stewart A, Simkin S, Montgomery $P$. The power of the web: a systematic review of studies of the influence of the internet on self-harm and suicide in young people. PloS ONE. 2013;8(10):e77555. 34. Westerlund M, Hadlaczky G, Wasserman D. The representation of suicide on the Internet: implications for clinicians. J Med Internet Res. 2012;14(5):122. doi:10.2196/jmir.1979p.

35. Global strategy to reduce the harmful use of alcohol. Geneva: World Health Organization; 2010

(http://www.who.int/substance_abuse/activities/gsrhua/en/, accessed 23 April 2014).

36. Chisholm D, Rehm J, Van Ommeren M, Monteiro M. Reducing the global burden of hazardous alcohol use: a comparative cost-effectiveness analysis. J Stud Alcohol. 2004;65(6):782-93.

37. Cho J, Lee WJ, Moon KT, Suh M, Sohn J, Ha KH et al. Medical care utilization during 1 year prior to death in suicides motivated by physical illnesses. J Prev Med Public Health. 2013;46(3):147-54.

38. Health literacy: the solid facts. Copenhagen: World Health Organization Regional Office for Europe; 2013 (http://www.euro.who.int/_data/assets/pdf_file/0008/190655/ e96854.pdf, accessed 23 April 2014).

39. Ajdacic-Gross V, Weiss MG, Ring M, Hepp U, Bopp M, Gutzwiller F et al. Methods of suicide: international suicide patterns derived from the WHO mortality database. Bull World Health Organ. 2008;86(9):726-32.

40. Towards evidence-based suicide prevention programmes. Manila: World Health Organization Regional Office for the Western Pacific; 2010

(http://www.wpro.who.int/mnh/TowardsEvidencebasedSPP.p df?ua=1, accessed 24 April 2014).

41. Yip PS, Caine E, Yousuf S, Chang SS, Wu KCC, Chen YY. Means restriction for suicide prevention. Lancet. 2012;379 (9834):2393-9.

42. Du Roscoät E, Beck F. Efficient interventions on suicide prevention: a literature review. Revue d'épidémiologie et de santé publique. 2013;61(4):363-74.

doi:10.1016/j.respe.2013.01.099.

43. Eddleston M, Karalliedde L, Buckley N, Fernando R, Hutchinson $\mathrm{G}$, Isbister $\mathrm{G}$ et al. Pesticide poisoning in the developing world - a minimum pesticides list. Lancet. 2002;360(9340):1163-7.

44. Gunnell D, Fernando R, Hewagama M, Priyangika WDD, Konradsen F, Eddleston M. The impact of pesticide regulations on suicide in Sri Lanka. In J Epid.

2007b;36:1235-42.
45. Safer access to pesticides: community interventions. Geneva: World Health Organization; 2006 (http://www.who.int/mental_health/prevention/suicide/pesticid es_safer_access.pdf, accessed 22 April 2014).

46. Guns, knives and pesticides: reducing access to lethal means. Geneva: World Health Organization; 2009 (http://www.who.int/violence_injury_prevention/violence-4th_ milestones_meeting/publications, accessed 23 April 2014). 47. Brent DA, Bridge J. Firearms availability and suicide: evidence, interventions, and future directions. Am Behav Sci. 2003;46(9): 1192-210.

48. Anglemyer A, Horvath T, Rutherford G. The accessibility of firearms and risk for suicide and homicide victimization among household members: a systematic review and meta-analysis. Ann Intern Med. 2014;160(2):101-10. doi:10.7326/M13-1301.

49. Ajdacic-Gross V, Killias M, Hepp U, Gadola E, Bopp M, Lauber $C$ et al. Changing times: a longitudinal analysis of international firearm suicide data. Am J Public Health. 2006;96:1752-5.

50. Cox GR, Robinson J, Nicholas A, Lockley A, Williamson $M$, Pirkis $J$ et al. Interventions to reduce suicides at suicide hotspots: a systematic review. BMC Public Health. 2013;13 (1):214. doi:10.1186/1471-2458-13-214.

51. Sarchiapone M, Mandelli L, losue M, Andrisano C, Roy A. Controlling access to suicide means. Int J Environ Res Public Health. 2011;8(12):4550-62. doi:10.3390/ijerph8124550. 52. Yip PSF, Law CK, Fu KW, Law YW, Wong PW, Xu Y. Restricting the means of suicide by charcoal burning. $\mathrm{Br} J$ Psychiatry, 2010;196:241-2.

53. Hegerl U, Wittenburg L. Focus on mental health care reforms in Europe: the European alliance against depression: a multilevel approach to the prevention of suicidal behaviour. Psychiatr Serv. 2009;60(5):596-9.

54. Hawton KL, Bergen H, Simkin S, Dodd S, Pocock P, Bernal $W$ et al. Long term effect of reduced pack sizes of paracetamol on poisoning deaths and liver transplant activity in England and Wales: interrupted time series analyses. BMJ. 2013;346:f403.

55. A prioritized research agenda for suicide prevention: an action plan to save lives. Rockville (MD): National Institute of Mental Health and the Research Prioritization Task Force; 2014.

56. Preventing suicide: a resource for media professionals. Geneva: World Health Organization; 2008

(http://www.who.int/mental_health/prevention/suicide/resourc e_media.pdf, accessed 23 April 2014).

57. Pirkis J. Suicide and the media. Psychiatry. 2009;8:269-271.

58. Bohanna I, Wang X. Media guidelines for the responsible reporting of suicide. A review of effectiveness. Crisis. 2012;33(4):190-8.

59. Collin PJ, Metcalf AT, Stephens-Reicher JC, Blanchard ME, Herrman HE, Rahilly K et al. ReachOut.com: the role of an online service for promoting help-seeking in young people. Advances in Mental Health. 2011;10(1):39-51. 60. Mishara BL, Kerkhof JFM, editors. Suicide prevention and 
new technologies: evidence based practice. Basingstoke:

Palgrave MacMillan; 2013

61. Youthhealthtalk (website). Oxford: University of Oxford (www.youthhealthtalk.org, accessed 14 April 2014).

62. Matsubayash T, Sawada Y, Ueda M. The effect of public awareness campaigns on suicides: evidence from Nagoya, Japan. J Affect Disord. 2014;152-154:526-9. doi:

10.1016/j.jad.2013.09.007

63. Reynders A, Kerkhof AJ, Molenberghs G, Van

Audenhove C. Attitudes and stigma in relation to

help-seeking intentions for psychological problems in low and high suicide rate regions. Soc Psychiatry Psychiatr

Epidemiol. 2014;49(2):231-9.

doi:10.1007/s00127-013-0745-4.

64. Carli V, Wasserman C, Wasserman D, Sarchiapone M, Apter A, Balazs $J$ et al. The saving and empowering young lives in Europe (SEYLE) randomized controlled trial (RCT): methodological issues and participant characteristics. BMC Public Health. 2013;13(1):479.

doi:10.1186/1471-2458-13-479

65. Wasserman C, Hoven CW, Wasserman D, Carli V, Sarchiapone M, Al-Halabi S et al. Suicide prevention for youth - a mental health awareness program: lessons learned from the Saving and Empowering Young Lives in Europe (SEYLE) intervention study. BMC Public Health. 2012;12:776. doi:10.1186/1471-2458-12-776.

66. Wasserman D, Hoven CW, Wasserman C, Wall M, Eisenberg R, Hadlaczky G et al. A randomized controlled trial of school-based suicide preventive programmes: the Saving and Empowering Young Lives in Europe (SEYLE) study. Lancet. 2014 (in press).

67. Kõlves K, Kõlves KE, De Leo D. Natural disasters and suicidal behaviours: a systematic literature review. J Affect Disord. 2013;146(1):1-14.

68. Fortune S, Hawton K. Culture and mental disorders: suicidal behaviour. In: Bhugra D, Bhui K, editors. Textbook of cultural psychiatry. Cambridge: Cambridge University Press; 2007:255-71.

69. Oliver LN, Peters PA, Kohen DE. Mortality rates among children and teenagers living in Inuit Nunangat, 1994 to 2008. Ottawa: Statistics Canada; 2012.

70. Goldston DB, Molock SD, Whitbeck LB, Murakami JL, Zayas LH, Hall GCN. Cultural considerations in adolescent suicide prevention and psychosocial treatment. Am Psychol. 2008;63(1):14-31.

71. Casiano H, Katz LY, Globerman D, Sareen J. Suicide and deliberate self-injurious behaviour in juvenile correctional facilities: a review. J Can Acad Child Adolesc Psychiatry. 2013;22(2):118-24.

72. Fazel S, Grann M, Kling B, Hawton K. Prison suicide in 12 countries: an ecological study of 861 suicides during 2003-2007. Soc Psychiatry Psychiatr Epidemiol.

2011;46:191-5. doi: 10.1007/s00127-010-0184-4. 73. Haas AP, Eliason M, Mays VM, Mathy RM, Cochran SD, D’Augelli AR. Suicide and suicide risk in lesbian, gay, bisexual, and transgender populations: review and recommendations. J Homosex. 2011;58(1):10-51. doi:10.1080/00918369.2011.534038.

74. Brunstein Klomek A, Sourander A, Gould M. The association of suicide and bullying in childhood to young adulthood: a review of cross-sectional and longitudinal research findings. Can J Psychiatry. 2010;55(5):282-8. 75. Kalt A, Hossain M, Kiss L, Zimmerman C. Asylum seekers, violence and health: a systematic review of research in high-income host countries. Am J Public Health. 2013;103(3):30-42.

76. Foster T. Adverse life events proximal to adult suicide: a synthesis of findings from psychological autopsy studies. Arch Suicide Res. 2011;15(1):1-15.

77. Johnson JG, Cohen P, Gould MS, Kasen S, Brown J, Brook JS. Childhood adversities, interpersonal difficulties, and risk for suicide attempts during late adolescence and early adulthood. Arch Gen Psychiatry. 2002;59(8):741-9. 78. Ben-Efraim YJ, Wasserman D, Wasserman J, Sokolowski M. Family-based study of HTR2A in suicide attempts: observed gene, gene $x$ environment and parent-of-origin associations. Mol Psychiatry. 2013;18(7):758-66.

doi:10.1038/mp.2012.86.

79. Kposowa AJ. Divorce and suicide risk. J Epidemiol Community Health. 2003;57(12):993.

80. Global and regional estimates of violence against women: prevalence and health effects of intimate partner violence and non-partner sexual violence. Geneva: World Health Organization; 2013

(http://www.who.int/reproductivehealth/publications/violence/ 9789241564625/en/ accessed 14 April 2014).

81. Garcia-Moreno C, Jansen HAFM, Ellsberg M, Heise L, Watts $\mathrm{CH}$. Prevalence of intimate partner violence: findings from the WHO multi-country study on women's health and domestic violence. Lancet. 2006;368:1260-9.

82. Matsubayashi T, Sawada Y, Ueda M. Natural disasters and suicide: evidence from Japan. Soc Sci Med.

2013;82:126-33. doi:10.1016/j.socscimed.2012.12.021.

83. Jankovic J, Bremner S, Bogic M, Lecic-Tosevski D, Ajdukovic D, Franciskovic T. Trauma and suicidality in war affected communities. Eur Psychiatry. 2013;28(8):514-20. doi:10.1016/j.eurpsy.2012.06.001.

84. Ratkowska KA, De Leo D. Suicide in immigrants: an overview. Open J Med Psychol. 2013;2:124-33.

85. Clifford AC, Doran CM, Tsey K. A systematic review of suicide prevention interventions targeting indigenous peoples in Australia, United States, Canada and New Zealand. BMC public health. 2013;13(1):463.

doi:10.1186/1471-2458-13-463

86. Fazel S, Cartwright J, Norman-Nott A, Hawton K. Suicide in prisoners: a systematic review of risk factors. J Clin Psychiatry. 2008;69(11):1721-31.

87. Marshal MP, Dietz LJ, Friedman MS, Stall R, Smith HA, McGinley $J$ et al. Suicidality and depression disparities between sexual minority and heterosexual youth: a meta-analytic review. J Adolesc Health. 2011;49(2):115-23. doi:10.1016/j.jadohealth.2011.02.005.

88. Szumilas M, Kutcher S. Post-suicide intervention programmes: a systematic review. Can J Public Health. 
2011;102(1):18-29.

89. Kang HK, Bullman TA. Is there an epidemic of suicides among current and former U.S. military personnel? Ann Epidemiol. 2009;19(10):757-60.

90. Kang HK, Bullman TA. Risk of suicide among US veterans after returning from the Iraq or Afghanistan war zones. JAMA. 2008;300(6):652-3.

91. Schoenbaum M, Kessler RC, Gilman SE, Colpe LJ, Heeringa SG, Stein MB et al. Predictors of suicide and accident death in the Army Study to Assess Risk and Resilience in Service members (Army STARRS). JAMA Psychiatry. 2014;71(5):493-503.

doi:10.1001/jamapsychiatry.2013.4417.

92. Kemp J. Suicide rates in VHA patients through 2011 with comparisons with other Americans and other veterans through 2010 (PowerPoint slides). Washington (DC):

Department of Veterans Affairs; 2014

(http://www.mentalhealth.va.gov/docs/Suicide_Data_Report_ Update_January_2014.pdf, accessed 7 June 2014).

93. Matthieu M, Hensley M. Gatekeeper training outcomes: enhancing the capacity of staff in substance abuse treatment programmes to prevent suicide in a high risk population. Ment Health Subst Use. 2013;6(4):274-86.

doi:10.1080/17523281.2012.744342.

94. Devries KM, Child JC, Bacchus LJ, Mak J, Falder G, Graham $\mathrm{K}$ et al. Intimate partner violence victimization and alcohol consumption in women: a systematic review and meta-analysis. Addiction. $2014 ; 109(3): 379-91$.

doi:10.1111/add.12393.

95. Tompkins TL, Witt J, Abraibesh N. Does a gatekeeper suicide prevention program work in a school setting?

Evaluating training outcome and moderators of effectiveness. Suicide Life Threat Behav. 2010;40(5):506-15.

doi:10.1521/suli.2010.40.5.506.

96. Mishara BL, Martin N. Effects of a comprehensive police suicide prevention program. Crisis. 2011;33(3):162-8.

97. Gould MS, Kalafat J, Harrismunfakh JL, Kleinman M. An evaluation of crisis hotline outcomes. Part 2: Suicidal callers. Suicide Life Threat Behav. 2007;37(3):338-52.

doi:10.1521/suli.2007.37.3.338.

98. Pil L, Pauwels K, Muijzers E, Portzky G, Annemans L. Cost-effectiveness of a helpline for suicide prevention. J Telemed Telecare. 2013;19(5):273-81.

doi:10.1177/1357633X13495487.

99. Yoshimasu K, Kiyohara C, Miyashita K. Suicidal risk factors and completed suicide: meta-analyses based on psychological autopsy studies. Environ Health Prev Med. 2008; 13(5):243-56.

100. Beautrais AL. Subsequent mortality in medically serious suicide attempts: a 5 year follow-up. Aust NZ J Psychiatry. 2003;37(5):595-9.

101. Cavanagh JT, Carson AJ, Sharpe M, Lawrie SM.

Psychological autopsy studies of suicide: a systematic review. Psychol med. 2003;33(3):395-405.

102. Radhakrishnan R, Andrade C. Suicide: an Indian perspective. Indian J Psychiatry. 2012;54(4):304-19. 103. Bostwick JM, Pankratz VS. Affective disorders and suicide risk: a re-examination. Am J Psychiatry. 2000; 157(12):1925-32.

104. Schneider B. Substance use disorders and risk for completed suicide. Arch Suicide Res. 2009;13(4):303-16. 105. Hawton KL, Sutton L, Haw C, Sinclair J, Harriss L. Suicide and attempted suicide in bipolar disorder: a systematic review of risk factors. J Clin Psychiatry. 2005; 66(6):693-704.

106. Nordentoft M, Mortensen PB, Pedersen CB. Absolute risk of suicide after first hospital contact in mental disorder. Arch Gen Psychiatry. 2011;68(10):1058-64.

107. Palmer BA, Pankratz VS, Bostwick JM. The lifetime risk of suicide in schizophrenia: a reexamination. Arch Gen Psychiatry. 2005;62(3):247-53.

108. Beautrais AL, Joyce PR, Mulder RT, Fergusson DM, Deavoll BJ, Nightingale SK. Prevalence and comorbidity of mental disorders in persons making serious suicide attempts: a case-control study. Am J Psychiatry. 1996; 153(8):1009-14.

109. Global status report on alcohol and health 2014

Geneva: World Health Organization; 2014

(http://www.who.int/substance_abuse/publications/global_alc ohol_report/en/, accessed 7 July 2014).

110. Bohnert KM, IIgen MA, McCarthy JF, Ignacio RV, Blow FC, Katz IR. Tobacco use disorder and the risk of suicide mortality. Addiction. 2014;109(1):155-62.

111. Chang SS, Stuckler D, Yip P, Gunnell D. Impact of 2008 global economic crisis on suicide: time trend study in 54 countries. BMJ. 2013;347: $\{5239$.

112. Stuckler D, Basu S. The body economic: why austerity kills: recession, budget battles, and the politics of life and death. London: Penguin Press; 2013.

113. O'Connor RC, Nock MK. The psychology of suicidal behaviour. Lancet Psychiatry. 2014;1(1):73-85.

doi:10.1016/S2215-0366(14)70222-6

114. Beck AT, Brown G, Berchick RJ, Stewart BL, Steer RA. Relationship between hopelessness and ultimate suicide: a replication with psychiatric outpatients. Am J Psychiatry. 1990;147(2): 190-5.

115. Tang NK, Crane C. Suicidality in chronic pain: a review of the prevalence, risk factors and psychological links.

Psychol Med. 2006;36(5):575-86.

116. Stenager E, Stenager E. Somatic diseases and suicidal behaviour. In: Wasserman D, Wasserman C, editors. Oxford textbook of suicidology and suicide prevention: a global perspective. Oxford: Oxford University Press; 2009:293-9. 117. Jordan JR, McIntosh JL, editors. Grief after suicide: understanding the consequences and caring for the survivors (Series in Death, Dying, and Bereavement). New York (NY): Routledge; 2011.

118. Van Orden KA, Witte TK, Cukrowicz KC, Braithwaite SR, Selby EA, Joiner Jr TE. The interpersonal theory of suicide. Psychol Rev. 2010;117(2):575-600.

119. Qin P, Agerbo E, Mortensen PB. Suicide risk in relation to family history of completed suicide and psychiatric disorders: a nested case-control study based on longitudinal registers. Lancet. 2002;360(9340):1126-30. 
120. Mann JJ, Currier DM. Stress, genetics and epigenetic effects on the neurobiology of suicidal behaviour and depression. Eur Psychiatry. 2010;25(5):268-71. 121. Luxton DD, June JD, Comtois KA. Can postdischarge follow-up contacts prevent suicide and suicidal behaviour? A review of the evidence. Crisis. 2013;34(1):32-41.

doi: 10.1027/0227-5910/a000158.

122. mhGAP Intervention Guide for mental, neurological and substance use disorders in non-specialized health settings: version 1.0. Geneva: World Health Organization; 2010 (http://whqlibdoc.who.int/publications/2010/9789241548069_ eng.pdf, accessed 23 April 2014).

123. Fleischmann A. Effectiveness of brief intervention and contact for suicide attempters: a randomized controlled trial in five countries. Bull World Health Organ. 2008;86(9):703-9. doi:10.2471/BLT.07.046995.

124. Michel K, Gysin-Maillart A, editors. Kurztherapie nach Suizidversuch: ASSIP - Attempted Suicide Short Intervention Program. Germany: Verlag Hans Huber; 2013.

125. Wasserman D, Rihmer Z, Rujescu D, Sarchiapone M, Sokolowski M, Titelman D et al. The European Psychiatric Association (EPA) guidance on suicide treatment and prevention. Eur Psychiatry. 2012;27(2):129-41.

doi:10.1016/j.eurpsy.2011.06.003.

126. Pearson A, Saini P, Da Cruz D, Miles C, While D, Swinson $\mathrm{N}$ et al. Primary care contact prior to suicide in individuals with mental illness. Br J Gen Pract. 2009;59 (568):825-32. doi:10.3399/bjgp09X472881.

127. Knox KL, Pflanz S, Talcott GW, Campise RL, Lavigne JE, Bajorska A et al. The US Air Force suicide prevention program: implications for public health policy. Am J Public Health. 2010;100(12):2457-63.

128. Hegerl U, Rummel-Kluge C, Värnik A, Arensman E, Koburger N. Alliances against depression - a community based approach to target depression and to prevent suicidal behaviour. Neurosci Biobehav Rev. 2013;37(10):2404-9. 129. Hegerl U, Network EAAD. The European Alliance Against Depression (EAAD): an evidence based cost-effective approach to improve depressed patients care and prevent suicidality. Eur Psychiatry. 2009;24:164. 130. While D, Bickley H, Roscoe A, Windfuhr K, Rahman S, Shaw J et al. Implementation of mental health service recommendations in England and Wales and suicide rates, 1997-2006: a cross-sectional and before-and-after observational study. Lancet. 2012;379(9820):1005-12. 131. Johnson J, Wood AM, Gooding P, Taylor PJ, Tarrier N. Resilience to suicidality: the buffering hypothesis. Clin Psychol Rev. 2011;31:563-91.

132. Van Praag $\mathrm{H}$. The role of religion in suicide prevention. In: Wasserman D, Wasserman C, editors. Oxford textbook of suicidology and suicide prevention: a global perspective. Oxford: Oxford University Press; 2009:7-12.

133. Rezaeian M. Epidemiology of self-immolation. Burns. 2013;39(1):184-6.

134. Sisask M, Värnik A, Kolves K, Konstabel K, Wasserman D. Subjective psychological well-being (WHO-5) in assessment of the severity of suicide attempt. Nord $J$
Psychiatry. 2008;62(6):431-5.

135. Luthar SS, editor. Resilience and vulnerability: adaptation in the context of childhood adversities. Cambridge: Cambridge University Press; 2003.

136. Davidson CL, Babson KA, Bonn-Miller MO, Souter T, Vannoy $\mathrm{S}$. The impact of exercise on suicide risk: examining pathways through depression, PTSD, and sleep in an inpatient sample of veterans. Suicide Life Threat Behav. 2013;43(3):279-89.

137. Sarchiapone M, Mandelli L, Carli V, Iosue M,

Wasserman C, Hadlaczky G et al. Hours of sleep in adolescents and its association with anxiety, emotional concerns, and suicidal ideation. Sleep Med. 2014;15(2):24854. doi:10.1016/j.sleep.2013.11.780.

138. Jané-Llopis E, Barry M, Hosman C, Patel V. Mental health promotion works: a review. Promot Educ. 2005;12(2):9-25. 139. Fergusson DM, McLeod GF, Horwood LJ. Childhood sexual abuse and adult developmental outcomes: findings from a 30-year longitudinal study in New Zealand. Child Abuse Negl. 2013;37(9):664-674. doi:

10.1016/j.chiabu.2013.03.013.

140. Mejdoubi J, van den Heijkant SC, van Leerdam FJ, Heymans MW, Hirasing RA, Crijnen AA. Effect of nurse home visits vs. usual care on reducing intimate partner violence in young high-risk pregnant women: a randomized controlled trial. PLoS ONE. 2013;8(10):e78185. doi:

10.1371/journal.pone.0078185.

141. Olds DL, Henderson CR, Chamberlin R, Tatelbaum R. Preventing child abuse and neglect: a randomized trial of nurse home visitation. Pediatrics. 1986;78(1):65-78.

142. Chan CS, Rhodes JE, Howard WJ, Lowe SR, Schwartz SE, Herrera C. Pathways of influence in school-based mentoring: the mediating role of parent and teacher relationships. J Sch Psychol. 2013;51(1):129-42. doi: 10.1016/j.jsp.2012.10.001

143. Hawkins JD, Oesterle S, Brown EC, Monahan KC, Abbott RD, Arthur MW. Sustained decreases in risk exposure and youth problem behaviours after installation of the Communities That Care prevention system in a randomized trial. Arch Pediatr Adolesc Med. 2012;166(2):141-8. doi: 10.1001/archpediatrics.2011.183.

144. Lewis KM, DuBois DL, Bavarian N, Acock A, Silverthorn $\mathrm{N}$, Day J. Effects of positive action on the emotional health of urban youth: a cluster-randomized trial. J Adolesc Health, 2013;53(6):706-11. doi: 10.1016/j.jadohealth.2013.06.012. 145. Public health action for the prevention of suicide: a framework. Geneva: World Health Organization; 2012 (http://apps.who.int/iris/bitstream/10665/75166/1/9789241503 570_eng.pdf, accessed 23 April 2014).

146. Soubrier JP. Looking back and ahead. Suicidology and suicide prevention: do we have perspectives? Forum Prevention of Suicide Worldwide. World Psychiatry. 2004;3 (3):159-60.

147. Chandler M J, Lalonde CE. Cultural continuity as a moderator of suicide risk among Canada's First Nations. In: Kirmayer L, Valaskakis G, editors. The mental health of Canadian aboriginal peoples: transformations, identity, and 
community. Vancouver: University of British Columbia Press; 2008:221-48.

148. Soubrier JP. Collaboration between psychiatrists and other physicians. In: Wasserman D, editor. Suicide - an unnecessary death. London: Martin Dunitz Ltd; 2001:231-6. 149. De Leo D, Cimitan A, Dyregrov K, Grad O , Andriessen $\mathrm{K}$, editors. Bereavement after traumatic death - helping the survivors. Boston (MA): Hogrefe Publishing; 2014.

150. Coveney CM, Pollock K, Armstrong S, Moore J. Callers experiences of contacting a national suicide prevention helpline. Crisis. 2012;33(6):313-24.

151. Mishara BL, Chagnon F, Daigle M, Balan B, Raymond S, Marcoux I et al. Comparing models of helper behavior to actual practice in telephone crisis intervention: a silent monitoring study of calls to the U.S. 1-800-SUICIDE Network. Suicide Life Threat Behav. 2007;37(3):291-307.

152. Mishara BL, Weisstub DN. Suicide Laws: An International Review. International Journal of Law and Psychiatry. 2014 (in press).

153. Benson KM. Evidence-based approaches to suicide prevention. In: Lester D, Rogers JR, editors. Suicide: a global issue, Volume 2: Prevention. Santa Barbara (CA): ABC-CLIO, LLC; 2013.

154. Framework for program evaluation in public health. MMWR Morb Mortal Wkly Rep. 1999 Sep 17;48(RR-11):1-40. 155. United Nations, 1996. Prevention of suicide: guidelines for the formulation and implementation of national strategies. New York (NY): United Nations; 1996.

156. Thacker SB, Berkelman RL. Public health surveillance in the United States. Epidemiol Rev. 1988;10:164-90.

157. How to change practice: understand, identify and overcome barriers to change. London: National Institute for Health and Clinical Excellence; 2007

(http://www.nice.org.uk/usingguidance/implementationtools/h owtoguide/barrierstochange.jsp, accessed 22 April 2014). 158. Developing an effective evaluation plan. Atlanta (GA): Centers for Disease Control and Prevention; 2011.

159. De Leo D, Evans RW. International suicide rates and prevention strategies. Göttingen: Hogrefe \& Huber; 2004. 160. Wasserman D. Evaluating suicide prevention: various approaches needed. World Psychiatry. 2004;3:153-4. 161. Wasserman GA, McReynolds LS, Musabegovic H, Whited AL, Keating JM, Huo Y. Evaluating Project Connect: improving juvenile probationers' mental health and substance use service access. Adm Policy Ment Health. 2009;36(6):393-405.

162. Suicide Prevention Strategy 2013-2016. Edinburgh: Scottish Government; 2013

(http://www.scotland.gov.uk/Publications/2013/12/7616/down loads\#res439429, accessed 14 April 2014).

163. National Strategy for Suicide Prevention: goals and objectives for action. A Report of the U.S. Surgeon General and of the National Action Alliance for Suicide Prevention. Washington (DC): U.S. Department of Health and Human Services; 2012.

164. Hjelmeland H, Dieserud G, Dyregrov K, Knizek BL, Leenaars AL. Psychological autopsy studies as diagnostic tools: are they methodologically flawed? Death Stud. 2012; 36(7):605-26.

165. Khan MM, Hyder AA. Suicides in the developing world: case study from Pakistan. Suicide Life Threat Behav. 2006;36(1):76-81.

166. Mitchell $P$, editor. Valuing young lives: evaluation of the national youth suicide prevention strategy. Melbourne: Australian Institute of Family Studies; 2000.

167. Scott A, Guo B, editors. For which strategies of suicide prevention is there evidence of effectiveness? HEN synthesis report. Copenhagen: World Health Organization Regional Office for Europe; 2012.

168. Zechmeister I, Kilian R, McDaid D. Is it worth investing in mental health promotion and prevention of mental illness? A systematic review of the evidence from economic evaluations. BMC Public Health, 2008;22(8):20.

169. Wickramasinghe K, Steele P, Dawson A, Dharmaratne $D$, Gunawardena A, Senarathna L et al. Cost to government health-care services of treating acute self-poisonings in a rural district in Sri Lanka. Bull World Health Organ. 2009;87:180-5.

170. Van Spijker BA, Majo MC, Smit F, van Straten A, Kerkhof A. Reducing suicidal ideation: cost-effectiveness analysis of a randomized controlled trial of unguided web-based self-help. J Med Internet Res. 2012;14:e141.

171. Byford S, Knapp M, Greenshields J, Ukoumunne OC, Jones V, Thompson S et al. Cost-effectiveness of brief cognitive behaviour therapy versus treatment as usual in recurrent deliberate self-harm: a decision-making approach. Psychol Med. 2003;33:977-86.

172. Vos T, Carter R, Barendregt J, Mihalopoulos C, Veerman JL, Magnus A et al, editors. Assessing cost-effectiveness in prevention (ACE-Prevention): final report. Brisbane and Melbourne: University of Queensland and Deakin University; 2010.

173. Saving lives: our healthier nation. London: Secretary of State for Health; 1999

(https://www.gov.uk/government/uploads/system/uploads/att achment_data/file/265576/4386.pdf, accessed 5 May 2014). 174. National suicide prevention strategy for England. Annual report on progress. London: National Mental Health

Development Unit; 2009

(https://www.gov.uk/government/uploads/system/uploads/att achment_data/file/265576/4386.pdf, accessed 5 May 2014). 


\begin{tabular}{|c|c|c|c|c|c|c|c|c|c|c|c|}
\hline \multirow{2}{*}{$\begin{array}{l}\text { Country } \\
\text { [quality of } \\
\text { mortality data**) }\end{array}$} & \multirow[t]{2}{*}{ Sex } & \multirow{2}{*}{$\begin{array}{l}\text { Number of } \\
\text { suicides } \\
\text { (all ages), } \\
2012\end{array}$} & \multicolumn{6}{|c|}{$\begin{array}{l}\text { Crude all ages and age-specific } \\
\text { suicide rates (per } 100 \text { 000), } 2012\end{array}$} & \multirow{2}{*}{$\begin{array}{l}\text { Age- } \\
\text { standardized } \\
\text { suicide } \\
\text { rates*** } \\
\text { (per } 100000 \text { ), } \\
2012\end{array}$} & \multirow{2}{*}{$\begin{array}{l}\text { Age- } \\
\text { standardized } \\
\text { suicide } \\
\text { rates*** } \\
\text { (per } 100000 \text { ), } \\
2000\end{array}$} & \multirow{2}{*}{$\begin{array}{l}\% \text { change in } \\
\text { age- } \\
\text { standardized } \\
\text { suicide rates, } \\
2000-2012\end{array}$} \\
\hline & & & $\begin{array}{l}\text { All } \\
\text { ages }\end{array}$ & $\begin{array}{l}5-14 \\
\text { years }\end{array}$ & $\begin{array}{l}15-29 \\
\text { years }\end{array}$ & $\begin{array}{l}30-49 \\
\text { years }\end{array}$ & $\begin{array}{l}50-69 \\
\text { years }\end{array}$ & $\begin{array}{l}70+ \\
\text { years }\end{array}$ & & & \\
\hline \multirow{3}{*}{$\begin{array}{l}\text { Afghanistan } \\
\text { (4) }\end{array}$} & both sexes & 1205 & 4.0 & 0.8 & 7.5 & 6.1 & 8.3 & 12.6 & 5.7 & 6.1 & $-5.9 \%$ \\
\hline & females & 643 & 4.4 & 0.9 & 9.8 & 5.4 & 5.4 & 8.5 & 5.3 & 4.7 & $14.4 \%$ \\
\hline & males & 562 & 3.7 & 0.7 & 5.1 & 6.7 & 11.4 & 17.9 & 6.2 & 7.6 & $-17.6 \%$ \\
\hline \multirow{3}{*}{$\begin{array}{l}\text { Albania } \\
\text { (2) }\end{array}$} & both sexes & 205 & 6.5 & 0.8 & 5.3 & 7.0 & 9.1 & 19.3 & 5.9 & 7.0 & $-15.3 \%$ \\
\hline & females & 93 & 5.9 & 1.0 & 4.9 & 5.8 & 8.3 & 17.4 & 5.2 & 5.6 & $-7.0 \%$ \\
\hline & males & 112 & 7.1 & 0.6 & 5.7 & 8.3 & 9.9 & 21.4 & 6.6 & 8.5 & $-22.0 \%$ \\
\hline \multirow{3}{*}{$\begin{array}{l}\text { Algeria } \\
\text { (4) }\end{array}$} & both sexes & 677 & 1.8 & 0.3 & 2.2 & 2.1 & 2.5 & 6.1 & 1.9 & 2.2 & $-12.8 \%$ \\
\hline & females & 277 & 1.5 & 0.3 & 2.0 & 1.6 & 1.8 & 5.1 & 1.5 & 1.9 & $-16.8 \%$ \\
\hline & males & 400 & 2.1 & 0.4 & 2.3 & 2.6 & 3.2 & 7.3 & 2.3 & 2.6 & $-10.6 \%$ \\
\hline \multirow{3}{*}{$\begin{array}{l}\text { Angola } \\
\text { (4) }\end{array}$} & both sexes & 2206 & 10.6 & 2.3 & 21.4 & 17.4 & 13.7 & 18.8 & 13.8 & 9.2 & $50.3 \%$ \\
\hline & females & 612 & 5.8 & 1.9 & 11.7 & 8.2 & 7.9 & 10.7 & 7.3 & 4.4 & $64.8 \%$ \\
\hline & males & 1594 & 15.5 & 2.7 & 31.3 & 26.8 & 20.2 & 29.3 & 20.7 & 14.3 & $45.1 \%$ \\
\hline \multirow{3}{*}{$\begin{array}{l}\text { Argentina } \\
\text { (2) }\end{array}$} & both sexes & 4418 & 10.8 & 1.1 & 13.8 & 10.9 & 15.8 & 21.6 & 10.3 & 12.4 & $-17.1 \%$ \\
\hline & females & 901 & 4.3 & 0.9 & 5.3 & 4.7 & 5.9 & 7.0 & 4.1 & 5.1 & $-20.4 \%$ \\
\hline & males & 3517 & 17.5 & 1.2 & 21.9 & 17.3 & 26.9 & 45.6 & 17.2 & 20.6 & $-16.5 \%$ \\
\hline & both sexes & 98 & 3.3 & 0.3 & 2.8 & 3.6 & 4.6 & 8.8 & 2.9 & 3.2 & $-8.1 \%$ \\
\hline $\begin{array}{l}\text { Armenia } \\
\text { (2) }\end{array}$ & females & 17 & 1.2 & 0.2 & 0.9 & 0.7 & 1.2 & 5.2 & 0.9 & 1.0 & $-5.2 \%$ \\
\hline & males & 81 & 5.3 & 0.4 & 4.3 & 6.4 & 8.3 & 14.0 & 5.0 & 5.9 & $-14.8 \%$ \\
\hline & both sexes & 2679 & 11.6 & 0.6 & 12.2 & 17.2 & 13.2 & 12.9 & 10.6 & 11.9 & $-10.6 \%$ \\
\hline $\begin{array}{l}\text { Australia } \\
\text { (1) }\end{array}$ & females & 649 & 5.6 & 0.8 & 6.5 & 7.9 & 6.2 & 5.4 & 5.2 & 5.0 & $4.6 \%$ \\
\hline & males & 2030 & 17.7 & 0.4 & 17.5 & 26.5 & 20.4 & 22.2 & 16.1 & 18.9 & $-15.1 \%$ \\
\hline & both sexes & 1319 & 15.6 & 1.0 & 9.5 & 14.3 & 21.5 & 32.9 & 11.5 & 16.3 & $-29.7 \%$ \\
\hline Austria & females & 330 & 7.6 & 0.7 & 3.3 & 6.5 & 12.2 & 14.0 & 5.4 & 7.4 & $-27.2 \%$ \\
\hline & males & 989 & 23.9 & 1.3 & 15.5 & 22.1 & 31.3 & 61.2 & 18.2 & 26.7 & $-32.1 \%$ \\
\hline & both sexes & 154 & 1.7 & 0.2 & 1.6 & 1.8 & 2.6 & 5.2 & 1.7 & 1.7 & $-4.6 \%$ \\
\hline $\begin{array}{l}\text { Azerbaljan } \\
\text { (2) }\end{array}$ & females & 48 & 1.0 & 0.2 & 1.2 & 0.8 & 1.3 & 4.3 & 1.0 & 0.9 & $17.6 \%$ \\
\hline & males & 106 & 2.3 & 0.3 & 2.1 & 2.9 & 4.1 & 6.6 & 2.4 & 2.7 & $-12.8 \%$ \\
\hline & both sexes & 9 & 2.3 & 0.2 & 1.0 & 1.8 & 4.5 & 14.8 & 2.3 & 3.0 & $-23.6 \%$ \\
\hline $\begin{array}{l}\text { Bahamas } \\
\text { (2) }\end{array}$ & females & 3 & 1.4 & 0.2 & 0.6 & 0.9 & 2.2 & 9.2 & 1.3 & 2.1 & $-39.7 \%$ \\
\hline & males & 6 & 3.3 & 0.3 & 1.4 & 2.7 & 7.1 & 23.6 & 3.6 & 4.2 & $-13.2 \%$ \\
\hline & both sexes & 95 & 7.3 & 1.1 & 8.7 & 8.2 & 8.9 & 36.4 & 8.1 & 8.0 & $0.1 \%$ \\
\hline $\begin{array}{l}\text { Bahrain } \\
\text { (2) }\end{array}$ & females & 11 & 2.2 & 0.3 & 2.9 & 2.2 & 3.2 & 16.6 & 2.9 & 3.0 & $-3.4 \%$ \\
\hline & males & 85 & 10.3 & 1.7 & 12.1 & 11.0 & 12.2 & 57.1 & 11.6 & 11.8 & $-1.8 \%$ \\
\hline & both sexes & 10167 & 6.6 & 1.0 & 8.1 & 6.4 & 13.6 & 28.9 & 7.8 & 7.8 & $-0.1 \%$ \\
\hline $\begin{array}{l}\text { Bangladesh } \\
\text { (4) }\end{array}$ & females & 5773 & 7.6 & 1.3 & 10.8 & 6.6 & 13.9 & 31.6 & 8.7 & 8.2 & $5.8 \%$ \\
\hline & males & 4394 & 5.6 & 0.7 & 5.5 & 6.1 & 13.4 & 26.4 & 6.8 & 7.3 & $-6.8 \%$ \\
\hline & both sexes & 7 & 2.6 & 0.2 & 2.2 & 2.2 & 4.0 & 8.1 & 2.3 & 3.4 & $-33.6 \%$ \\
\hline $\begin{array}{l}\text { Barbados } \\
\text { (2) }\end{array}$ & females & 1 & 0.7 & 0.1 & 0.5 & 0.6 & 0.8 & 2.5 & 0.6 & 1.0 & $-44.7 \%$ \\
\hline & males & 6 & 4.6 & 0.3 & 3.7 & 3.7 & 7.4 & 16.7 & 4.1 & 6.0 & $-31.3 \%$ \\
\hline & both sexes & 2051 & 21.8 & 0.9 & 20.1 & 27.2 & 26.0 & 31.7 & 18.3 & 35.5 & $-48.4 \%$ \\
\hline Belarus & females & 400 & 7.9 & 0.5 & 6.2 & 8.9 & 9.5 & 13.4 & 6.4 & 8.8 & $-27.9 \%$ \\
\hline & males & 1651 & 37.8 & 1.2 & 33.4 & 46.6 & 47.0 & 76.6 & 32.7 & 66.2 & $-50.6 \%$ \\
\hline & both sexes & 1955 & 17.7 & 0.7 & 9.5 & 24.1 & 24.6 & 25.1 & 14.2 & 18.0 & $-21.1 \%$ \\
\hline $\begin{array}{l}\text { Belgium } \\
\text { (1) }\end{array}$ & females & 548 & 9.7 & 0.5 & 4.9 & 11.1 & 16.4 & 12.4 & 7.7 & 9.2 & $-16.4 \%$ \\
\hline & males & 1407 & 25.9 & 0.8 & 14.0 & 36.8 & 33.0 & 43.8 & 21.0 & 27.4 & $-23.1 \%$ \\
\hline & both sexes & 6 & 2.0 & 0.3 & 1.6 & 2.7 & 2.5 & 21.9 & 2.6 & 3.9 & $-32.6 \%$ \\
\hline Belize & females & 1 & 0.6 & 0.0 & 1.2 & 0.8 & 0.0 & 0.0 & 0.5 & 0.6 & $-12.1 \%$ \\
\hline & males & 6 & 3.5 & 0.5 & 1.9 & 4.7 & 5.0 & 48.6 & 4.9 & 7.3 & $-32.2 \%$ \\
\hline & both sexes & 368 & 3.7 & 0.7 & 5.5 & 4.5 & 8.0 & 26.5 & 5.7 & 6.0 & $-5.5 \%$ \\
\hline Benin & females & 105 & 2.1 & 0.5 & 3.1 & 2.2 & 5.0 & 14.1 & 3.1 & 3.2 & $-2.2 \%$ \\
\hline & males & 262 & 5.2 & 1.0 & 7.9 & 6.7 & 11.3 & 44.7 & 8.8 & 9.6 & $-7.7 \%$ \\
\hline & both sexes & 119 & 16.0 & 1.9 & 15.7 & 24.6 & 28.8 & 37.9 & 17.8 & 23.8 & $-25.1 \%$ \\
\hline $\begin{array}{l}\text { Bhutan } \\
\text { (4) }\end{array}$ & females & 35 & 10.2 & 1.4 & 13.1 & 14.2 & 16.7 & 19.1 & 11.2 & 16.1 & $-30.5 \%$ \\
\hline & males & 83 & 20.9 & 2.4 & 18.0 & 32.4 & 38.2 & 53.0 & 23.1 & 30.6 & $-24.5 \%$ \\
\hline & both sexes & 1224 & 11.7 & 4.8 & 20.6 & 13.3 & 12.0 & 13.9 & 12.2 & 12.5 & $-2.2 \%$ \\
\hline $\begin{array}{l}\text { Bolivia } \\
\text { (2) }\end{array}$ & females & 450 & 8.6 & 4.9 & 17.2 & 7.7 & 5.5 & 8.6 & 8.5 & 9.3 & $-9.4 \%$ \\
\hline & males & 774 & 14.8 & 4.8 & 23.9 & 19.1 & 19.2 & 20.9 & 16.2 & 15.9 & $2.0 \%$ \\
\hline & both sexes & 532 & 13.9 & 0.4 & 6.8 & 13.2 & 23.8 & 29.0 & 10.8 & 12.0 & $-10.6 \%$ \\
\hline Herzegovina & females & 114 & 5.8 & 0.3 & 1.4 & 4.4 & 10.3 & 15.1 & 4.1 & 4.9 & $-16.5 \%$ \\
\hline & males & 418 & 22.3 & 0.5 & 12.0 & 22.1 & 38.8 & 48.2 & 18.0 & 20.2 & $-10.7 \%$ \\
\hline
\end{tabular}




\begin{tabular}{|c|c|c|c|c|c|c|c|c|c|c|c|}
\hline \multirow{2}{*}{$\begin{array}{l}\text { Country } \\
\text { (quality of } \\
\text { mortality data**) }\end{array}$} & \multirow[t]{2}{*}{ Sex } & \multirow{2}{*}{$\begin{array}{l}\text { Number of } \\
\text { suicides } \\
\text { (all ages), } \\
2012\end{array}$} & \multicolumn{6}{|c|}{$\begin{array}{l}\text { Crude all ages and age-specific } \\
\text { suicide rates (per } 100 \text { 000), } 2012\end{array}$} & \multirow{2}{*}{$\begin{array}{l}\text { Age- } \\
\text { standardized } \\
\text { suicide } \\
\text { rates*** } \\
\text { (per } 100000 \text { ), } \\
2012\end{array}$} & \multirow{2}{*}{$\begin{array}{l}\text { Age- } \\
\text { standardized } \\
\text { suicide } \\
\text { rates*** } \\
\text { (per } 100000 \text { ), } \\
2000\end{array}$} & \multirow{2}{*}{$\begin{array}{l}\% \text { change in } \\
\text { age- } \\
\text { standardized } \\
\text { suicide rates, } \\
2000-2012\end{array}$} \\
\hline & & & $\begin{array}{l}\text { All } \\
\text { ages }\end{array}$ & $\begin{array}{l}5-14 \\
\text { years }\end{array}$ & $\begin{array}{l}15-29 \\
\text { years }\end{array}$ & $\begin{array}{l}30-49 \\
\text { years }\end{array}$ & $\begin{array}{l}50-69 \\
\text { years }\end{array}$ & $\begin{array}{l}70+ \\
\text { years }\end{array}$ & & & \\
\hline \multirow{3}{*}{$\begin{array}{l}\text { Botswana } \\
\text { (4) }\end{array}$} & both sexes & 64 & 3.2 & 0.6 & 4.5 & 3.8 & 5.2 & 12.6 & 3.8 & 4.1 & $-7.8 \%$ \\
\hline & females & 17 & 1.7 & 0.3 & 2.2 & 1.4 & 3.4 & 8.7 & 2.0 & 2.3 & $-11.8 \%$ \\
\hline & males & 48 & 4.7 & 0.8 & 6.9 & 5.9 & 7.4 & 19.4 & 5.7 & 6.2 & $-7.0 \%$ \\
\hline \multirow{3}{*}{$\begin{array}{l}\text { Brazil } \\
\text { (1) }\end{array}$} & both sexes & 11821 & 6.0 & 0.4 & 6.7 & 8.4 & 8.0 & 9.8 & 5.8 & 5.3 & $10.4 \%$ \\
\hline & females & 2623 & 2.6 & 0.3 & 2.6 & 3.7 & 3.8 & 3.3 & 2.5 & 2.1 & $17.8 \%$ \\
\hline & males & 9198 & 9.4 & 0.4 & 10.7 & 13.3 & 12.7 & 18.5 & 9.4 & 8.7 & $8.2 \%$ \\
\hline & both sexes & 25 & 6.2 & 0.2 & 6.0 & 8.0 & 11.2 & 15.1 & 6.4 & 5.5 & $16.9 \%$ \\
\hline Darussalam & females & 10 & 4.9 & 0.2 & 4.5 & 6.1 & 9.3 & 13.7 & 5.2 & 4.2 & $24.2 \%$ \\
\hline & males & 15 & 7.4 & 0.2 & 7.5 & 10.0 & 13.0 & 16.7 & 7.7 & 6.8 & $12.6 \%$ \\
\hline & both sexes & 1054 & 14.5 & 0.8 & 8.0 & 14.4 & 21.2 & 24.1 & 10.8 & 15.5 & $-30.5 \%$ \\
\hline Bulgaria & females & 288 & 7.7 & 0.5 & 3.2 & 6.9 & 10.6 & 14.9 & 5.3 & 8.0 & $-34.3 \%$ \\
\hline & males & 766 & 21.6 & 1.1 & 12.5 & 21.5 & 33.1 & 38.6 & 16.6 & 23.5 & $-29.3 \%$ \\
\hline & both sexes & 485 & 3.0 & 0.6 & 4.8 & 3.9 & 6.4 & 21.5 & 4.8 & 4.8 & $0.0 \%$ \\
\hline Burkina Faso & females & 151 & 1.8 & 0.4 & 2.9 & 1.9 & 4.5 & 12.7 & 2.8 & 2.6 & $8.1 \%$ \\
\hline & males & 334 & 4.1 & 0.8 & 6.7 & 5.9 & 9.0 & 36.0 & 7.3 & 7.6 & $-3.8 \%$ \\
\hline & both sexes & 1617 & 16.4 & 5.2 & 27.3 & 21.0 & 29.2 & 82.4 & 23.1 & 19.6 & $17.8 \%$ \\
\hline $\begin{array}{l}\text { Burundi } \\
\text { (4) }\end{array}$ & females & 401 & 8.0 & 4.2 & 11.4 & 7.0 & 16.7 & 70.8 & 12.5 & 10.3 & $21.7 \%$ \\
\hline & males & 1216 & 25.0 & 6.3 & 44.2 & 35.1 & 41.7 & 96.5 & 34.1 & 29.6 & $15.4 \%$ \\
\hline & both sexes & 19 & 3.9 & 0.3 & 2.5 & 2.7 & 7.2 & 38.7 & 4.8 & 5.4 & $-12.3 \%$ \\
\hline Cabo Verde & females & 4 & 1.5 & 0.1 & 0.6 & 0.8 & 2.8 & 14.2 & 1.6 & 2.0 & $-18.2 \%$ \\
\hline & males & 16 & 6.4 & 0.6 & 4.3 & 4.5 & 12.8 & 77.7 & 9.1 & 10.0 & $-8.7 \%$ \\
\hline & both sexes & 1339 & 9.0 & 2.1 & 13.0 & 12.8 & 9.4 & 15.8 & 9.4 & 11.5 & $-18.0 \%$ \\
\hline & females & 474 & 6.2 & 1.8 & 8.7 & 6.9 & 9.2 & 11.5 & 6.5 & 8.5 & $-24.2 \%$ \\
\hline & males & 865 & 11.9 & 2.4 & 17.2 & 19.2 & 9.7 & 21.9 & 12.6 & 14.9 & $-15.2 \%$ \\
\hline & both sexes & 1070 & 4.9 & 1.2 & 7.9 & 6.0 & 8.6 & 30.5 & 7.0 & 6.8 & $3.1 \%$ \\
\hline Cameroon & females & 257 & 2.4 & 0.7 & 3.2 & 2.7 & 5.6 & 15.1 & 3.4 & 3.4 & $0.9 \%$ \\
\hline & males & 814 & 7.5 & 1.7 & 12.5 & 9.2 & 11.8 & 49.6 & 10.9 & 10.5 & $3.6 \%$ \\
\hline & both sexes & 3983 & 11.4 & 0.6 & 10.0 & 15.2 & 15.6 & 11.3 & 9.8 & 11.0 & $-11.1 \%$ \\
\hline & females & 958 & 5.5 & 0.5 & 5.2 & 7.1 & 8.0 & 3.3 & 4.8 & 4.9 & $-2.8 \%$ \\
\hline & males & 3026 & 17.5 & 0.6 & 14.6 & 23.2 & 23.5 & 22.0 & 14.9 & 17.2 & $-13.5 \%$ \\
\hline Central African & both sexes & 356 & 7.9 & 1.4 & 13.1 & 11.6 & 11.3 & 17.8 & 9.5 & 7.8 & $22.7 \%$ \\
\hline Republic & females & 100 & 4.4 & 1.3 & 6.7 & 5.6 & 7.5 & 11.8 & 5.3 & 4.5 & $18.4 \%$ \\
\hline & males & 256 & 11.5 & 1.6 & 19.6 & 17.7 & 15.9 & 26.1 & 14.1 & 11.3 & $24.6 \%$ \\
\hline & both sexes & 336 & 2.7 & 0.5 & 4.1 & 4.0 & 7.4 & 21.4 & 4.7 & 4.5 & $4.2 \%$ \\
\hline $\begin{array}{l}\text { Chad } \\
41\end{array}$ & females & 81 & 1.3 & 0.4 & 1.7 & 1.5 & 4.8 & 10.6 & 2.3 & 2.1 & $8.5 \%$ \\
\hline & males & 255 & 4.1 & 0.7 & 6.4 & 6.5 & 10.3 & 34.5 & 7.4 & 7.2 & $2.4 \%$ \\
\hline & both sexes & 2262 & 13.0 & 1.0 & 16.5 & 16.0 & 16.2 & 16.8 & 12.2 & 10.7 & $14.3 \%$ \\
\hline $\begin{array}{l}\text { Chile } \\
\text { (1) }\end{array}$ & females & 533 & 6.0 & 1.1 & 8.0 & 7.9 & 6.9 & 5.0 & 5.8 & 2.9 & $98.6 \%$ \\
\hline & males & 1729 & 20.0 & 0.9 & 24.8 & 24.2 & 26.1 & 33.9 & 19.0 & 19.1 & $-0.7 \%$ \\
\hline & both sexes & 120730 & 8.7 & 0.5 & 4.2 & 5.1 & 15.7 & 51.5 & 7.8 & 19.4 & $-59.6 \%$ \\
\hline $\begin{array}{l}\text { China } \\
\text { (3) }\end{array}$ & females & 67542 & 10.1 & 0.5 & 5.9 & 7.1 & 17.0 & 47.7 & 8.7 & 21.7 & $-59.7 \%$ \\
\hline & males & 53188 & 7.4 & 0.4 & 2.7 & 3.2 & 14.4 & 55.8 & 7.1 & 17.4 & $-59.3 \%$ \\
\hline & both sexes & 2517 & 5.3 & 1.1 & 8.0 & 6.4 & 6.6 & 7.1 & 5.4 & 7.0 & $-22.8 \%$ \\
\hline Colombia & females & 471 & 1.9 & 1.2 & 3.6 & 1.6 & 2.2 & 0.4 & 1.9 & 3.0 & $-35.6 \%$ \\
\hline & males & 2046 & 8.7 & 0.9 & 12.4 & 11.4 & 11.5 & 16.3 & 9.1 & 11.3 & $-19.3 \%$ \\
\hline & both sexes & 75 & 10.5 & 1.9 & 12.9 & 13.0 & 28.6 & 82.1 & 16.9 & 15.6 & $8.6 \%$ \\
\hline Comoros & females & 21 & 6.0 & 1.5 & 6.5 & 5.5 & 16.3 & 67.0 & 10.3 & 9.6 & $7.4 \%$ \\
\hline & males & 54 & 14.9 & 2.2 & 19.2 & 20.5 & 41.4 & 101.6 & 24.0 & 21.9 & $9.7 \%$ \\
\hline & both sexes & 338 & 7.8 & 1.4 & 14.4 & 11.7 & 10.1 & 16.8 & 9.6 & 10.5 & $-8.7 \%$ \\
\hline Congo & females & 82 & 3.8 & 1.0 & 6.7 & 5.3 & 5.3 & 9.1 & 4.6 & 5.6 & $-17.6 \%$ \\
\hline & males & 256 & 11.8 & 1.7 & 22.1 & 18.1 & 15.1 & 26.2 & 14.7 & 15.6 & $-5.6 \%$ \\
\hline & both sexes & 331 & 6.9 & 0.6 & 7.9 & 10.4 & 8.5 & 7.2 & 6.7 & 7.0 & $-3.7 \%$ \\
\hline Costa Rica & females & 53 & 2.2 & 0.2 & 3.2 & 3.2 & 2.5 & 0.6 & 2.2 & 1.8 & $24.6 \%$ \\
\hline & males & 278 & 11.4 & 1.0 & 12.3 & 17.4 & 14.5 & 15.1 & 11.2 & 12.1 & $-7.8 \%$ \\
\hline & both sexes & 1063 & 5.4 & 1.5 & 8.5 & 6.8 & 9.1 & 26.7 & 7.4 & 6.5 & $15.0 \%$ \\
\hline Côte d'Ivoire & females & 279 & 2.9 & 1.0 & 4.1 & 3.7 & 6.2 & 13.7 & 4.1 & 3.5 & $16.3 \%$ \\
\hline & males & 785 & 7.8 & 2.0 & 12.8 & 9.7 & 11.4 & 37.7 & 10.6 & 9.2 & $15.5 \%$ \\
\hline & both sexes & 709 & 16.5 & 0.4 & 8.0 & 14.6 & 23.2 & 37.2 & 11.6 & 16.4 & $-29.1 \%$ \\
\hline Croatia & females & 155 & 7.0 & 0.1 & 2.7 & 5.1 & 9.7 & 16.0 & 4.5 & 6.9 & $-35.5 \%$ \\
\hline & males & 554 & 26.7 & 0.6 & 13.0 & 23.9 & 37.8 & 73.0 & 19.8 & 27.4 & $-27.8 \%$ \\
\hline & both sexes & 1648 & 14.6 & 0.8 & 6.0 & 14.8 & 24.4 & 36.1 & 11.4 & 14.6 & $-21.9 \%$ \\
\hline $\begin{array}{l}\text { Cuba } \\
\text { (1) }\end{array}$ & females & 334 & 6.0 & 1.5 & 1.5 & 4.2 & 13.4 & 12.0 & 4.5 & 8.7 & $-48.1 \%$ \\
\hline & males & 1315 & 23.2 & 0.1 & 10.2 & 25.0 & 35.7 & 65.1 & 18.5 & 20.8 & $-11.3 \%$ \\
\hline & both sexes & 58 & 5.2 & 0.0 & 5.9 & 7.8 & 5.0 & 4.7 & 4.7 & 1.3 & $269.8 \%$ \\
\hline Cyprus & females & 9 & 1.6 & 0.0 & 2.4 & 2.0 & 1.5 & 1.5 & 1.5 & 1.1 & $41.5 \%$ \\
\hline & males & 49 & 8.6 & 0.0 & 9.0 & 13.1 & 8.6 & 8.7 & 7.7 & 1.5 & $416.9 \%$ \\
\hline
\end{tabular}




\begin{tabular}{|c|c|c|c|c|c|c|c|c|c|c|c|}
\hline \multirow{2}{*}{$\begin{array}{l}\text { Country } \\
\text { [quality of } \\
\text { mortality data**] }\end{array}$} & \multirow[t]{2}{*}{ Sex } & \multirow{2}{*}{$\begin{array}{l}\text { Number of } \\
\text { suicides } \\
\text { (all ages), } \\
2012\end{array}$} & \multicolumn{6}{|c|}{$\begin{array}{l}\text { Crude all ages and age-specific } \\
\text { suicide rates (per } 100 \text { 000), } 2012\end{array}$} & \multirow{2}{*}{$\begin{array}{l}\text { Age- } \\
\text { standardized } \\
\text { suicide } \\
\text { rates*** } \\
\text { (per } 100000 \text { ), } \\
2012\end{array}$} & \multirow{2}{*}{$\begin{array}{l}\text { Age- } \\
\text { standardized } \\
\text { suicide } \\
\text { rates*** } \\
\text { (per } 100000 \text { ), } \\
2000\end{array}$} & \multirow{2}{*}{$\begin{array}{l}\% \text { change in } \\
\text { age- } \\
\text { standardized } \\
\text { suicide rates, } \\
2000-2012\end{array}$} \\
\hline & & & $\begin{array}{l}\text { All } \\
\text { ages }\end{array}$ & $\begin{array}{l}5-14 \\
\text { years }\end{array}$ & $\begin{array}{l}15-29 \\
\text { years }\end{array}$ & $\begin{array}{l}30-49 \\
\text { years }\end{array}$ & $\begin{array}{l}50-69 \\
\text { years }\end{array}$ & $\begin{array}{l}70+ \\
\text { years }\end{array}$ & & & \\
\hline \multirow{3}{*}{$\begin{array}{l}\text { Czech Republic } \\
\text { (1) }\end{array}$} & both sexes & 1663 & 15.6 & 0.2 & 10.6 & 17.8 & 23.8 & 19.4 & 12.5 & 13.7 & $-8.4 \%$ \\
\hline & females & 269 & 5.0 & 0.0 & 3.6 & 5.5 & 6.8 & 7.3 & 3.9 & 5.2 & $-24.8 \%$ \\
\hline & males & 1394 & 26.6 & 0.3 & 17.1 & 29.5 & 42.0 & 39.0 & 21.5 & 23.0 & $-6.5 \%$ \\
\hline \multirow{3}{*}{$\begin{array}{l}\text { Democratic } \\
\text { People's Republic } \\
\text { of Korea (4) }\end{array}$} & both sexes & - & - & - & - & - & - & - & - & - & - \\
\hline & females & - & - & - & - & - & - & - & - & - & - \\
\hline & males & - & - & - & - & - & - & - & - & - & - \\
\hline & both sexes & 5248 & 8.0 & 1.9 & 14.9 & 12.5 & 11.0 & 15.2 & 10.1 & 8.0 & $26.3 \%$ \\
\hline Democratic Republic & females & 1287 & 3.9 & 1.6 & 7.2 & 4.9 & 5.7 & 8.4 & 4.8 & 3.6 & $32.7 \%$ \\
\hline & males & 3961 & 12.1 & 2.3 & 22.6 & 20.3 & 16.8 & 24.3 & 15.8 & 12.8 & $23.6 \%$ \\
\hline & both sexes & 625 & 11.2 & 0.2 & 5.7 & 12.9 & 18.3 & 16.9 & 8.8 & 12.0 & $-27.0 \%$ \\
\hline Denmark & females & 154 & 5.5 & 0.1 & 2.9 & 5.1 & 9.8 & 8.4 & 4.1 & 6.0 & $-31.6 \%$ \\
\hline & males & 471 & 17.0 & 0.2 & 8.4 & 20.7 & 26.9 & 28.2 & 13.6 & 18.4 & $-26.2 \%$ \\
\hline & both sexes & 92 & 10.7 & 1.8 & 12.5 & 9.8 & 22.7 & 85.3 & 15.1 & 14.7 & $2.9 \%$ \\
\hline $\begin{array}{l}\text { DjiboutI } \\
\text { (4) }\end{array}$ & females & 27 & 6.3 & 1.4 & 6.4 & 4.4 & 13.4 & 69.9 & 9.5 & 9.3 & $2.1 \%$ \\
\hline & males & 65 & 15.0 & 2.2 & 18.5 & 15.1 & 32.4 & 103.9 & 20.9 & 20.2 & $3.4 \%$ \\
\hline Dominican & both sexes & 375 & 3.7 & 0.4 & 3.3 & 4.7 & 7.1 & 13.8 & 4.1 & 5.9 & $-31.1 \%$ \\
\hline Republic & females & 95 & 1.9 & 0.4 & 1.4 & 2.1 & 4.0 & 7.9 & 2.1 & 3.1 & $-34.2 \%$ \\
\hline & males & 280 & 5.4 & 0.3 & 5.2 & 7.3 & 10.3 & 20.3 & 6.1 & 8.6 & $-29.4 \%$ \\
\hline & both sexes & 1377 & 8.9 & 2.0 & 15.7 & 8.6 & 10.7 & 15.9 & 9.2 & 8.9 & $3.4 \%$ \\
\hline Ecuador & females & 410 & 5.3 & 1.8 & 10.9 & 4.0 & 4.4 & 9.4 & 5.3 & 5.7 & $-8.0 \%$ \\
\hline & males & 967 & 12.5 & 2.2 & 20.4 & 13.4 & 17.4 & 23.4 & 13.2 & 12.1 & $9.0 \%$ \\
\hline & both sexes & 1264 & 1.6 & 0.3 & 1.9 & 2.0 & 2.4 & 5.3 & 1.7 & 2.6 & $-33.6 \%$ \\
\hline Egypt & females & 433 & 1.1 & 0.2 & 1.3 & 1.2 & 1.6 & 4.2 & 1.2 & 2.1 & $-45.3 \%$ \\
\hline & males & 831 & 2.1 & 0.4 & 2.4 & 2.8 & 3.3 & 7.1 & 2.4 & 3.1 & $-24.1 \%$ \\
\hline & both sexes & 806 & 12.8 & 1.6 & 17.6 & 18.1 & 17.5 & 20.6 & 13.6 & 13.7 & $-1.3 \%$ \\
\hline $\begin{array}{l}\text { El Salvador } \\
\text { (2) }\end{array}$ & females & 191 & 5.8 & 1.8 & 9.6 & 5.9 & 6.5 & 6.9 & 5.7 & 7.5 & $-24.5 \%$ \\
\hline & males & 615 & 20.6 & 1.5 & 25.8 & 34.0 & 32.1 & 39.3 & 23.5 & 21.3 & $10.1 \%$ \\
\hline Equatorial & both sexes & 102 & 13.9 & 2.7 & 24.8 & 18.3 & 19.5 & 30.1 & 16.6 & 13.8 & $20.4 \%$ \\
\hline Guinea & females & 26 & 7.4 & 2.1 & 14.3 & 7.5 & 10.4 & 16.4 & 8.6 & 6.3 & $35.6 \%$ \\
\hline & males & 76 & 20.1 & 3.2 & 35.2 & 28.1 & 27.2 & 44.8 & 24.1 & 20.8 & $15.9 \%$ \\
\hline & both sexes & 510 & 8.3 & 1.0 & 8.3 & 11.6 & 35.0 & 79.0 & 16.3 & 16.4 & $-0.4 \%$ \\
\hline Eritrea & females & 124 & 4.0 & 0.6 & 3.0 & 4.1 & 18.0 & 57.8 & 8.7 & 9.2 & $-5.5 \%$ \\
\hline & males & 386 & 12.6 & 1.3 & 13.6 & 19.4 & 55.1 & 116.6 & 25.8 & 25.3 & $2.0 \%$ \\
\hline & both sexes & 226 & 17.5 & 1.6 & 13.3 & 15.6 & 25.1 & 33.6 & 13.6 & 25.0 & $-45.9 \%$ \\
\hline $\begin{array}{l}\text { Estonia } \\
\text { (1) }\end{array}$ & females & 46 & 6.6 & 0.0 & 3.7 & 3.1 & 7.3 & 19.5 & 3.8 & 9.5 & $-59.7 \%$ \\
\hline & males & 181 & 30.2 & 3.0 & 22.6 & 28.3 & 47.8 & 65.5 & 24.9 & 43.6 & $-42.8 \%$ \\
\hline & both sexes & 6852 & 7.5 & 1.7 & 10.7 & 8.1 & 15.9 & 61.3 & 11.5 & 13.1 & $-12.7 \%$ \\
\hline $\begin{array}{l}\text { Ethiopıa } \\
\text { (4) }\end{array}$ & females & 1781 & 3.9 & 1.2 & 4.1 & 2.7 & 9.5 & 52.2 & 6.7 & 7.5 & $-11.1 \%$ \\
\hline & males & 5071 & 11.1 & 2.1 & 17.2 & 13.6 & 22.9 & 71.4 & 16.5 & 18.9 & $-13.0 \%$ \\
\hline & both sexes & 52 & 5.9 & 0.3 & 3.8 & 6.1 & 14.5 & 36.5 & 7.3 & 8.5 & $-13.7 \%$ \\
\hline $\begin{array}{l}\text { Fiji } \\
\text { (2) }\end{array}$ & females & 14 & 3.2 & 0.2 & 1.7 & 2.6 & 7.8 & 27.0 & 4.1 & 5.5 & $-25.4 \%$ \\
\hline & males & 38 & 8.5 & 0.3 & 5.8 & 9.4 & 21.3 & 48.4 & 10.6 & 11.5 & $-8.4 \%$ \\
\hline & both sexes & 901 & 16.7 & 0.3 & 18.8 & 21.0 & 21.2 & 16.5 & 14.8 & 20.8 & $-28.9 \%$ \\
\hline $\begin{array}{l}\text { Finland } \\
\text { (1) }\end{array}$ & females & 224 & 8.1 & 0.1 & 10.7 & 10.0 & 10.9 & 5.6 & 7.5 & 10.0 & $-25.3 \%$ \\
\hline & males & 677 & 25.5 & 0.5 & 26.6 & 31.5 & 31.8 & 33.3 & 22.2 & 31.8 & $-30.2 \%$ \\
\hline & both sexes & 10093 & 15.8 & 0.6 & 7.6 & 19.3 & 23.1 & 28.9 & 12.3 & 14.9 & $-17.2 \%$ \\
\hline $\begin{array}{l}\text { France } \\
\text { (1) }\end{array}$ & females & 2618 & 7.9 & 0.5 & 3.2 & 8.8 & 13.0 & 12.7 & 6.0 & 7.4 & $-19.5 \%$ \\
\hline & males & 7475 & 24.2 & 0.6 & 11.8 & 29.9 & 34.1 & 54.0 & 19.3 & 23.3 & $-17.4 \%$ \\
\hline & both sexes & 114 & 7.0 & 0.9 & 12.0 & 8.8 & 9.6 & 20.4 & 8.2 & 7.9 & $3.8 \%$ \\
\hline $\begin{array}{l}\text { Gabon } \\
\text { (4) }\end{array}$ & females & 31 & 3.8 & 0.8 & 6.2 & 4.5 & 5.7 & 12.1 & 4.5 & 4.3 & $3.0 \%$ \\
\hline & males & 83 & 10.1 & 1.1 & 17.6 & 13.1 & 13.7 & 31.5 & 12.1 & 11.7 & $3.2 \%$ \\
\hline & both sexes & 58 & 3.2 & 0.8 & 5.4 & 4.3 & 6.3 & 20.9 & 5.0 & 5.2 & $-3.1 \%$ \\
\hline Gambia & females & 15 & 1.6 & 0.5 & 2.3 & 2.2 & 4.3 & 9.9 & 2.6 & 2.7 & $-4.8 \%$ \\
\hline & males & 43 & 4.9 & 1.2 & 8.7 & 6.6 & 8.3 & 31.7 & 7.6 & 7.7 & $-1.9 \%$ \\
\hline & both sexes & 165 & 3.8 & 0.4 & 2.9 & 4.4 & 4.7 & 8.1 & 3.2 & 4.3 & $-26.1 \%$ \\
\hline Georgia & females & 32 & 1.4 & 0.1 & 1.4 & 0.8 & 1.3 & 4.4 & 1.0 & 1.4 & $-25.2 \%$ \\
\hline & males & 132 & 6.4 & 0.6 & 4.5 & 8.4 & 8.8 & 14.3 & 5.7 & 7.6 & $-25.3 \%$ \\
\hline & both sexes & 10745 & 13.0 & 0.3 & 7.7 & 12.7 & 16.9 & 23.7 & 9.2 & 11.1 & $-17.0 \%$ \\
\hline $\begin{array}{l}\text { Germany } \\
\text { (1) }\end{array}$ & females & 2621 & 6.2 & 0.2 & 3.1 & 5.6 & 8.0 & 11.6 & 4.1 & 5.2 & $-20.2 \%$ \\
\hline & males & 8124 & 20.0 & 0.3 & 12.0 & 19.4 & 26.0 & 40.7 & 14.5 & 17.5 & $-17.4 \%$ \\
\hline & both sexes & 577 & 2.3 & 0.5 & 3.4 & 2.4 & 4.1 & 13.7 & 3.1 & 2.6 & $18.0 \%$ \\
\hline $\begin{array}{l}\text { Ghana } \\
\text { (4) }\end{array}$ & females & 205 & 1.6 & 0.4 & 2.0 & 1.6 & 3.5 & 9.6 & 2.2 & 1.8 & $19.4 \%$ \\
\hline & males & 372 & 3.0 & 0.6 & 4.7 & 3.3 & 4.8 & 19.7 & 4.2 & 3.4 & $23.4 \%$ \\
\hline & both sexes & 548 & 4.9 & 0.1 & 3.0 & 5.9 & 6.4 & 7.6 & 3.8 & 3.4 & $10.5 \%$ \\
\hline $\begin{array}{l}\text { Greece } \\
\text { (2) }\end{array}$ & females & 99 & 1.8 & 0.0 & 0.9 & 1.9 & 2.4 & 2.8 & 1.3 & 1.2 & $8.5 \%$ \\
\hline & males & 449 & 8.2 & 0.1 & 5.0 & 9.7 & 10.6 & 14.1 & 6.3 & 5.7 & $10.3 \%$ \\
\hline
\end{tabular}




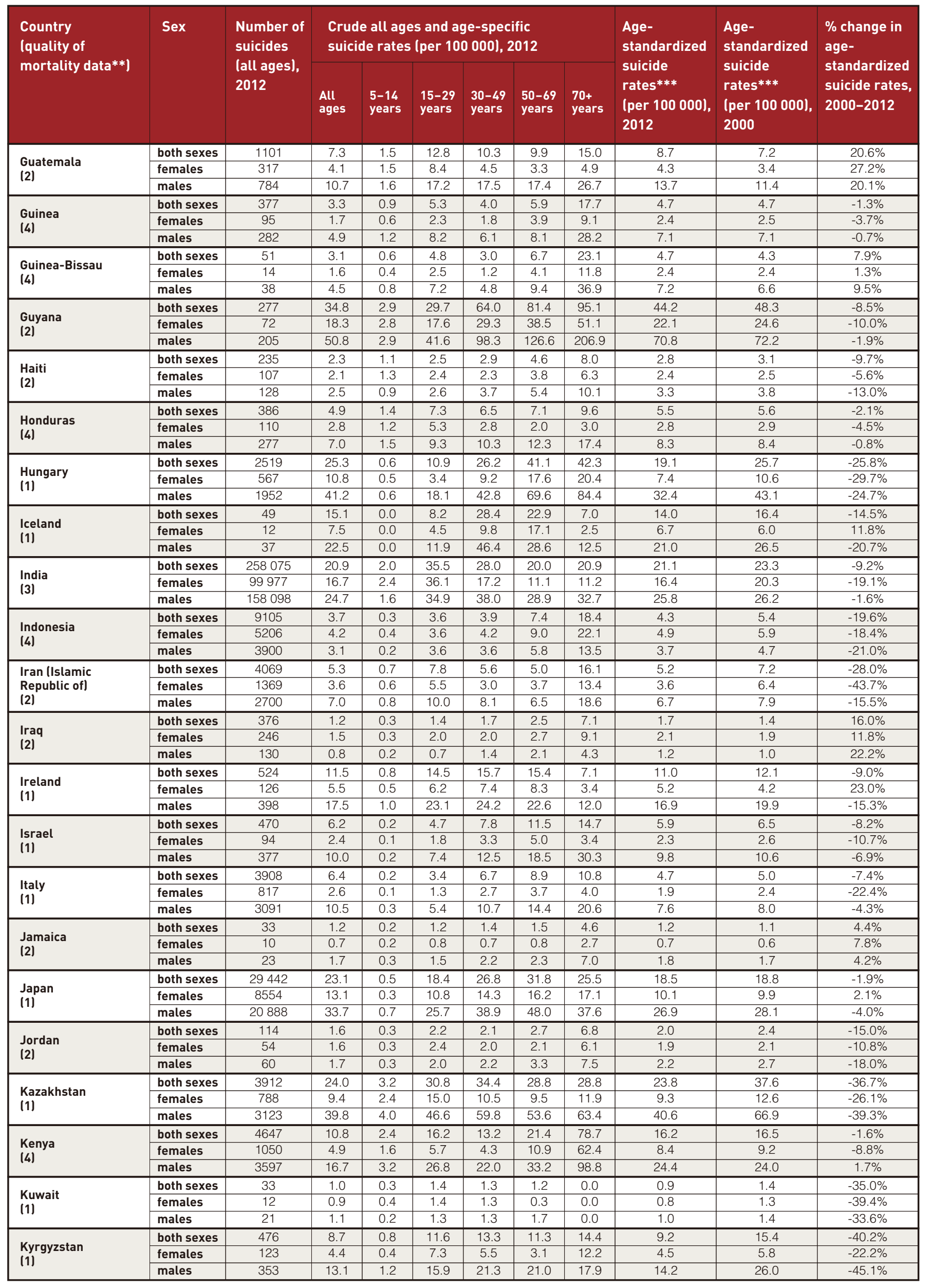




\begin{tabular}{|c|c|c|c|c|c|c|c|c|c|c|c|}
\hline \multirow{2}{*}{$\begin{array}{l}\text { Country } \\
\text { (quality of } \\
\text { mortality data**) }\end{array}$} & \multirow[t]{2}{*}{ Sex } & \multirow{2}{*}{$\begin{array}{l}\text { Number of } \\
\text { suicides } \\
\text { (all ages), } \\
2012\end{array}$} & \multicolumn{6}{|c|}{$\begin{array}{l}\text { Crude all ages and age-specific } \\
\text { suicide rates (per } 100000 \text { ), } 2012\end{array}$} & \multirow{2}{*}{$\begin{array}{l}\text { Age- } \\
\text { standardized } \\
\text { suicide } \\
\text { rates*** } \\
\text { (per } 100 \text { 000), } \\
2012\end{array}$} & \multirow{2}{*}{$\begin{array}{l}\text { Age- } \\
\text { standardized } \\
\text { suicide } \\
\text { rates*** } \\
\text { (per } 100000 \text { ), } \\
2000\end{array}$} & \multirow{2}{*}{$\begin{array}{l}\% \text { change in } \\
\text { age- } \\
\text { standardized } \\
\text { suicide rates } \\
2000-2012\end{array}$} \\
\hline & & & $\begin{array}{l}\text { All } \\
\text { ages }\end{array}$ & $\begin{array}{l}5-14 \\
\text { years }\end{array}$ & $\begin{array}{l}15-29 \\
\text { years }\end{array}$ & $\begin{array}{l}30-49 \\
\text { years }\end{array}$ & $\begin{array}{l}50-69 \\
\text { years }\end{array}$ & $\begin{array}{l}70+ \\
\text { years }\end{array}$ & & & \\
\hline \multirow{3}{*}{$\begin{array}{l}\text { Lao People's } \\
\text { Democratic } \\
\text { Republic (4) }\end{array}$} & both sexes & 422 & 6.4 & 0.4 & 6.9 & 8.4 & 15.6 & 36.4 & 8.8 & 14.4 & $-38.9 \%$ \\
\hline & females & 161 & 4.8 & 0.3 & 4.7 & 5.6 & 13.3 & 29.2 & 6.6 & 11.8 & $-44.2 \%$ \\
\hline & males & 261 & 7.9 & 0.5 & 9.1 & 11.5 & 18.1 & 45.9 & 11.2 & 17.2 & $-34.6 \%$ \\
\hline \multirow{3}{*}{$\begin{array}{l}\text { Latvia } \\
\text { (1) }\end{array}$} & both sexes & 419 & 20.4 & 0.3 & 13.8 & 23.9 & 30.4 & 26.2 & 16.2 & 29.0 & $-44.2 \%$ \\
\hline & females & 68 & 6.1 & 0.3 & 2.8 & 4.9 & 9.4 & 10.7 & 4.3 & 9.3 & $-54.1 \%$ \\
\hline & males & 351 & 37.3 & 0.3 & 24.5 & 43.5 & 58.2 & 62.4 & 30.7 & 52.8 & $-42.0 \%$ \\
\hline & both sexes & 43 & 0.9 & 0.1 & 0.6 & 0.6 & 1.5 & 5.6 & 0.9 & 1.7 & $-46.4 \%$ \\
\hline Lebanon & females & 14 & 0.6 & 0.1 & 0.7 & 0.4 & 0.6 & 3.4 & 0.6 & 1.2 & $-52.5 \%$ \\
\hline & males & 29 & 1.2 & 0.1 & 0.6 & 0.8 & 2.3 & 7.9 & 1.2 & 2.2 & $-45.5 \%$ \\
\hline & both sexes & 110 & 5.4 & 1.4 & 8.3 & 6.3 & 7.2 & 16.8 & 6.1 & 4.0 & $53.7 \%$ \\
\hline Lesotho & females & 32 & 3.1 & 1.1 & 4.6 & 3.0 & 4.5 & 10.1 & 3.4 & 2.3 & $49.8 \%$ \\
\hline & males & 78 & 7.7 & 1.7 & 12.0 & 9.6 & 11.5 & 27.6 & 9.2 & 6.0 & $53.8 \%$ \\
\hline & both sexes & 109 & 2.6 & 0.5 & 3.7 & 2.9 & 6.7 & 21.3 & 4.3 & 5.0 & $-14.1 \%$ \\
\hline Liberia & females & 26 & 1.2 & 0.3 & 1.5 & 1.1 & 4.0 & 10.1 & 2.0 & 2.2 & $-9.0 \%$ \\
\hline & males & 84 & 4.0 & 0.6 & 5.8 & 4.6 & 9.6 & 34.6 & 6.8 & 7.9 & $-14.8 \%$ \\
\hline & both sexes & 90 & 1.5 & 0.2 & 1.4 & 1.7 & 3.0 & 8.4 & 1.8 & 2.7 & $-33.7 \%$ \\
\hline Libya & females & 38 & 1.2 & 0.2 & 1.5 & 1.4 & 1.7 & 5.8 & 1.4 & 2.0 & $-31.8 \%$ \\
\hline & males & 53 & 1.7 & 0.2 & 1.2 & 1.9 & 4.2 & 11.7 & 2.2 & 3.3 & $-32.9 \%$ \\
\hline & both sexes & 1007 & 33.3 & 0.6 & 26.8 & 46.6 & 43.6 & 35.3 & 28.2 & 44.9 & $-37.2 \%$ \\
\hline $\begin{array}{l}\text { Lithuania } \\
\text { (1) }\end{array}$ & females & 177 & 10.9 & 0.4 & 6.5 & 14.0 & 11.3 & 20.2 & 8.4 & 15.0 & $-44.4 \%$ \\
\hline & males & 830 & 59.5 & 0.7 & 46.5 & 80.8 & 86.0 & 72.5 & 51.0 & 79.3 & $-35.6 \%$ \\
\hline & both sexes & 56 & 10.8 & 0.3 & 6.1 & 12.9 & 18.9 & 13.4 & 8.7 & 13.3 & $-34.7 \%$ \\
\hline Luxembourg & females & 14 & 5.5 & 0.0 & 4.4 & 5.7 & 8.0 & 9.6 & 4.4 & 7.1 & $-38.5 \%$ \\
\hline & males & 42 & 16.1 & 0.6 & 7.7 & 19.9 & 29.6 & 19.0 & 13.0 & 20.0 & $-35.0 \%$ \\
\hline & both sexes & 1625 & 7.3 & 2.2 & 10.6 & 8.0 & 16.0 & 52.4 & 11.0 & 10.8 & $1.0 \%$ \\
\hline Madagascar & females & 474 & 4.2 & 1.5 & 5.6 & 3.2 & 10.3 & 44.3 & 6.9 & 7.2 & $-3.6 \%$ \\
\hline & males & 1151 & 10.4 & 2.9 & 15.6 & 12.9 & 22.2 & 61.8 & 15.2 & 14.6 & $3.8 \%$ \\
\hline & both sexes & 1376 & 8.7 & 1.6 & 10.5 & 9.7 & 24.7 & 96.7 & 16.0 & 13.1 & $22.5 \%$ \\
\hline Malawi & females & 370 & 4.7 & 1.4 & 5.0 & 2.8 & 12.4 & 70.0 & 8.9 & 7.1 & $26.0 \%$ \\
\hline & males & 1006 & 12.6 & 1.8 & 15.9 & 16.4 & 39.4 & 129.0 & 23.9 & 19.6 & $22.1 \%$ \\
\hline & both sexes & 772 & 2.6 & 0.1 & 2.3 & 2.8 & 5.5 & 13.3 & 3.0 & 4.0 & $-23.9 \%$ \\
\hline $\begin{array}{l}\text { Malaysia } \\
\text { (2) }\end{array}$ & females & 183 & 1.2 & 0.1 & 1.0 & 1.1 & 2.9 & 7.7 & 1.5 & 2.3 & $-35.4 \%$ \\
\hline & males & 588 & 4.2 & 0.2 & 3.8 & 4.7 & 8.1 & 18.6 & 4.7 & 5.7 & $-18.1 \%$ \\
\hline & both sexes & 17 & 5.0 & 0.5 & 4.1 & 4.1 & 11.9 & 40.2 & 6.4 & 20.9 & $-69.4 \%$ \\
\hline $\begin{array}{l}\text { Maldives } \\
\text { (?) }\end{array}$ & females & 6 & 3.6 & 0.4 & 2.2 & 2.4 & 9.9 & 36.9 & 4.9 & 18.3 & $-73.0 \%$ \\
\hline & males & 11 & 6.4 & 0.5 & 5.9 & 6.0 & 13.8 & 43.0 & 7.8 & 23.3 & $-66.4 \%$ \\
\hline & both sexes & 410 & 2.8 & 0.6 & 4.3 & 3.5 & 6.3 & 25.8 & 4.8 & 5.2 & $-7.7 \%$ \\
\hline Mali & females & 129 & 1.7 & 0.5 & 2.9 & 1.8 & 4.0 & 12.6 & 2.7 & 2.8 & $-4.2 \%$ \\
\hline & males & 282 & 3.8 & 0.6 & 5.5 & 5.3 & 9.2 & 42.1 & 7.2 & 7.8 & $-8.8 \%$ \\
\hline & both sexes & 29 & 6.8 & 0.0 & 4.0 & 11.2 & 8.6 & 5.6 & 6.0 & 6.0 & $-0.3 \%$ \\
\hline $\begin{array}{l}\text { Malta } \\
11\end{array}$ & females & 2 & 0.7 & 0.0 & 2.1 & 0.0 & 1.2 & 0.0 & 0.7 & 2.2 & $-68.8 \%$ \\
\hline & males & 27 & 12.8 & 0.0 & 5.8 & 21.8 & 16.1 & 13.0 & 11.1 & 9.8 & $13.0 \%$ \\
\hline & both sexes & 68 & 1.8 & 0.3 & 2.4 & 1.8 & 4.0 & 17.6 & 2.9 & 3.1 & $-5.6 \%$ \\
\hline Mauritania & females & 18 & 1.0 & 0.2 & 1.2 & 0.8 & 2.5 & 9.2 & 1.5 & 1.6 & $-5.6 \%$ \\
\hline & males & 49 & 2.6 & 0.4 & 3.5 & 2.7 & 5.6 & 29.1 & 4.5 & 4.8 & $-5.0 \%$ \\
\hline & both sexes & 105 & 8.5 & 0.8 & 10.7 & 12.1 & 8.8 & 7.4 & 8.0 & 9.8 & $-18.5 \%$ \\
\hline Mauritius & females & 19 & 3.0 & 1.4 & 4.5 & 3.0 & 3.4 & 2.8 & 2.9 & 5.0 & $-42.7 \%$ \\
\hline & males & 86 & 14.1 & 0.2 & 16.8 & 21.1 & 14.5 & 14.4 & 13.2 & 14.8 & $-10.6 \%$ \\
\hline & both sexes & 4951 & 4.1 & 0.9 & 6.0 & 5.3 & 5.1 & 5.8 & 4.2 & 3.6 & $16.6 \%$ \\
\hline Mexico & females & 1055 & 1.7 & 0.8 & 3.1 & 2.0 & 1.3 & 0.5 & 1.7 & 1.1 & $55.1 \%$ \\
\hline & males & 3896 & 6.7 & 1.0 & 8.9 & 9.1 & 9.6 & 12.7 & 7.1 & 6.5 & $10.0 \%$ \\
\hline & both sexes & 261 & 9.4 & 0.7 & 8.9 & 15.7 & 13.6 & 19.0 & 9.8 & 10.4 & $-6.3 \%$ \\
\hline Mongolia & females & 47 & 3.4 & 0.3 & 3.4 & 4.6 & 5.4 & 11.6 & 3.7 & 5.6 & $-34.9 \%$ \\
\hline & males & 214 & 15.5 & 1.0 & 14.3 & 27.1 & 23.1 & 29.8 & 16.3 & 15.4 & $5.9 \%$ \\
\hline & both sexes & 117 & 18.9 & 0.8 & 11.2 & 17.4 & 31.0 & 48.7 & 15.3 & 11.3 & $35.0 \%$ \\
\hline $\begin{array}{l}\text { Montenegro } \\
\text { (2) }\end{array}$ & females & 28 & 9.0 & 0.3 & 3.2 & 5.8 & 15.0 & 30.1 & 6.4 & 5.0 & $28.8 \%$ \\
\hline & males & 89 & 29.0 & 1.2 & 18.8 & 29.3 & 48.1 & 74.9 & 24.7 & 18.2 & $36.2 \%$ \\
\hline & both sexes & 1628 & 5.0 & 0.9 & 5.9 & 6.4 & 7.2 & 14.4 & 5.3 & 2.7 & $97.8 \%$ \\
\hline $\begin{array}{l}\text { Morocco } \\
\text { ? }\end{array}$ & females & 198 & 1.2 & 0.2 & 1.7 & 1.3 & 1.3 & 3.7 & 1.2 & 1.3 & $-6.1 \%$ \\
\hline & males & 1431 & 8.9 & 1.5 & 10.1 & 12.0 & 13.5 & 30.1 & 9.9 & 4.2 & $135.0 \%$ \\
\hline & both sexes & 4360 & 17.3 & 5.0 & 25.2 & 19.2 & 36.7 & 144.7 & 27.4 & 24.6 & $11.5 \%$ \\
\hline Mozambique & females & 1639 & 12.7 & 4.5 & 14.2 & 10.5 & 29.4 & 147.9 & 21.1 & 19.1 & $11.0 \%$ \\
\hline & males & 2721 & 22.1 & 5.4 & 36.3 & 29.3 & 45.4 & 140.1 & 34.2 & 30.9 & $10.5 \%$ \\
\hline & both sexes & 6558 & 12.4 & 1.3 & 15.7 & 12.7 & 19.4 & 41.7 & 13.1 & 12.1 & $8.2 \%$ \\
\hline Myanmar & females & 2704 & 10.0 & 1.1 & 11.8 & 10.3 & 15.7 & 31.6 & 10.3 & 10.3 & $-0.2 \%$ \\
\hline & males & 3854 & 15.0 & 1.5 & 19.8 & 15.2 & 23.8 & 55.8 & 16.5 & 14.3 & $15.5 \%$ \\
\hline
\end{tabular}




\begin{tabular}{|c|c|c|c|c|c|c|c|c|c|c|c|}
\hline \multirow{2}{*}{$\begin{array}{l}\text { Country } \\
\text { [quality of } \\
\text { mortality data**) }\end{array}$} & \multirow[t]{2}{*}{ Sex } & \multirow{2}{*}{$\begin{array}{l}\text { Number of } \\
\text { suicides } \\
\text { (all ages), } \\
2012\end{array}$} & \multicolumn{6}{|c|}{$\begin{array}{l}\text { Crude all ages and age-specific } \\
\text { suicide rates (per } 100 \text { 000), } 2012\end{array}$} & \multirow{2}{*}{$\begin{array}{l}\text { Age- } \\
\text { standardized } \\
\text { suicide } \\
\text { rates*** } \\
\text { (per } 100000 \text { ), } \\
2012\end{array}$} & \multirow{2}{*}{$\begin{array}{l}\text { Age- } \\
\text { standardized } \\
\text { suicide } \\
\text { rates*** } \\
\text { (per } 100000 \text { ), } \\
2000\end{array}$} & \multirow{2}{*}{$\begin{array}{l}\% \text { change in } \\
\text { age- } \\
\text { standardized } \\
\text { suicide rates, } \\
2000-2012\end{array}$} \\
\hline & & & $\begin{array}{l}\text { All } \\
\text { ages }\end{array}$ & $\begin{array}{l}5-14 \\
\text { years }\end{array}$ & $\begin{array}{l}15-29 \\
\text { years }\end{array}$ & $\begin{array}{l}30-49 \\
\text { years }\end{array}$ & $\begin{array}{l}50-69 \\
\text { years }\end{array}$ & $\begin{array}{l}70+ \\
\text { years }\end{array}$ & & & \\
\hline \multirow{3}{*}{$\begin{array}{l}\text { Namibia } \\
\text { (4) }\end{array}$} & both sexes & 46 & 2.0 & 0.4 & 2.6 & 2.5 & 4.3 & 11.2 & 2.7 & 3.0 & $-7.5 \%$ \\
\hline & females & 13 & 1.1 & 0.2 & 1.3 & 1.2 & 2.5 & 6.0 & 1.4 & 1.7 & $-13.9 \%$ \\
\hline & males & 33 & 3.0 & 0.6 & 3.9 & 3.9 & 6.8 & 18.9 & 4.4 & 4.5 & $-2.0 \%$ \\
\hline \multirow{3}{*}{$\begin{array}{l}\text { Nepal } \\
\text { (4) }\end{array}$} & both sexes & 5572 & 20.3 & 2.0 & 25.8 & 22.3 & 45.2 & 82.2 & 24.9 & 33.5 & $-25.7 \%$ \\
\hline & females & 2468 & 17.5 & 2.1 & 25.4 & 19.8 & 29.0 & 57.5 & 20.0 & 27.1 & $-26.2 \%$ \\
\hline & males & 3104 & 23.3 & 1.9 & 26.2 & 25.2 & 61.3 & 110.3 & 30.1 & 40.5 & $-25.5 \%$ \\
\hline & both sexes & 1666 & 10.0 & 0.3 & 6.7 & 13.0 & 14.8 & 11.9 & 8.2 & 7.9 & $3.3 \%$ \\
\hline Netherlands & females & 496 & 5.9 & 0.1 & 3.6 & 7.9 & 8.4 & 7.4 & 4.8 & 5.1 & $-7.0 \%$ \\
\hline & males & 1171 & 14.1 & 0.5 & 9.7 & 18.0 & 21.1 & 18.2 & 11.7 & 10.9 & $6.9 \%$ \\
\hline & both sexes & 459 & 10.3 & 1.3 & 13.0 & 13.2 & 12.6 & 10.7 & 9.6 & 12.2 & $-21.4 \%$ \\
\hline New Zealand & females & 122 & 5.4 & 0.9 & 7.3 & 7.1 & 5.5 & 5.5 & 5.0 & 4.3 & $15.8 \%$ \\
\hline & males & 337 & 15.4 & 1.7 & 18.5 & 19.8 & 20.1 & 17.1 & 14.4 & 20.6 & $-29.8 \%$ \\
\hline & both sexes & 547 & 9.1 & 1.4 & 13.4 & 13.9 & 11.5 & 13.2 & 10.0 & 11.5 & $-13.1 \%$ \\
\hline Nicaragua & females & 146 & 4.8 & 1.8 & 8.1 & 5.5 & 4.8 & 5.5 & 4.9 & 6.2 & $-21.5 \%$ \\
\hline & males & 401 & 13.5 & 1.0 & 18.7 & 22.9 & 18.8 & 22.4 & 15.4 & 17.0 & $-9.3 \%$ \\
\hline & both sexes & 315 & 1.8 & 0.4 & 2.6 & 2.3 & 5.7 & 19.3 & 3.5 & 3.5 & $2.3 \%$ \\
\hline Niger & females & 87 & 1.0 & 0.3 & 1.4 & 1.0 & 3.8 & 9.9 & 1.9 & 1.9 & $0.5 \%$ \\
\hline & males & 227 & 2.6 & 0.4 & 4.0 & 3.6 & 7.3 & 30.8 & 5.3 & 5.2 & $1.1 \%$ \\
\hline & both sexes & 7238 & 4.3 & 1.3 & 7.0 & 5.1 & 8.9 & 25.6 & 6.5 & 6.4 & $2.0 \%$ \\
\hline Nigeria & females & 1584 & 1.9 & 0.8 & 2.8 & 1.8 & 5.0 & 11.3 & 2.9 & 2.6 & $8.7 \%$ \\
\hline & males & 5653 & 6.6 & 1.8 & 11.0 & 8.2 & 12.9 & 41.6 & 10.3 & 10.3 & $-0.7 \%$ \\
\hline & both sexes & 508 & 10.2 & 0.3 & 10.2 & 12.9 & 14.6 & 10.8 & 9.1 & 11.5 & $-20.4 \%$ \\
\hline $\begin{array}{l}\text { Norway } \\
\text { (1) }\end{array}$ & females & 145 & 5.8 & 0.3 & 5.5 & 7.6 & 8.6 & 5.2 & 5.2 & 5.5 & $-5.6 \%$ \\
\hline & males & 364 & 14.6 & 0.3 & 14.7 & 18.0 & 20.4 & 18.5 & 13.0 & 17.5 & $-25.4 \%$ \\
\hline & both sexes & 32 & 1.0 & 0.1 & 1.3 & 1.0 & 1.3 & 3.5 & 1.0 & 2.0 & $-50.3 \%$ \\
\hline Oman & females & 6 & 0.5 & 0.1 & 0.7 & 0.5 & 1.0 & 2.5 & 0.6 & 1.2 & $-52.0 \%$ \\
\hline & males & 26 & 1.3 & 0.1 & 1.6 & 1.3 & 1.6 & 4.3 & 1.2 & 2.5 & $-51.4 \%$ \\
\hline & both sexes & 13377 & 7.5 & 1.1 & 9.1 & 8.5 & 16.3 & 33.7 & 9.3 & 9.1 & $2.6 \%$ \\
\hline Pakistan & females & 7085 & 8.1 & 1.6 & 12.0 & 7.5 & 15.4 & 32.5 & 9.6 & 9.6 & $0.3 \%$ \\
\hline & males & 6291 & 6.8 & 0.7 & 6.3 & 9.4 & 17.2 & 34.8 & 9.1 & 8.7 & $5.0 \%$ \\
\hline & both sexes & 170 & 4.5 & 0.7 & 5.8 & 5.2 & 8.0 & 7.6 & 4.7 & 6.2 & $-23.7 \%$ \\
\hline Panama & females & 25 & 1.3 & 0.6 & 3.0 & 0.4 & 2.0 & 0.9 & 1.3 & 1.6 & $-15.8 \%$ \\
\hline & males & 146 & 7.6 & 0.8 & 8.4 & 9.8 & 14.1 & 15.2 & 8.1 & 10.8 & $-25.1 \%$ \\
\hline & both sexes & 550 & 7.7 & 0.6 & 6.5 & 9.9 & 27.8 & 55.1 & 12.4 & 14.8 & $-15.9 \%$ \\
\hline Papua New Guinea & females & 193 & 5.5 & 0.5 & 4.5 & 5.2 & 20.2 & 52.0 & 9.1 & 10.9 & $-16.8 \%$ \\
\hline & males & 356 & 9.7 & 0.7 & 8.4 & 14.4 & 36.1 & 59.8 & 15.9 & 18.8 & $-15.4 \%$ \\
\hline & both sexes & 357 & 5.3 & 0.5 & 6.3 & 7.9 & 9.9 & 12.2 & 6.1 & 6.2 & $-1.9 \%$ \\
\hline Paraguay & females & 94 & 2.8 & 0.6 & 3.8 & 3.4 & 5.1 & 6.3 & 3.2 & 3.5 & $-9.5 \%$ \\
\hline & males & 262 & 7.8 & 0.5 & 8.7 & 12.3 & 14.6 & 19.0 & 9.1 & 9.0 & $0.9 \%$ \\
\hline & both sexes & 942 & 3.1 & 0.6 & 4.9 & 3.7 & 3.8 & 5.2 & 3.2 & 4.4 & $-27.1 \%$ \\
\hline Peru & females & 311 & 2.1 & 0.6 & 4.0 & 1.9 & 2.0 & 3.1 & 2.1 & 2.9 & $-29.6 \%$ \\
\hline & males & 631 & 4.2 & 0.6 & 5.8 & 5.6 & 5.8 & 7.7 & 4.4 & 6.0 & $-26.2 \%$ \\
\hline & both sexes & 2558 & 2.7 & 0.3 & 4.3 & 3.8 & 3.3 & 4.6 & 2.9 & 2.6 & $13.5 \%$ \\
\hline Philippines & females & 550 & 1.1 & 0.3 & 2.2 & 1.3 & 1.0 & 1.9 & 1.2 & 1.4 & $-13.0 \%$ \\
\hline & males & 2009 & 4.2 & 0.3 & 6.4 & 6.3 & 5.8 & 8.6 & 4.8 & 3.9 & $24.4 \%$ \\
\hline & both sexes & 7848 & 20.5 & 0.5 & 12.7 & 24.6 & 31.2 & 29.0 & 16.6 & 18.5 & $-10.5 \%$ \\
\hline Poland & females & 1028 & 5.2 & 0.3 & 2.6 & 4.7 & 7.8 & 10.8 & 3.8 & 4.8 & $-20.1 \%$ \\
\hline & males & 6820 & 37.0 & 0.8 & 22.5 & 44.2 & 57.7 & 61.2 & 30.5 & 33.8 & $-9.8 \%$ \\
\hline & both sexes & 1324 & 12.5 & 0.3 & 3.8 & 10.4 & 16.3 & 34.8 & 8.2 & 8.8 & $-7.0 \%$ \\
\hline Portugal & females & 300 & 5.5 & 0.1 & 1.7 & 4.7 & 7.0 & 13.6 & 3.5 & 3.4 & $4.8 \%$ \\
\hline & males & 1024 & 19.9 & 0.6 & 5.9 & 16.2 & 26.6 & 66.3 & 13.6 & 15.1 & $-9.6 \%$ \\
\hline & both sexes & 95 & 4.7 & 0.2 & 4.6 & 5.6 & 6.2 & 16.1 & 4.6 & 4.1 & $12.6 \%$ \\
\hline Qatar & females & 3 & 0.7 & 0.1 & 0.8 & 0.6 & 2.0 & 8.1 & 1.2 & 1.9 & $-34.9 \%$ \\
\hline & males & 92 & 5.9 & 0.3 & 5.6 & 6.7 & 7.7 & 20.2 & 5.7 & 5.2 & $10.7 \%$ \\
\hline & both sexes & 17908 & 36.6 & 1.2 & 18.2 & 35.7 & 50.4 & 116.2 & 28.9 & 13.8 & $109.4 \%$ \\
\hline Republic of Korea & females & 5755 & 23.4 & 1.0 & 14.9 & 23.5 & 25.3 & 69.1 & 18.0 & 8.1 & $123.5 \%$ \\
\hline & males & 12153 & 49.9 & 1.3 & 21.3 & 47.6 & 76.7 & 192.1 & 41.7 & 20.4 & $104.6 \%$ \\
\hline & both sexes & 566 & 16.1 & 2.1 & 10.1 & 19.4 & 28.9 & 16.6 & 13.7 & 15.4 & $-11.1 \%$ \\
\hline Republic of Moldova & females & 102 & 5.5 & 2.8 & 3.5 & 4.8 & 9.7 & 8.0 & 4.8 & 4.0 & $20.6 \%$ \\
\hline & males & 463 & 27.8 & 1.4 & 16.8 & 35.0 & 51.9 & 33.4 & 24.1 & 28.9 & $-16.8 \%$ \\
\hline & both sexes & 2781 & 12.8 & 1.0 & 7.8 & 15.4 & 20.6 & 15.3 & 10.5 & 11.3 & $-7.3 \%$ \\
\hline Romania & females & 418 & 3.7 & 0.7 & 2.2 & 3.7 & 5.7 & 6.3 & 2.9 & 3.6 & $-19.5 \%$ \\
\hline & males & 2364 & 22.3 & 1.3 & 13.0 & 26.7 & 37.6 & 29.3 & 18.4 & 19.4 & $-5.2 \%$ \\
\hline & both sexes & 31997 & 22.4 & 1.7 & 27.3 & 26.5 & 22.6 & 32.1 & 19.5 & 35.0 & $-44.4 \%$ \\
\hline Russian Federation & females & 5781 & 7.5 & 1.3 & 8.0 & 7.5 & 6.9 & 15.4 & 6.2 & 9.6 & $-34.9 \%$ \\
\hline & males & 26216 & 39.7 & 2.2 & 46.1 & 46.8 & 43.7 & 72.3 & 35.1 & 64.3 & $-45.3 \%$ \\
\hline
\end{tabular}




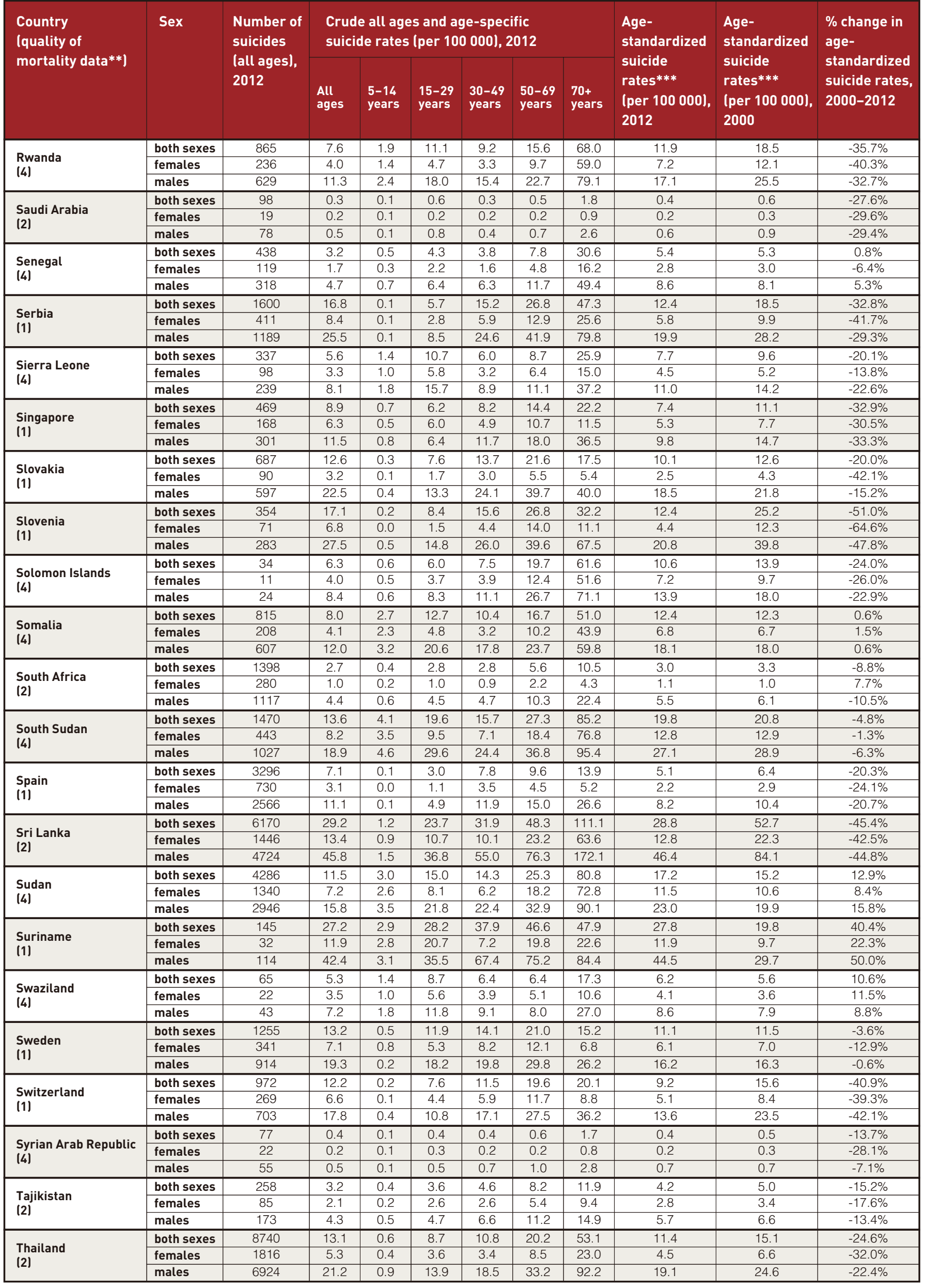




\begin{tabular}{|c|c|c|c|c|c|c|c|c|c|c|c|}
\hline \multirow{2}{*}{$\begin{array}{l}\text { Country } \\
\text { (quality of } \\
\text { mortality data**) }\end{array}$} & \multirow[t]{2}{*}{ Sex } & \multirow{2}{*}{$\begin{array}{l}\text { Number of } \\
\text { suicides } \\
\text { (all ages), } \\
2012\end{array}$} & \multicolumn{6}{|c|}{$\begin{array}{l}\text { Crude all ages and age-specific } \\
\text { suicide rates (per } 100 \text { 000), } 2012\end{array}$} & \multirow{2}{*}{$\begin{array}{l}\text { Age- } \\
\text { standardized } \\
\text { suicide } \\
\text { rates*** } \\
\text { (per } 100000 \text { ), } \\
2012\end{array}$} & \multirow{2}{*}{$\begin{array}{l}\text { Age- } \\
\text { standardized } \\
\text { suicide } \\
\text { rates*** } \\
\text { (per } 100000 \text { ), } \\
2000\end{array}$} & \multirow{2}{*}{$\begin{array}{l}\% \text { change in } \\
\text { age- } \\
\text { standardized } \\
\text { suicide rates, } \\
2000-2012\end{array}$} \\
\hline & & & $\begin{array}{l}\text { All } \\
\text { ages }\end{array}$ & $\begin{array}{l}5-14 \\
\text { years }\end{array}$ & $\begin{array}{l}15-29 \\
\text { years }\end{array}$ & $\begin{array}{l}30-49 \\
\text { years }\end{array}$ & $\begin{array}{l}50-69 \\
\text { years }\end{array}$ & $\begin{array}{l}70+ \\
\text { years }\end{array}$ & & & \\
\hline \multirow{3}{*}{$\begin{array}{l}\text { The former } \\
\text { Yugoslav Republic } \\
\text { of Macedonia (1) }\end{array}$} & both sexes & 140 & 6.7 & 0.2 & 2.1 & 6.0 & 13.9 & 15.1 & 5.2 & 6.7 & $-22.0 \%$ \\
\hline & females & 45 & 4.2 & 0.0 & 1.1 & 4.4 & 7.1 & 11.8 & 3.2 & 4.0 & $-20.0 \%$ \\
\hline & males & 96 & 9.1 & 0.3 & 3.0 & 7.6 & 20.9 & 19.6 & 7.3 & 9.4 & $-22.5 \%$ \\
\hline \multirow{3}{*}{$\begin{array}{l}\text { Timor-Leste } \\
\text { (4) }\end{array}$} & both sexes & 60 & 5.4 & 0.7 & 9.0 & 7.4 & 11.9 & 27.8 & 8.0 & 12.1 & $-34.0 \%$ \\
\hline & females & 23 & 4.2 & 0.6 & 7.3 & 4.0 & 10.3 & 22.0 & 5.8 & 8.3 & $-29.8 \%$ \\
\hline & males & 37 & 6.6 & 0.8 & 10.7 & 10.6 & 13.6 & 34.5 & 10.2 & 15.8 & $-35.6 \%$ \\
\hline \multirow{3}{*}{$\begin{array}{l}\text { Togo } \\
\text { (4) }\end{array}$} & both sexes & 247 & 3.7 & 1.0 & 6.1 & 4.1 & 7.2 & 22.5 & 5.5 & 4.9 & $12.8 \%$ \\
\hline & females & 64 & 1.9 & 0.6 & 2.8 & 1.9 & 4.7 & 11.3 & 2.8 & 2.6 & $8.0 \%$ \\
\hline & males & 183 & 5.6 & 1.3 & 9.5 & 6.3 & 10.1 & 36.6 & 8.5 & 7.5 & $13.2 \%$ \\
\hline \multirow{3}{*}{$\begin{array}{l}\text { Trinidad and Tobago } \\
\text { (1) }\end{array}$} & both sexes & 193 & 14.4 & 0.6 & 7.6 & 22.2 & 25.1 & 17.4 & 13.0 & 12.6 & $3.8 \%$ \\
\hline & females & 46 & 6.9 & 0.2 & 4.2 & 13.3 & 7.5 & 6.8 & 6.2 & 4.5 & $36.4 \%$ \\
\hline & males & 146 & 22.1 & 1.0 & 10.9 & 31.1 & 43.4 & 32.7 & 20.4 & 20.8 & $-2.0 \%$ \\
\hline \multirow{3}{*}{$\begin{array}{l}\text { Tunisia } \\
\text { (4) }\end{array}$} & both sexes & 262 & 2.4 & 0.3 & 2.7 & 2.8 & 3.0 & 7.3 & 2.4 & 2.5 & $-5.6 \%$ \\
\hline & females & 76 & 1.4 & 0.2 & 1.5 & 1.4 & 1.7 & 5.6 & 1.4 & 1.6 & $-17.2 \%$ \\
\hline & males & 186 & 3.5 & 0.4 & 3.9 & 4.4 & 4.3 & 9.3 & 3.4 & 3.4 & $0.9 \%$ \\
\hline & both sexes & 5898 & 8.0 & 2.7 & 12.4 & 10.3 & 4.2 & 16.4 & 7.9 & 12.6 & $-37.8 \%$ \\
\hline Turkey & females & 1613 & 4.3 & 1.8 & 7.6 & 4.2 & 2.2 & 9.8 & 4.2 & 7.9 & $-47.0 \%$ \\
\hline & males & 4285 & 11.8 & 3.6 & 17.0 & 16.6 & 6.6 & 25.5 & 11.8 & 17.8 & $-33.4 \%$ \\
\hline & both sexes & 1003 & 19.4 & 2.1 & 25.7 & 30.3 & 22.8 & 18.4 & 19.6 & 15.2 & $28.9 \%$ \\
\hline Turkmenistan & females & 197 & 7.5 & 1.2 & 12.0 & 8.0 & 9.4 & 12.0 & 7.5 & 7.0 & $8.0 \%$ \\
\hline & males & 806 & 31.7 & 2.9 & 39.3 & 53.5 & 38.5 & 28.6 & 32.5 & 24.0 & $35.1 \%$ \\
\hline & both sexes & 4323 & 11.9 & 3.8 & 19.3 & 15.8 & 26.0 & 91.8 & 19.5 & 18.6 & $5.1 \%$ \\
\hline Uganda & females & 1278 & 7.1 & 3.0 & 10.0 & 6.9 & 16.4 & 80.7 & 12.3 & 11.2 & $10.0 \%$ \\
\hline & males & 3045 & 16.7 & 4.5 & 28.5 & 24.6 & 35.9 & 105.2 & 26.9 & 26.2 & $2.5 \%$ \\
\hline & both sexes & 9165 & 20.1 & 1.4 & 19.5 & 24.4 & 22.9 & 28.8 & 16.8 & 29.8 & $-43.6 \%$ \\
\hline Ukraine & females & 1690 & 6.9 & 0.9 & 5.5 & 6.3 & 7.8 & 13.7 & 5.3 & 9.1 & $-41.2 \%$ \\
\hline & males & 7474 & 35.6 & 1.8 & 32.8 & 43.4 & 43.3 & 61.7 & 30.3 & 54.5 & $-44.4 \%$ \\
\hline & both sexes & 274 & 3.0 & 0.4 & 3.8 & 3.1 & 3.4 & 13.7 & 3.2 & 3.7 & $-12.9 \%$ \\
\hline United Arab Emirates & females & 31 & 1.1 & 0.2 & 1.8 & 1.0 & 1.9 & 10.9 & 1.7 & 2.5 & $-32.7 \%$ \\
\hline & males & 243 & 3.8 & 0.5 & 4.7 & 3.7 & 4.1 & 15.3 & 3.9 & 4.3 & $-9.0 \%$ \\
\hline & both sexes & 4360 & 6.9 & 0.1 & 5.9 & 10.5 & 9.2 & 6.3 & 6.2 & 7.8 & $-21.1 \%$ \\
\hline United Kingdom & females & 960 & 3.0 & 0.1 & 2.5 & 4.3 & 4.0 & 3.1 & 2.6 & 3.4 & $-23.6 \%$ \\
\hline & males & 3400 & 11.0 & 0.1 & 9.1 & 16.7 & 14.7 & 10.5 & 9.8 & 12.3 & $-20.9 \%$ \\
\hline United Republic & both sexes & 7228 & 15.1 & 3.5 & 20.7 & 17.7 & 36.8 & 133.2 & 24.9 & 23.8 & $4.6 \%$ \\
\hline of Tanzania & females & 2445 & 10.2 & 3.1 & 10.7 & 8.3 & 27.5 & 133.6 & 18.3 & 18.6 & $-1.5 \%$ \\
\hline & males & 4783 & 20.0 & 3.9 & 30.7 & 26.9 & 47.2 & 132.7 & 31.6 & 29.1 & $8.8 \%$ \\
\hline United States & both sexes & 43361 & 13.7 & 0.8 & 12.7 & 17.4 & 20.1 & 16.5 & 12.1 & 9.8 & $24.2 \%$ \\
\hline of America & females & 9306 & 5.8 & 0.5 & 4.7 & 8.0 & 9.2 & 4.0 & 5.2 & 3.8 & $36.6 \%$ \\
\hline & males & 34055 & 21.8 & 1.0 & 20.4 & 26.9 & 31.7 & 33.8 & 19.4 & 16.2 & $19.9 \%$ \\
\hline & both sexes & 469 & 13.8 & 0.3 & 12.1 & 14.6 & 19.5 & 34.4 & 12.1 & 14.7 & $-17.9 \%$ \\
\hline Uruguay & females & 108 & 6.2 & 0.1 & 3.8 & 7.4 & 7.4 & 16.0 & 5.2 & 4.9 & $4.5 \%$ \\
\hline & males & 361 & 22.0 & 0.5 & 20.2 & 21.9 & 33.3 & 65.9 & 20.0 & 26.2 & $-23.9 \%$ \\
\hline & both sexes & 2184 & 7.7 & 1.0 & 8.6 & 10.0 & 14.4 & 19.1 & 8.5 & 10.4 & $-18.5 \%$ \\
\hline & females & 538 & 3.8 & 0.5 & 4.9 & 4.0 & 6.1 & 11.8 & 4.1 & 4.9 & $-16.7 \%$ \\
\hline & males & 1646 & 11.6 & 1.4 & 12.2 & 16.3 & 23.5 & 29.5 & 13.2 & 16.3 & $-19.0 \%$ \\
\hline Venezuela & both sexes & 748 & 2.5 & 0.4 & 3.2 & 3.5 & 3.1 & 5.7 & 2.6 & 6.8 & $-61.3 \%$ \\
\hline (Bolivarian & females & 141 & 1.0 & 0.6 & 1.2 & 1.0 & 1.4 & 1.4 & 1.0 & 1.9 & $-48.7 \%$ \\
\hline Republic of) (1) & males & 607 & 4.0 & 0.3 & 5.2 & 6.0 & 4.8 & 10.9 & 4.3 & 11.8 & $-63.3 \%$ \\
\hline & both sexes & 4600 & 5.1 & 0.4 & 5.0 & 5.1 & 7.7 & 20.5 & 5.0 & 5.7 & $-12.2 \%$ \\
\hline Viet Nam & females & 1169 & 2.5 & 0.3 & 1.8 & 1.4 & 4.2 & 15.1 & 2.4 & 3.0 & $-20.7 \%$ \\
\hline & males & 3431 & 7.7 & 0.5 & 8.1 & 8.7 & 11.7 & 30.5 & 8.0 & 8.8 & $-9.2 \%$ \\
\hline & both sexes & 733 & 3.1 & 0.8 & 5.2 & 4.6 & 3.8 & 6.7 & 3.7 & 3.6 & $0.3 \%$ \\
\hline Yemen & females & 320 & 2.7 & 0.7 & 5.1 & 3.3 & 2.7 & 5.3 & 3.0 & 3.0 & $1.0 \%$ \\
\hline & males & 413 & 3.4 & 0.9 & 5.2 & 5.8 & 5.1 & 8.3 & 4.3 & 4.4 & $-0.2 \%$ \\
\hline & both sexes & 1346 & 9.6 & 3.0 & 15.4 & 10.4 & 21.5 & 82.7 & 15.7 & 24.4 & $-35.4 \%$ \\
\hline $\begin{array}{l}\text { Zambia } \\
\text { (4) }\end{array}$ & females & 433 & 6.1 & 3.0 & 8.2 & 4.3 & 14.0 & 79.2 & 10.8 & 18.8 & $-42.8 \%$ \\
\hline & males & 913 & 13.0 & 2.9 & 22.7 & 16.4 & 29.3 & 87.0 & 20.8 & 29.9 & $-30.3 \%$ \\
\hline & both sexes & 2281 & 16.6 & 4.1 & 30.9 & 18.5 & 16.4 & 41.6 & 18.1 & 19.2 & $-5.7 \%$ \\
\hline Zimbabwe & females & 619 & 8.9 & 3.8 & 15.3 & 7.7 & 9.8 & 28.9 & 9.7 & 10.1 & $-4.0 \%$ \\
\hline & males & 1663 & 24.6 & 4.4 & 46.7 & 29.0 & 25.1 & 58.5 & 27.2 & 28.8 & $-5.6 \%$ \\
\hline
\end{tabular}

* In 172 WHO Member States with populations of 300000 or more. These estimates represent the best estimates of WHO, computed using standard categories, definitions and methods to ensure cross-country comparability, and may not be the same as official national estimates. The estimates are rounded to the appropriate number of significant figures.

** 1. Comprehensive vital registration with at least five years of data; 2 . Vital registration with low coverage, a high proportion of indeterminate causes or no recent results; 3. Sample registration of national population; 4. No vital registration.

*** Standardized to the WHO World Standard Population. 


\section{Annex 2: WHO Member States grouped by WHO Region and average income per capita*}

\begin{tabular}{|c|c|c|}
\hline High-income & & $\begin{array}{l}\text { Andorra, Antigua and Barbuda, Australia, Austria, Bahamas, Bahrain, } \\
\text { Barbados, Belgium, Brunei Darussalam, Canada, Chile, Croatia, Cyprus, } \\
\text { Czech Republic, Denmark, Estonia, Finland, France, Germany, Greece, } \\
\text { Iceland, Ireland, Israel, Italy, Japan, Kuwait, Latvia, Lithuania, Luxembourg, } \\
\text { Malta, Monaco, Netherlands, New Zealand, Norway, Oman, Poland, Portugal, } \\
\text { Qatar, Republic of Korea, Russian Federation, Saint Kitts and Nevis, San } \\
\text { Marino, Saudi Arabia, Singapore, Slovakia, Slovenia, Spain, Sweden, } \\
\text { Switzerland, Trinidad and Tobago, United Arab Emirates, United Kingdom, } \\
\text { United States of America, Uruguay }\end{array}$ \\
\hline \multirow[t]{6}{*}{$\begin{array}{l}\text { Low- and middle- } \\
\text { income }\end{array}$} & $\begin{array}{l}\text { WHO African } \\
\text { Region }\end{array}$ & $\begin{array}{l}\text { Algeria, Angola, Benin, Botswana, Burkina Faso, Burundi, Cabo Verde, } \\
\text { Cameroon, Central African Republic, Chad, Comoros, Congo, Côte d'Ivoire, } \\
\text { Democratic Republic of the Congo, Eritrea, Ethiopia, Equatorial Guinea, } \\
\text { Gabon, Gambia, Ghana, Guinea, Guinea-Bissau, Kenya, Lesotho, Liberia, } \\
\text { Madagascar, Malawi, Mali, Mauritania, Mauritius, Mozambique, Namibia, } \\
\text { Niger, Nigeria, Rwanda, Sao Tome and Principe, Senegal, Seychelles, Sierra } \\
\text { Leone, South Africa, Swaziland, Togo, Uganda, United Republic of Tanzania, } \\
\text { Zambia, Zimbabwe }\end{array}$ \\
\hline & $\begin{array}{l}\text { WHO Region of } \\
\text { the Americas }\end{array}$ & $\begin{array}{l}\text { Argentina, Belize, Bolivia (Plurinational State of), Brazil, Colombia, Costa } \\
\text { Rica, Cuba, Dominica, Dominican Republic, Ecuador, El Salvador, Grenada } \\
\text { Guatemala, Guyana, Haiti, Honduras, Jamaica, Mexico, Nicaragua, Panama, } \\
\text { Paraguay, Peru, Saint Lucia, Saint Vincent and the Grenadines, Suriname, } \\
\text { Venezuela (Bolivarian Republic of) }\end{array}$ \\
\hline & $\begin{array}{l}\text { WHO South-East } \\
\text { Asia Region }\end{array}$ & $\begin{array}{l}\text { Bangladesh, Bhutan, Democratic People's Republic of Korea, India, } \\
\text { Indonesia, Maldives, Myanmar, Nepal, Sri Lanka, Thailand, Timor-Leste }\end{array}$ \\
\hline & $\begin{array}{l}\text { WHO European } \\
\text { Region }\end{array}$ & $\begin{array}{l}\text { Albania, Armenia, Azerbaijan, Belarus, Bosnia and Herzegovina, Bulgaria, } \\
\text { Georgia, Hungary, Kazakhstan, Kyrgyzstan, Montenegro, Republic of } \\
\text { Moldova, Romania, Serbia, Tajikistan, The former Yugoslav Republic of } \\
\text { Macedonia, Turkey, Turkmenistan, Ukraine, Uzbekistan }\end{array}$ \\
\hline & $\begin{array}{l}\text { WHO Eastern } \\
\text { Mediterranean } \\
\text { Region }\end{array}$ & $\begin{array}{l}\text { Afghanistan, Djibouti, Egypt, Iran (Islamic Republic of), Iraq, Jordan, } \\
\text { Lebanon, Libya, Morocco, Pakistan, Somalia, South Sudan**, Sudan, Syrian } \\
\text { Arab Republic, Tunisia, Yemen }\end{array}$ \\
\hline & $\begin{array}{l}\text { WHO Western } \\
\text { Pacific Region }\end{array}$ & $\begin{array}{l}\text { Cambodia, China, Cook Islands, Fiji, Kiribati, Lao People's Democratic } \\
\text { Republic, Malaysia, Marshall Islands, Micronesia (Federated States of), } \\
\text { Mongolia, Nauru, Niue, Palau, Papua New Guinea, Philippines, Samoa, } \\
\text { Solomon Islands, Tonga, Tuvalu, Vanuatu, Viet Nam }\end{array}$ \\
\hline
\end{tabular}


*This regional grouping classifies WHO Member States according to the WHO regional groupings as of 2012, and the World Bank analytical income of economies for the fiscal year 2014, which is based on the 2012 Atlas gross national income per capita estimates (World Bank list of economies, July 2013).

**South Sudan was reassigned to the WHO African Region in May 2013. As this revision of global health estimates relates to time periods prior to this date, estimates for South Sudan are included in the figures given for the WHO Eastern Mediterranean Region. 